University of San Diego

Digital USD

2012-05-01

\title{
Advising to Promote Self-Authorship: Exploring Advising Strategies and Advisor Characteristics among New Student Affairs Professionals
}

\author{
Emily Marx PhD \\ University of San Diego
}

Follow this and additional works at: https://digital.sandiego.edu/dissertations

Part of the Leadership Studies Commons

\section{Digital USD Citation}

Marx, Emily PhD, "Advising to Promote Self-Authorship: Exploring Advising Strategies and Advisor Characteristics among New Student Affairs Professionals" (2012). Dissertations. 835.

https://digital.sandiego.edu/dissertations/835

This Dissertation: Open Access is brought to you for free and open access by the Theses and Dissertations at Digital USD. It has been accepted for inclusion in Dissertations by an authorized administrator of Digital USD. For more information, please contact digital@sandiego.edu. 


\title{
ADVISING TO PROMOTE SELF-AUTHORSHIP: EXPLORING ADVISING STRATEGIES AND ADVISOR CHARACTERISTICS AMONG NEW STUDENT AFFAIRS PROFESSIONALS
}

\author{
by \\ Emily Marx \\ A dissertation submitted in partial fulfillment \\ of the requirements for the degree of
}

Doctor of Philosophy

May 2012

Dissertation Committee

Cheryl Getz, Ed.D., Chair

Marilee Bresciani, Ph.D., Member

Roxanne Ruzic, Ed.D., Member

University of San Diego 
(C) Copyright by Emily Marx, 2012

All Rights Reserved 


\begin{abstract}
Self-authorship, a theory developed by Robert Kegan (1982) and applied to college students by Marcia Baxter Magolda, is the ability to internally define one's own beliefs, identity, and relationships (Baxter Magolda, 2001). People who self-author have the ability to make career, academic, relationship, and life decisions that take into consideration their own internal voice rather than relying on others' advice. The development of self-authorship has been correlated with gains in key learning outcomes, such as cognitive complexity and independence (Baxter Magolda, 2001; Pizzolato, 2008; Pizzolato \& Ozaki, 2007). Achievement of self-authorship does not typically occur until after college, when young adults face increased life challenges and have fewer supports (Baxter Magolda, 2001).

However, research indicates that it may be possible for mentoring relationships between students and campus administrators to serve as a primary vehicle for promoting self-authorship during college (Baxter Magolda, 2001; Daloz Parks, 2000; Hodge, Baxter Magolda, \& Haynes, 2009; Pizzolato 2005; Pizzolato \& Ozaki, 2007). New student affairs professionals, who tend to work most directly with students, have the potential to advise in ways that promote self-authorship.
\end{abstract}

The purpose of this study was to explore characteristics of new student affairs professionals (age, gender, education, and new professionals' stage of self-authorship), and their advising approaches with undergraduate students. Twelve new student affairs professionals participated in semi-structured interviews and submitted journal entries about their advising experiences with students. Grounded theory coding, a coding 
scheme based on existing literature, and within-case and cross-case analysis were used to analyze the data, and several themes emerged.

New professionals who were themselves in late stages of self-authorship development used a greater number and broader range of strategies promoting selfauthorship, and those in earlier stages of self-authorship development gave more concrete direction and instruction to students. Women tended to use more supportive advising strategies, while men tended to use more challenging approaches. Those who attended student affairs masters programs used more challenging advising approaches than those who did not. These findings may inform the ways supervisors, graduate preparation programs, and mentors support the development of new professionals and the college students with whom they work. 


\section{ACKNOWLEDGEMENTS}

I'd like to offer my gratitude to those who have inspired, supported, and challenged me in the process of writing this dissertation.

First, I'd like to thank my dissertation committee members who, through their thoughtful and supportive feedback, have helped to usher this project from concept into fruition. The insightful questions and feedback of my chair, Dr. Cheryl Getz, helped to continually prune the study's concept and design. Our advising sessions served as a consistent space of support and generativity. Dr. Roxanne Ruzic provided both nuanced feedback and big picture perspectives that propelled me forward at just the right times along the journey. Dr. Marilee Bresciani's passion for student growth in college inspired new understandings and many meaningful improvements to the study.

The work of Dr. Marcia Baxter Magolda ignited my passion for promoting discovery of self in college. I am incredibly grateful for her generosity, guidance, and resources as I designed the study.

Dr. Sara Henry and Dr. Jeff Bolster, whose mindful work in student affairs inspire me and whose feedback and guidance on aspects of my dissertation have been invaluable.

A number of people have generously extended their warmth and support during the process by offering an ear, a new perspective, a brainstorming partner, and occasionally, a good reason to take study break. Thank you Jeff Berg, Kari Blaeuer, Kathleen Gallagher, Jessica Harris, the Herold family, Erin Kelly, Jenni Lastoka, Vladek Nodelman, Lori Weiner, Alisa Zych. 
Dr. David Facer, I have treasured your support, friendship, and wisdom throughout the journey.

Center for Student Involvement staff have so often served as examples of caring and artful student affairs work. Teri Brazell, thank you for inspiring me daily with your masterful use of language and for offering your editing skills.

I am grateful for my parents, who instilled the importance of education at an early age. I'd also like to thank my uncle, Paul Zucker, for his support of my Ph.D. program. I feel an extra sense of pride after putting my doctorate in the context of the family stories you've shared and feeling your love and pride in my accomplishments.

Finally, I'd like to dedicate this dissertation to student affairs professionals, whose support, guidance, warmth, and challenging questions so often make the college years a rich time of growth and development for students. 
TABLE OF CONTENTS

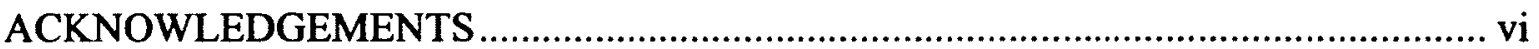

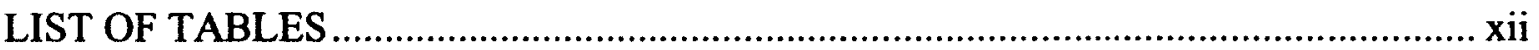

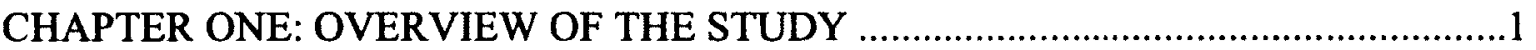

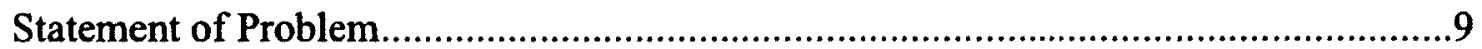

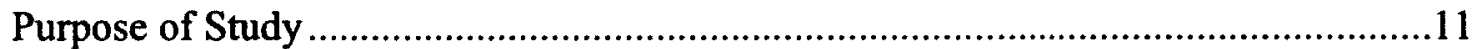

Research Questions ............................................................................... 12

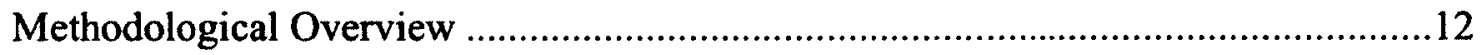

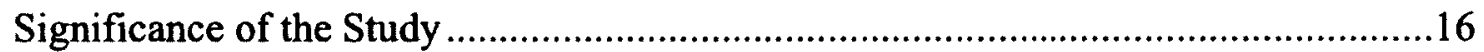

CHAPTER TWO: LITERATURE REVIEW ......................................................

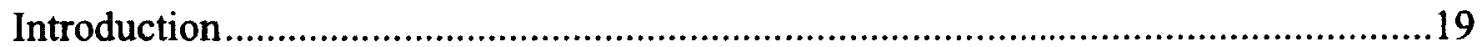

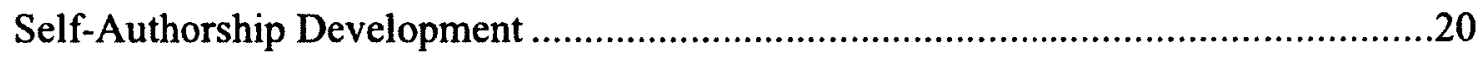

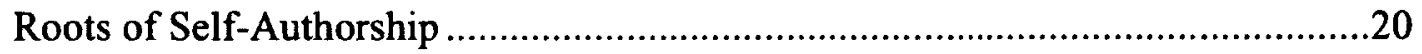

The Case for Promoting Self-Authorship in College.....................................26

The Process of Self-Authorship Development ..........................................30

Nuances and Complexities of the Journey Towards Self-Authorship ..................35

The Role of Student Affairs Professionals in Students' Development

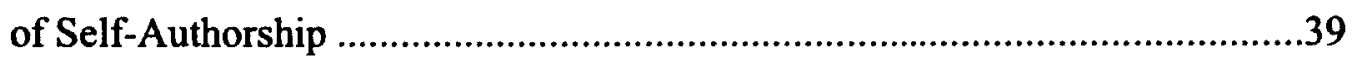

New Professional Competencies for Promoting Self-Authorship ............................43

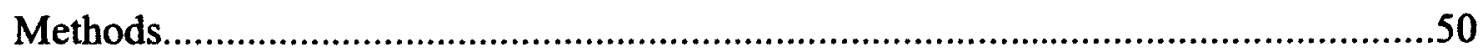

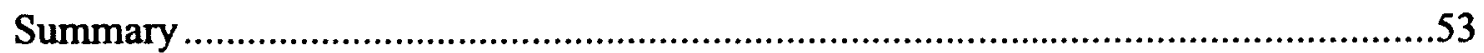


CHAPTER THREE: METHODOLOGY

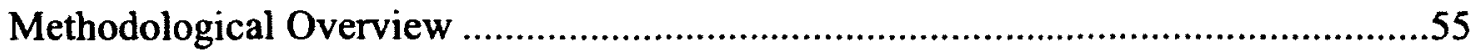

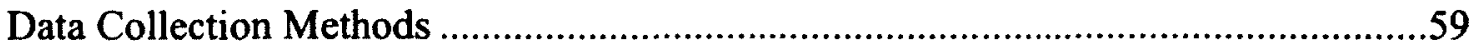

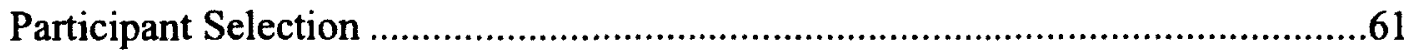

Interview Procedures .........................................................................6.

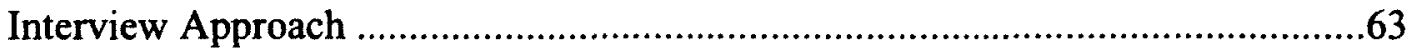

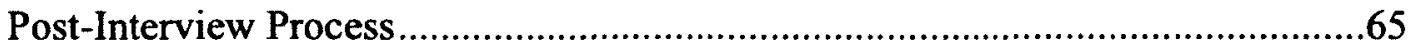

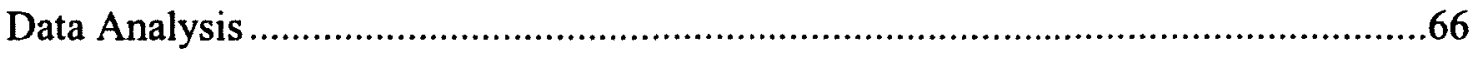

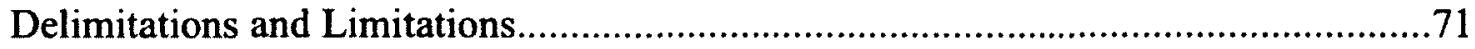

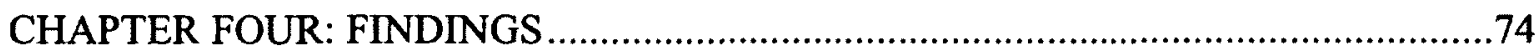

Review of Study Purpose and Research Questions ...........................................74

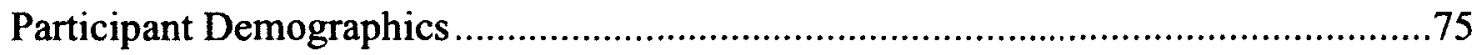

Data Analysis of New Professional Interviews and Journal Entries.......................76

Early Stage of Self-Authorship Development ........................................ 77

Middle Stage of Self-Authorship Development .......................................80

Late Stage of Self-Authorship Development ..............................................8

Influences and Trends in New Professional Self-Authorship Development .............84

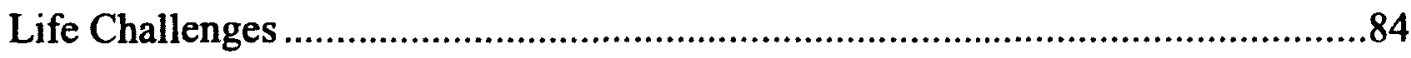

Student Affairs Master's Degree Programs ...............................................85

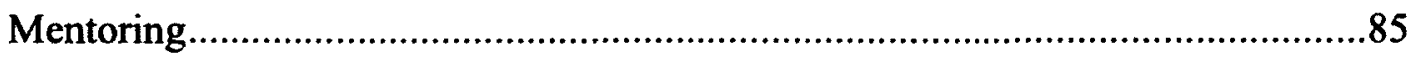

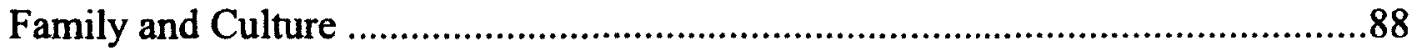


Feedback

New Professionals' Use of Advising Strategies That Promote Self-

Authorship Among College Students

Advisors in Early Self-Authorship Offered More Directions.

Advisors in Late Self-Authorship Use More Strategies That Promote

Self-Authorship. .96

Transactional versus Developmental Advising Approaches 99

Student Affairs Master's Programs and Advising Strategies 103

Gender and Advising Strategies. 106

Summary of Findings. 110

CHAPTER FIVE: DISCUSSION 113

Justification for Study 113

Overview of Purpose of the Study and Findings 115

Summary of Methods Used in the Study 116

Summary of Study Findings

Interpretation of the Findings 120

Development of Self-Authorship Among New Professionals

Advisors in Early Self-Authorship Offered More Direction 124

Advisors in Late Self-Authorship Used More Strategies That Promote

Self-Authorship. 126

Transactional versus Developmental Advising Approaches 127

Student Affairs Master's Programs and Advising Strategies 128 


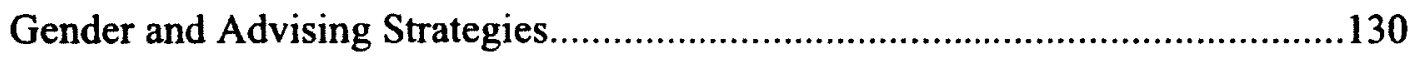

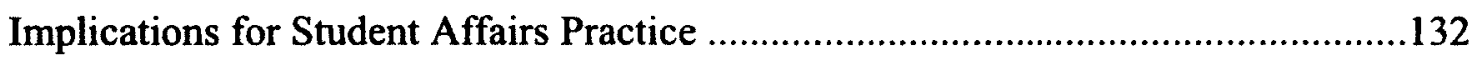

Promoting Self-Authorship Development Among New Professionals

Through Student Affairs Graduate Preparation Programs................................132

Supervising and Mentoring New Professionals to Promote Self-

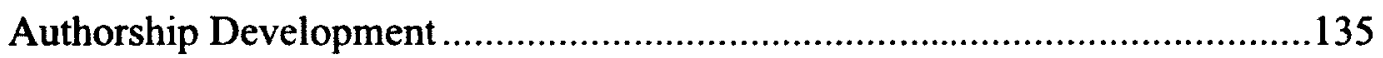

Developing Mentoring Communities to Promote Development of

Self-Authorship in Undergraduate Students ...................................................137

Professional Development Opportunities for New Professionals.........................141

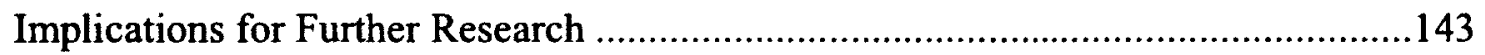

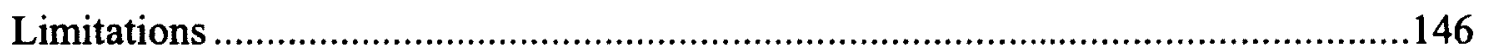

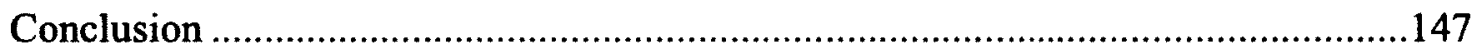

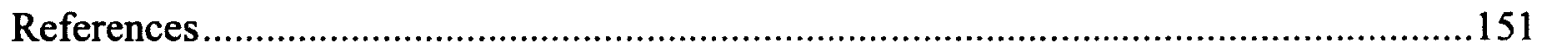

Appendices

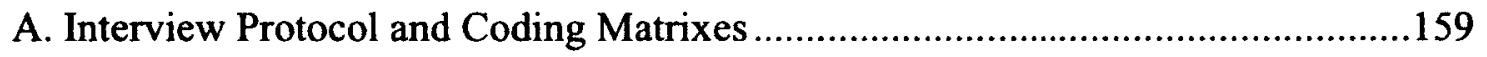

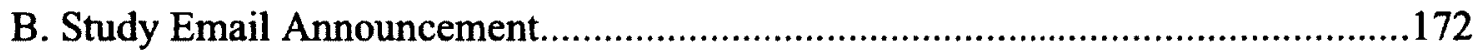

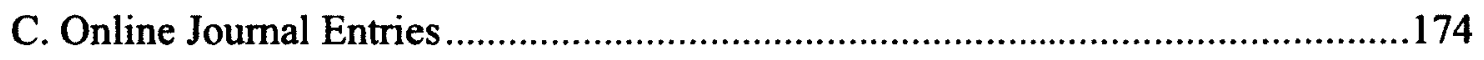




\section{LIST OF TABLES}

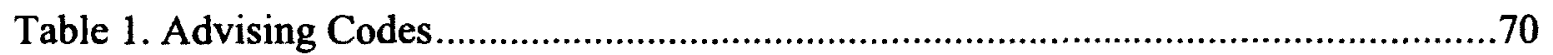

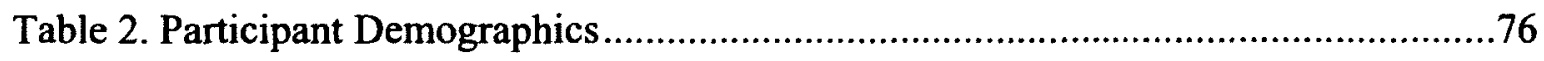




\section{CHAPTER ONE}

\section{OVERVIEW OF THE STUDY}

A primary goal of higher education, both inside and outside of the classroom, is to prepare students to handle the complexities of adult life. National reports have increasingly highlighted the role of higher education in helping students achieve learning outcomes that promote the development of complex epistemological, intrapersonal, and interpersonal capacities. Campus' increased focus on learning outcomes has provided more information about the degree to which young adults are leaving college with the capacity to handle the intricacies of their adult lives, relationships, and future employment.

Unfortunately, there are increasing data that may indicate that campuses are not adequately preparing students for life after college. For example, in the Job Outlook 2011 report from the National Association of Colleges and Employers (2010), analytical and problem-solving skills were ranked among the most important skills by employers, and in another national survey of employers, $64 \%$ of employers wanted colleges to place greater emphasis on complex problem-solving skills (Association of American Colleges and Universities [AACU], 2007). At the same time, a recent 4-year longitudinal study assessing college student learning conducted by Arum and Roska (2011) made national headlines. Over 4,000 college students at 29 diverse institutions were administered the Collegiate Learning Assessment (CLA), which assessed critical thinking, analytical reasoning, and written communication. The study found that $45 \%$ of the students in the sample made no statistically significant increases in critical thinking, complex reasoning, 
and writing skills during their college years (Arum \& Roska, 2011). While the Arum and Roska study is frequently cited, concerns about the CLA methodology have been raised, specifically its effectiveness, its lack of questions about discipline-specific knowledge, its validity, and its inability to account for non-school factors. College educators continue to identify the best ways to measure student learning in college (Arum \& Roska, 2011; Perez-Pena, 2012). Nevertheless, collectively such reports suggest the need to focus on and improve our effectiveness in promoting student growth and development in college. These studies also suggest that campuses would benefit from placing greater emphasis on practices known to promote important learning outcomes.

In the last two decades, many researchers have explored the role of student affairs practitioners and co-curricular programs in addressing the developmental needs and learning outcomes of students (Astin, 1993; Harper \& Quaye, 2009; Kuh, Kinzie, Schuh, Whitt, \& Associates, 2005; Kuh, Schuh, Whitt, \& Associates; 1991). The field of student affairs has simultaneously increased its focus on assessment of learning outcomes that measure student development and learning (Astin, 1993; Keeling, 2006; Kuh et al., 2005; Pascarella \& Terenzini, 2005). The Association of American of Colleges and Universities (2007), the Council for the Advancement of Standards (2006), and a joint publication from seven national associations in student affairs entitled Learning Reconsidered 2 (Keeling, 2006), each published sets of essential learning outcomes for colleges and universities. Examples of learning outcomes from Learning Reconsidered 2 include: cognitive complexity, knowledge acquisition, integrity acquisition, integration and application, humanitarianism, and civic engagement (Keeling, 2006). Achievement 
of such a broad set of learning outcomes depends not solely on students' acquisition of knowledge, but on students' developmental capacities, as well (Keeling, 2006; Meszaros, 2007).

Student development theories provide an understanding of contexts for learning in college and development processes that occur in young adulthood. In 1959 Arthur Chickering created an identity theory that acknowledged students need to balance autonomy and independence in the college years (Evans, Forney, Guido, Patton, \& Renn, 2010). Chickering's seven vectors describe developmental and identity issues facing college students, such as managing emotions, developing purpose, and developing integrity. This theory became a foundation for understanding the developmental issues students face in college. In 1967, Nevitt Sanford identified two influential concepts that have remained mainstays for practitioners and theorists. Sanford identified cycles of differentiation and integration occurring in young adulthood and the need for a balance between challenge and support in the college years (Evans et al., 2010). In 1969, Lawrence Kohlberg developed a theory of moral reasoning. His research has resulted in programs that focus on reasoning through moral dilemmas across higher education (Evans et al., 2010). Kohlberg's theory was based primarily on research on men, and in 1982, Carol Gilligan developed care-based rationales of moral decision making of women (Evans et al., 2010). Adult development theorists have since begun to identify more holistic, nuanced, and integrative theories.

Until Robert Kegan (1982) developed an integrative and comprehensive metapsychology theory, no theorist had developed a comprehensive and integrated theory 
of evolution incorporating development of the self, meaning making, learning, and affect across the lifespan. While Kegan's theory spanned the lifespan, his influential work became a foundational work for understanding college student development. Unlike other development theories, Kegan's theory addresses the intersection of cognitive and affective processes through the meaning-making structures people use to make sense of their world. Kegan argued that cognitive and psychological development occur not separately, but with significant interplay and within a context of meaning making. Kegan (1982) developed the concept of self-authorship, which explains the developmental shift in which adults develop the ability to reflect on multiple points of view and integrate them with their own perspectives to create an understanding of their own experience and identity. The theory of self-authorship is more holistic than previous theories, and it focuses on the interplay between meaning making and development in cognitive, identity and relationship domains. Kegan's foundational work will be discussed in further detail in chapter 2 .

The framework of self-authorship developed by Robert Kegan $(1982,1994)$ was applied to college students by Marcia Baxter Magolda (1999). Self-authorship provides a context for understanding the developmental shifts and intellectual growth that occur in young adulthood. Self-authorship is the ability to internally define one's own beliefs, identity, and relationships (Baxter Magolda, 2001). Self-authorship is a developmental process in which young adults in their 20 s and 30 s move from reliance on others for decision making and knowledge generation into a period in which they integrate their own knowledge and judgment with that acquired from others (Baxter Magolda, 2001). 
The ability to self-author is the result of the resolution of disequilibrium caused by cognitive dissonance between external and internal voices (Baxter Magolda, 2001; Kegan, 1982; Pizzolato, 2005). This cognitive dissonance has the potential to open access to one's internal voice, values and belief systems.

The capacity to self-author is crucial to the development of complex reasoning skills, healthy relationships, and sense of identity described in higher education learning outcomes. Key learning outcomes and developmental gains associated with young adulthood are linked to self-authorship. In 2005, the Association of American Colleges and Universities launched a decade-long initiative, the Liberal Education and America's Promise, which identified "Essential Learning Outcomes" for education in a new century (AACU, 2007). Many of these learning outcomes are advanced by the development of self-authorship, including: inquiry and analysis, critical and creative thinking, and problem solving (Baxter Magolda, 2001; Pizzolato, 2008; Pizzolato \& Ozaki, 2007), civic knowledge and engagement (Baxter Magolda \& King, 2004), intercultural knowledge and competence (Abes, Jones, \& McEwen, 2007; Kegan, 1994; Taylor, 2008), ethical reasoning and action (Appel-Silbaugh, 2007; Baxter Magolda \& King, 2004), foundations and skills for lifelong learning (Baxter Magolda \& King, 2004), and synthesis and advanced accomplishment across general and specialized studies (Baxter Magolda \& King, 2004).

Similarly, Learning Reconsidered 2 (Keeling, 2006), a joint publication from seven national associations in student affairs, including American College Personnel Association (ACPA), Association of College Unions-International (ACUI), and 
National Association of Student Personnel Administrators (NASPA), describes a number of learning outcomes for higher education, many of which are also facilitated by the development of self-authorship. These include: increases in cognitive complexity (Baxter Magolda, 2001; Pizzolato, 2008; Pizzolato \& Ozaki, 2007), knowledge acquisition (Baxter Magolda, 2001; Pizzolato 2008), integrity acquisition, integration and application (Appel-Silbaugh, 2007).

Many additional learning outcomes, including those developed by the Counsel for the Advancement of Standards (CAS) in Higher Education (2006), are also advanced by the ability to self-author, including: intellectual growth (Baxter Magolda, 2001; Pizzolato, 2008; Pizzolato \& Ozaki, 2007), clarified values (Baxter Magolda, 2001; Pizzolato, 2008; Pizzolato \& Ozaki, 2007), career choices (Baxter Magolda, 2001; Creamer \& Laughlin, 2005), meaningful interpersonal relationships (Baxter Magolda, 2001; Pizzolato, 2008), independence (Baxter Magolda, 2001), appreciating diversity (Abes et al., 2007; Taylor, 2008); personal and educational goals (Baxter Magolda, 2001; Creamer \& Laughlin, 2005).

The cognitive and developmental gains associated with self-authorship in college have a number of implications for students' everyday lives. Students who have the ability to self-author during college are more likely to make more informed career, academic, relationship, and life decisions that take into account their internal voice. Selfauthorship involves young adults' abilities to be reflective and purposeful and thus be more able to make decisions that reconcile input from outside sources with their own perspectives. Based on results of her longitudinal study and research on promising 
practices for self-authorship development, Baxter Magolda (2003) concludes that if campus administrators surround students with experiences that make self central to learning in college, students may choose a major or career path based on their skills and interests rather than the wishes of their parents. Students' abilities to make decisions based on their internal voices would result in deeper engagement with their coursework and co-curricular involvement (Baxter Magolda, 2003). They may choose relationships based on a sense of what is right for them rather than the desire to please others. For example, the University of Nevada Las Vegas instituted a community standards program based on the tenets of self-authorship development. Students in the program reported having become more self-aware, responsible, confident, capable of standing up for what they believed, and more understanding of others than before starting the program (Baxter Magolda, 2003).

While, ideally, students would develop the capacity for self-authorship in college, achievement of self-authored thinking typically does not occur until after college, when traditionally-aged college graduates face increased life challenges and have fewer supports (Baxter Magolda, 2001). However, research indicates that it may be possible for campuses to intentionally speed-up the self-authorship process to allow more students to reach self-authorship during college (Baxter Magolda, 2001; Hodge et al., 2009; Pizzolato, 2005).

Mentoring relationships between students and student affairs practitioners, faculty and other administrators can serve as a primary vehicle for encouraging movement through the stages of self-authorship during college (Baxter Magolda, 2001; Daloz Parks, 
2000; Pizzolato \& Ozaki, 2007). These relationships occur throughout campus life, including in academic advising, student organization advising, student activities, residential life, and career advising. Research has shown that, as college students face particularly difficult challenges for which their existing mental models are inadequate, advisors and mentors have the potential to provide the tailored and challenging questions and support necessary to open pathways to more self-authored ways of thinking (Baxter Magolda, 2001; Daloz Parks, 2000; Pizzolato \& Ozaki, 2005). One of the reasons why self-authorship rarely occurs in college "may be the way advice is given and the lack of opportunities for guided reflection" (Magolda \& King, 2008, p. 9). No studies have been conducted to investigate the degree to which campus advisors are providing the type of mentoring relationships that promote self-authorship among students, which is the subject of this study.

New student affairs professionals work most often and most directly with undergraduate students in mentoring and advising relationships. New professionals, many of whom are in their early- to mid-20s, are often on their own journey towards selfauthorship. In the book Job One: Experiences of New Professionals in Student Affairs, Peter Magolda and Jill Ellen Carnaghi (2004) conclude, in part, that self-authorship is a "cornerstone" of new professional development. In order to promote self-authorship in others, it is assumed that new professionals must have the capacity to self-author (Abes et al., 2007; Baxter Magolda, 2007; Baxter Magolda \& King, 2004; Mills \& Strong, 2004). No research has been conducted that directly addresses the development of selfauthorship among new professionals or the impact this may have on the development of 
self-authorship among the college students they advise. This study investigated the possible connection between self-authorship development among new professionals and its development in students, and sought to understand the degree to which new student affairs professionals may be prepared to assist students on their journey toward selfauthorship.

\section{Statement of Problem}

Extended support from parents may be preventing young adults in their 20 s and 30s from having significant enough crossroads experiences to achieve self-authored thinking, suggesting that young adults in this generation who have not reached selfauthorship during college may experience further delays in development. Recent research indicates that young adults in their 20s and 30s appear to be choosing a slower and more meandering path to adulthood than those in previous generations (Arnett, 2004; Settersten \& Ray, 2010), which may further delay the process of self-authorship development. Recent studies on emerging adulthood indicate that many of the stages traditionally marking adulthood that formerly occurred in one's early 20 s (higher education, marriage, children) are often delayed until the late 20 s and often the 30 s (Arnett, 2004; Settersten \& Ray, 2010). For example, in one study more than half of emerging adults aged 18-24 had not left home and were living with their parents, a 37\% increase from 1970. The percentage of those aged 25-34 living at home has increased 139\% since 1970 (Settersten \& Ray, 2010). Such delays in leaving the parents' home, coupled with the extended hands-on support characteristic of the current generation of parents may provide fewer disorienting crossroads experiences in one's early 20 s in 
which the emerging adult must identify and rely on his own voice. College is a time when students are surrounded by those who have the potential to intentionally promote their development, which makes college an ideal time to promote self-authorship.

Based on her 25-year longitudinal research study on self-authorship, Baxter Magolda concludes that campuses are currently providing too much support and too little challenge to promote progression towards self-authorship during college (Baxter Magolda, 2001; Baxter Magolda, personal communication, November 4, 2010). A level of challenge is required to create cognitive dissonance necessary to promote self-authored thinking (Baxter Magolda, 2001; Kegan, 1982). Campuses could better prepare students for self-authored purposeful adult lives by intentionally structuring programs for increasing independence and ensuring that student affairs professionals, who frequently interact with students, have the capacity to advise students in ways that may advance students' development of self-authorship.

This study explored characteristics of new student affairs professionals (e.g., age, gender, education, new professional's stage of self-authorship) that may influence the degree to which their advising approaches may promote self-authorship in undergraduate students. I have chosen to explore the relationship between self-authorship development and age because with age comes increased life experience and the potential for more crossroads experiences that could lead to self-authorship. The study also investigated gender differences, which have been linked to epistemological development and learning differences (Baxter Magolda, 1992), and may, therefore, impact advising styles. In addition, this study identified differences in advising strategies between those who 
attended student affairs master's programs and those who did not. This study also explored the assumption made by several researchers that in order to promote selfauthorship in others, one must have the capacity for self-authored thinking (Abes et al., 2007; Baxter Magolda, 2007; Baxter Magolda \& King, 2004; Mills \& Strong, 2004).

New student affairs professionals, who often have the most contact with students and who frequently serve as advisors and mentors to undergraduate students, are in a particularly good position to promote student development. To determine the degree to which new professionals have the capacity to assist with the development of selfauthorship among the college students with whom they work, it is important to learn more about the development of self-authorship among new professionals. There is no research that assesses the degree to which new student affairs professionals are assisting undergraduate students through challenging life experiences in ways that help students move towards self-authorship. This study investigated the degree to which characteristics such as age, education, gender, and new student affairs professionals' own level of selfauthorship may, or may not, influence the types of advising strategies they used and, ultimately, the development of the students they advised.

\section{Purpose of Study}

This study explored the level of self-authorship of new student affairs professionals, possible links between characteristics of new professionals and the advising approaches they use with undergraduate students, and the degree to which advising and mentoring styles may assist with the development of self-authorship among the college students with whom they work. For the purposes of this study, new 
professionals are considered to be those who have worked for approximately 2 years or less in the field of student affairs. These new professionals often have the most contact with students and are therefore in a particularly good position to assist college students in the self-authorship process. The purpose of this study is to explore the relationship between advisor characteristics such as age, education, gender and stage of development of self-authorship, and the advising strategies that promote the development of selfauthorship in the students with whom they work.

\section{Research Questions}

The following questions guided this study:

RQ \#1: To what degree do new student affairs professionals demonstrate evidence of self-authorship? What common characteristics and trends emerge among new professionals in different stages of self-authorship development?

RQ \#2: In what ways, if any, do new student affairs professionals use strategies and approaches that facilitate self-authorship with undergraduate students?

a. What are the differences in advising approaches used by new student affairs professionals based on characteristics such as gender, age, education, and their own demonstrated stage of self-authorship development?

\section{Methodological Overview}

Qualitative research is appropriate for studies of constructivist development and self-authorship because these phenomena are complex and multi-faceted. Exploration of the nuances involved in the epistemological, interpersonal, and intrapersonal dimensions of self-authorship development and in advising relationships require a methodology that 
is dynamic, adaptable and responsive to new and emerging data. This study explored the degree to which new professionals demonstrate evidence of self-authorship and advise in ways known to promote self-authorship development in students, the possible relationship between self-authorship development of students and student affairs advisors, and the degree to which other advisor characteristics (such as gender, age, or education) may influence advising strategies used by new professionals.

Participants in this study have worked full-time in the field of student affairs for approximately 2 years or less. The 12 new professionals in the study each participated in one 60- to 90-minute semi-structured interview and submitted journal entries about their advising experiences with students in the weeks following the interviews. Interviews were divided into two parts. Part 1 was designed to gather background information and assess the level of self-authorship of study participants in three domains (epistemological, intrapersonal, and interpersonal). Since no research has been conducted that assesses the stages of self-authorship development in new student affairs professionals, existing interview protocols (that have been used for assessing self-authorship in young adults) were adapted for this study in consultation with self-authorship researcher Marcia BaxterMagolda.

Part 2 of the interviews included a series of questions developed to delve deeply into a recent advising experience in which a student came to the student affairs professional to discuss a significant life challenge. Following each interview, participants were asked to respond electronically to 5 journal entry prompts after advising experiences with students during a 2-week period following the interview. A total of 40 
journal entries were received from study participants. The interview protocol and coding schemes for part 2 were also reviewed by Marcia Baxter-Magolda.

This study used multiple strategies for data analysis, including grounded theory coding (open, axial, and selective coding), pre-existing coding derived from the literature, and within-case and cross-case analysis in order to explore characteristics of new student affairs professionals and their advising approaches with undergraduate students.

Constructivist grounded theory methodology is commonly used to assess selfauthorship because it captures the nuances of the complex meaning participants make of their experiences in the epistemological, interpersonal, and intrapersonal dimensions (Baxter Magolda, 2001; Creamer \& Laughlin, 2005; Kegan, 1982, 1994; Pizzolato, 2005). Constructivist grounded theory methodologies focus on the ways people make meaning of their experiences, their assumptions, and their mental models (Charmaz, 2006). This approach involves using samples to build a theory and is not intended to be representative of the population (Charmaz, 2006). In this study, grounded theory coding, in conjunction with codes derived from the literature, were used to generate a list of codes for within-case and cross-case analysis. This analysis identified patterns among new professionals with similar characteristics (e.g., age, education, gender, stage of selfauthorship development) and explored unidentified patterns in their advising approaches with undergraduate students.

After conducting and transcribing the interviews, data was analyzed in multiple stages, first by coding using grounded theory coding (e.g., open, axial, and selective coding). I chose to begin analysis using grounded theory coding that emerged solely 
from the transcripts and journal entries themselves, in part because self-authorship has never been applied to new student affairs professionals, therefore coding first from the data insures that new themes and concepts not previously identified in the literature may emerge. To avoid any bias based on the demonstrated stage of self-authorship of the new professional, the portion of the interview that focused on advising strategies of new professionals and journal entries about advising experiences were analyzed first, prior to identifying the stage of self-authorship demonstrated in the interview narratives.

Next, following grounded theory coding, data were coded utilizing coding schemes identified in the literature about stages of self-authorship development and advising strategies that promote self-authorship in college students. Both coding schemes that were derived from the literature were reviewed and approved by Marcia Baxter Magolda. Codes gathered from existing literature were applied after critical examination to ensure that the findings were grounded in the data itself (Charmaz, 2006). As with grounded theory coding, interviews and journal entries were again coded starting with the data on advising strategies to avoid bias based on identified stage of self-authorship. This section was coded based on advising strategies identified in Baxter Magolda and King's Learning Partnership Model (2004) and other research which identified advising strategies that promote self-authorship in students (this literature will be discussed in more detail in chapter 2). Next, section 1 of the interview, designed to identify participants' demonstrated stages of self-authorship, was coded using a coding scheme adapted primarily from the multi-institutional Wabash study (Baxter Magolda, King, Taylor, \& Perez, 2008; King, Baxter Magolda, Perez, \& Taylor, 2009). This coding 
scheme enhanced those used in prior studies by identifying more nuanced stages of selfauthorship development. Since the interview protocol for this study used the common approach of asking for specific examples of challenges that would typically call upon one's most complex level of meaning making (Baxter Magolda \& King, 2007), the study identified primary stage of self-authorship based solely on demonstrations of selfauthorship described in their examples.

Finally, within-case and cross-case analysis (Patton, 2002) were used to explore patterns among new professionals in similar stages of self-authorship development, and possible relationships between new professional's characteristics and the advising strategies they use with students. Characteristics included age, identified stage of selfauthorship of the new professional, education, and gender. These characteristics were analyzed to identify themes in advising strategies based on characteristics of new professionals. Differences in personal characteristics (e.g., age, gender, education) among participants within differing levels of self-authorship were also be assessed using a similar approach, to better understand the possible factors that may have influenced the self-authorship development and advising styles of new professionals in the study. Patterns and themes that emerged from within and across cases were identified.

\section{Significance of the Study}

A number of characteristics of new student affairs professionals in this study were associated with the advising strategies they used with students. This study suggests that by understanding the factors associated with student affairs professionals' advising strategies, student affairs administrators may be able to identify new ways to support new 
professionals in ways that encourage their personal and professional development and the development of the students they advise.

Among the findings, the study identified a link between the stage of selfauthorship development of new professionals in the study and their use of advising strategies that promote self-authorship in students. This suggests that campus administrators could support student development by promoting the development of selfauthorship among new professionals. Other advisor characteristics, such as gender, age, and education were also analyzed in relation to both self-authorship development and advising strategies.

Several new professionals in the study demonstrated evidence of self-authored thinking, and they are in a particularly good position to intentionally assist the college students with whom they work in the students' journey toward self-authorship. However, the majority of new professionals in this study were in early or middle stages of selfauthorship. This may have a set of implications for graduate preparation programs, for the field of student affairs and for supervisors and mentors of new professionals. Master's degree programs, supervisors, and mentors may be called upon to take up the work of meeting the developmental needs of new professionals.

This study explored the capacity of new student affairs professionals to promote development along the self-authorship continuum. By investigating the degree to which new student affairs professionals are promoting self-authorship development and by identifying potential developmental needs of new student affairs professionals, we may 
build our collective capacity to advance complex reasoning skills and other key learning outcomes among undergraduate students.

Ultimately, if challenging and reflective conversations that promote selfauthorship among students become common throughout students' advising and mentoring experiences on campus, "reflection could become a mainstay of their college learning, and advising a richer context for learning" (Magolda \& King, 2008). Students will be more likely to make career and personal decisions based on their own values, interests, skills and goals. They would be more capable of taking advantage of learning opportunities, would have access to more complex ways of thinking, and would be more capable of achieving college learning outcomes. By understanding the degree to which new professionals are promoting self-authorship as they advise students, and the characteristics that may influence their advising styles, we may make more informed decisions that support the development of self-authorship in college. 


\section{CHAPTER TWO}

\section{LITERATURE REVIEW}

\section{Introduction}

Several bodies of literature have informed the foundation and design of this study. This chapter begins with a review of the theoretical underpinnings of the theory of selfauthorship, and is followed by discussion of its application to college students, the role of new professionals in facilitating self-authorship development, and finally methodologies used to study self-authorship. First, the chapter introduces discussion of the constructivist developmental tradition, the foundation upon which self-authorship is based, which provides insight into some of its key tenets. Next, the work of Robert Kegan, who first identified the concept of self-authorship, is discussed. Marcia Baxter Magolda's research applied Kegan's work to college students; her work and that of subsequent researchers has yielded more nuanced understanding of the developmental process of self-authorship. This research informs our understanding of the development of both college students and the new professionals who advise them. Literature on the process of self-authorship development is followed by a discussion of the nuances and complexities of self-authorship development, research on the role of advising by student affairs administrators in promoting self-authorship, and exploration of core student affairs competencies and skill sets needed to promote self-authorship in college students.

Finally, methodologies used in the study of self-authorship are also discussed. 


\section{Self-Authorship Development}

\section{Roots of Self-Authorship}

The concept of self-authorship stems from a body of constructivist developmental work which aims to understand how people interpret and make meaning of their experiences (Baxter Magolda, 2001; Creamer \& Laughlin, 2005; Daloz Parks, 2000; Kegan, 1982, 1994). Constructivism refers to the notion that both people and organic institutions build or construct the reality they perceive. Developmentalism is the idea that people and meaning-making systems evolve over time through stages of increasing complexity, in cycles of alternating stability and change (Kegan, 1994). The constructivist development tradition, and research on self-authorship, focuses on how people know rather than the content of what they know (Abes et al., 2007; Baxter Magolda, 2001; Daloz Parks, 2000; Kegan, 1982, 1994). The foundation of constructivist development tradition stems from Piaget's work on cognitive structures (Baxter Magolda \& King, 2007). Self-authorship, and many other college student development theories, are predicated on Piaget's theory that development occurs as a result of cognitive dissonance within one's current meaning-making structure, promoting the potential for emergence of a new, more complex structure (Baxter Magolda, 2001; Kegan, 1982; Perry, 1968/1999). In this section, the foundational work of Robert Kegan, who built on Piaget's theory and developed the concept of self-authorship, will be discussed in relation to its contributions to the work on self-authorship and meaning making in young adults. 
Kegan developed a theory that underscores the centrality of meaning making to human development (Baxter Magolda, 2009; Kegan, 1982). His theory identified a relationship between people's psychological experiences and their social influences, thereby integrating theories of human cognition and affect (Kegan, 1982). Central to the theory is the subject-object relationship, the primary mental model we use to organize our mental states. The mental structures with which we make meaning consist of that over which we have control (objects) and that which has control over us (subjects) (Kegan, 1982, 1994). The term subject means "those elements of our knowing or organizing that we are identified with, tied to, fused with, or embedded in" (Kegan, 1994, p. 32). Object "refers to those elements of our knowing or organizing that we can reflect on, handle, look at, be responsible for, relate to each other, take control of, internalize, assimilate, or otherwise operate on" (Kegan, 1994, p. 32). In other words, we are subject to subjects, but have control over objects. The process of human development involves progression through a succession of stages in which embedded subjects become objects under our control.

Kegan $(1982,1994)$ identifies five meaning-making structures, which he calls orders of consciousness. People evolve from childhood through adulthood in a series of stages that mark increasingly complex ways of understanding. As people move to a new higher order, they are able to reflect on prior subjects that have now become object. Progression through the orders of consciousness happens when previously held meaningmaking systems are no longer adequate to meet the demands of the current situation. Kegan's stages are not solid structures; they are moving patterns of meaning making that 
evolve to include increasing levels of complexity over time (Kegan, 1982; Daloz Parks, 2000).

In Kegan's stage 0, the incorporative order of consciousness, the subject is reflexes, and there is no object. This means that a baby does not differentiate between itself and its environment; its senses, movements, and reflexes define its experience in the world. In stage 1, impulsive, mastery over reflexes has made them object, and impulses and perceptions become the new subject. For example, a young child in this order has begun to control his reflexes. He is now subject to his perceptions and may use transitional objects to distinguish self from others (i.e., imaginary friends). In stage 2, imperial, impulses and perceptions become object and needs and interests become subject. The imperial order typically takes place during the early teen years and is characterized by control over impulses and perceptions and the development of an enduring disposition. Teens begin to bargain and demand more control over these aspects of their lives, and are now subject to their own needs, interests, and desires. People generally move through the first two stages by the time they reach adolescence; therefore, for the purposes of this study, the third and fourth orders are most relevant to college students and young adults. It is important to note that adults don't necessarily progress through all of the stages; they may, for example, remain in the 3rd order of consciousness for their entire adult lives. If progression through the following orders occurs, it may happen at any time during adulthood.

During the 3rd order, interpersonal, needs, interests, and wishes become object and interpersonal mutuality becomes subject. In this order, adults become able to 
recognize the difference between their desires, needs, and interests and those of others. Adults explore mutual one-on-one relationships and identify with shared values and feelings. Adults in this stage become subject to interpersonal relationships and, since adults in this stage do not yet have access to a solid sense of self, the thoughts and feelings of trusted others are often internalized. If adults move to the 4 th order, they typically do so after they graduate from college, when they face greater challenges and have fewer supports (Abes et al., 2007; Baxter Magolda, 2001).

In the 4th order, institutional, interpersonal mutuality becomes subject and selfauthorship, identity, psychic administration, and ideology become object. This order is characterized by achievement of mutual relationships, paving the way for movement towards self-authorship, or the development of a sense of self and an identity no longer based on others' definitions. In this stage, adults are subject to personal autonomy, independence, self-definition, achievement, and need for ideological support. Particularly germane to this study, Kegan (1982) mentions that the shock and loneliness of going away to college can serve as a catalyst for a new evolutionary truce. He emphasizes the necessity for college advisors to resist the urge to "hand-hold" too much during this stage. He also identifies the need for campus advisors to provide a "bridging environment that both recognizes the old interpersonalism but refuses to be swept into it" and claims that excessive support "is actually more than hand holding ... it is a holding of the whole life enterprise" (p. 186). The degree to which college students are advised in ways that strike a fruitful balance between autonomy and support to promote selfauthorship is the subject of this study. 
During the 5th and final interindividual order of consciousness, authorship, identity, psychic administration, and ideology are now object, and interindividuality, interpenetrability of self-systems becomes subject (Kegan, 1982). In this order, a person has a solid sense of self and identity, and has the ability to understand and reflect on meaning-making systems which are different from their own.

Kegan's (1982) theory added to the work of Piaget in several ways. While Piaget's theory of development ends in adolescence, Kegan $(1982,1994)$ recognized that development continues into adulthood. Research on the continued development of college students and young adults in their 20 s and 30s supports the assertion that development continues through adulthood (Arnett, 2004; Astin, 1993; Baxter Magolda, 2001; Pascarella \& Terenzini, 2005; Settersten \& Ray, 2010). Kegan $(1982,1994)$ also extended Piaget's theory and introduced the concept that development includes combined growth in three dimensions: epistemological, intrapersonal, and interpersonal.

Subsequent research confirmed that dissonance occurring in any of the three dimensions can promote development (Pizzolato, 2005).

Evolution through Kegan's stages occurs when a person recognizes that his current meaning-making system is inadequate to understand an experience, ushering in a new "evolutionary truce." The cognitive dissonance and psychic discomfort occurring during times of transition can cause one to hold onto previous ways of knowing. In order to move to the next phase, one must let go of old ways of knowing to embrace new ones. Progression through Kegan's stages involves oscillation between independence and inclusion, or what Kegan calls "differentiation and reintegration" (Kegan, 1994, p. 39). 
This journey takes place in a holding environment, an environment that ideally supports both holding onto previous ways of knowing and letting go of old and inadequate thought patterns. A person's support systems (such as parents or advisors), institutions (such as college campuses), or belief systems may serve as holding environments for young adults as they grow. Kegan (1994) advocates for developmental approaches to education that "support and foster (not just promote and expect) its consciousness curriculum for youth" (p. 56). This study seeks to identify the ways in which interactions with new student affairs professionals may serve as holding environments that foster growth for students in times of transition.

The constructivist developmental framework of Robert Kegan was applied to college students by Marcia Baxter Magolda (2001). Her 25-year longitudinal study of the development of self-authorship in college students and young adults has served as a foundational work in the field of college student development. Kegan (1994) described self-authorship as:

A new whole, an internal identity ... that can coordinate, integrate, act upon, or invent values, beliefs, convictions, generalizations, ideals, abstractions, interpersonal loyalties and intrapersonal states. It is no longer authored by them, it authors them and thereby achieves a personal authority. (p. 185)

Baxter Magolda defines self-authorship as a developmental process typically occurring in one's 20 s and 30 s involving the ability to internally define one's beliefs, identity, and relationships (Baxter Magolda, 2001). It requires the ability to think logically through multiple points of view in a way that also recognizes and respects one's internal voice, goals, values and beliefs, and the ability to act in alignment with that 
reasoning (Pizzolato, 2005). The ability to make choices based on consideration of both internal and external sources of knowledge is a hallmark of self-authorship.

The majority of adults are between Kegan's 3rd and 4th orders of consciousness (Debold, 2002; Kegan, 1994). Kegan's 3rd order of consciousness has emerged as the most prevalent meaning-making structure among traditional-aged college students (Abes et al., 2007; Baxter Magolda, 2001). The 3rd stage is characterized by the capacity for conversations with multiple voices, though it is limited by an inability to consult with the self in the dialogue (Kegan, 1982). Self-authorship develops in Kegan's 4th stage. The transition to Kegan's 4th stage, the institutional period, is characterized by selfownership, self-dependence, and self-authorship (Kegan, 1982). Kegan (1994) argues that 3 rd order consciousness is inadequate to meet the demands of modern life. College has the potential to promote movement to Kegan's 4th order of consciousness through advising approaches, programs, and systems that support the development of selfauthorship in students (Baxter Magolda, 2001; Baxter Magolda \& King, 2004; Pizzolato \& Ozaki, 2007).

\section{The Case for Promoting Self-Authorship in College}

Self-authorship typically occurs after young adults leave the supportive college environment and begin to experience the challenges of leading more independent lives (Baxter Magolda, 2001). However, as previously mentioned, research indicates that it may be possible to facilitate self-authorship during the students' college career (Baxter Magolda, 2001, 2003; Daloz Parks, 2000; Hodge et al., 2009; Pizzolato, 2005). Since college students often experience powerful and challenging experiences during college, 
student affairs administrators and faculty may be "particularly well positioned for selfauthorship interventions" (Pizzolato, 2005). Students have the capacity to rise to the level of complexity in their environment (Baxter Magolda, 2003). Campuses can promote development of self-authorship through revamped curriculum, co-curricular experiences, and campus structures that support knowledge creation, programs that challenge students to identify with the well-being of others, and advising and mentoring relationships that promote development of the self (Baxter Magolda, 2001). This study will explore college advising and mentoring relationships.

There are a number of benefits to speeding up the self-authorship process. As mentioned in chapter 1, self-authorship is linked to the development of other key learning outcomes in higher education. For example, the Association of American Colleges and Universities' Liberal Education and America's Promise (LEAP) initiative identified "Essential Learning Outcomes" for education in a new century (AACU, 2007). Many of these learning outcomes could be advanced by the development of self-authorship, including: inquiry and analysis, critical and creative thinking, and problem solving (Baxter Magolda, 2001; Pizzolato, 2008; Pizzolato \& Ozaki, 2007), civic knowledge and engagement (Baxter Magolda \& King, 2004), intercultural knowledge and competence (Abes et al., 2007; Kegan, 1994; Taylor, 2008), ethical reasoning and action (AppelSilbaugh, 2007; Baxter Magolda \& King, 2004), foundations and skills for lifelong learning (Baxter Magolda \& King, 2004), and synthesis and advanced accomplishment across general and specialized studies (Baxter Magolda \& King, 2004). 
The Council for the Advancement of Standards in Higher Education, a nationwide organization created in 1979 to establish national standards in student affairs, developed a set of learning outcomes for student learning. Many of these outcomes are also linked to the development of self-authorship, including: intellectual growth (Baxter Magolda, 2001; Pizzolato, 2008; Pizzolato \& Ozaki, 2007), clarified values (Baxter Magolda, 2001; Pizzolato, 2008; Pizzolato \& Ozaki, 2007), career choices (Baxter Magolda, 2001; Creamer \& Laughlin, 2005), meaningful interpersonal relationships (Baxter Magolda, 2001; Pizzolato, 2008), independence (Baxter Magolda, 2001), appreciating diversity (Abes et al., 2007; Taylor, 2008); and personal and educational goals (Baxter Magolda, 2001; Creamer \& Laughlin, 2005).

Similarly, outcomes published in Learning Reconsidered 2, a joint publication of seven national associations in the field of student affairs, are also linked to selfauthorship development. These include: increases in cognitive complexity (Baxter Magolda, 2001; Pizzolato, 2008; Pizzolato \& Ozaki, 2007), knowledge acquisition (Baxter Magolda, 2001; Pizzolato 2008), and integrity acquisition, integration and application (Appel-Silbaugh, 2007).

In addition to gains in learning outcome achievement, students who reach the selfauthorship stage during college could also make more mature and informed decisions about their beliefs, identities, relationships with others, and their futures. Based on the results of her longitudinal research, Baxter Magolda (2003) concludes that these students would be more likely to choose a major and a career based on their personal values and less likely to choose one because they felt that someone else wanted them to do so. They 
would be less likely to change majors and more engaged in deep learning experiences that are connected to their area of interest. Students would be better able to communicate their learning to potential employers and would make informed personal and relationship decisions. (Baxter Magolda, 2003).

Students who have reached self-authorship have greater appreciation for multiple viewpoints and increased intercultural competence.

Intercultural competence requires three dimensions of development, which are associated with the three domains of self-authorship development. These include an acceptance of multiple perspectives (epistemological complexity), the capacity for interdependent relations with others (interpersonal complexity), and an internal sense of self that is not threatened by difference (intrapersonal complexity). (Baxter Magolda, 2003, p. 234)

Campuses that prioritize the development of self-authorship may be more likely to provide richly diverse and inclusive campus environments that promote internal reflection about identities and values (Kegan, 1994).

In addition to the practical outcomes of reaching self-authorship during college, there are intrinsic benefits as well. Developing a stronger and more finely tuned internal voice may allow students to more deeply pursue questions of meaning and purpose in their lives. Sharon Daloz Parks (2000) calls for campuses to provide opportunities for students to reflect on big questions that are "both deeply intimate and ultimate" (p. 25). Reflective conversations with advisors and mentors can prompt these questions, including those that promote self-authorship and help students in their process of "becoming at home in the Universe" (Daloz Parks, 2000, p. 34). Not surprisingly, such intrinsic gains have other benefits as well. In one study of 344 undergraduate students at a large Midwestern university, students who scored highly on the Purpose in Life Scale 
(which may be more characteristic of self-authoring students) also persisted at a higher rate in college than those who did not (Dewitz, Woolsey, \& Walsh, 2009).

Finally, institutions of higher education are not fully preparing students for the complex world after college, a time when they no longer have such a robust system of support (Baxter Magolda, 2003). Because higher education provides "excessive support and formulas for being successful, students have not needed to develop complex epistemological orientations" (Pizzolato, 2008, p. 230). Student affairs professionals have the potential to fill this gap. The next section will discuss research conducted about how self-authorship develops, its stages, and the ways campuses and student affairs professionals can promote it.

\section{The Process of Self-Authorship Development}

Before identifying the stages of self-authorship, it is important to understand the domains of one's life where self-authorship develops. Baxter Magolda's work on selfauthorship supports Kegan's (1982) assertion that self-authorship integrates development and maturation in three domains: (a) deciding what we know or believe (epistemological complexity); (b) understanding our identities and how we will use our internal voice to guide personal decisions (intrapersonal complexity); and (c) choosing how we will interact with others (interpersonal complexity) (Baxter Magolda, 1999, 2001, 2003). The epistemological dimension refers to assumptions people have about the nature of knowledge and how they decide what they believe (Baxter Magolda, 2007; Perry, 1968/1999). The intrapersonal dimension involves the ability to choose values and construct an internal identity that is not dependent on others (Baxter Magolda, 2007; 
Kegan, 1994). Those who self-author in the interpersonal dimension have the capacity to manage multiple perspectives, coordinate their own needs with the needs of others, and engage in genuine, interdependent relationships (Kegan, 1994). Lacking complexity in one domain can hinder utilization of the others (Hodge et al., 2009). For example, one may have the epistemological capacity to self-author, but not the ability to apply it in her intrapersonal or interpersonal life. While development in one dimension may precede development of another, achievement of self-authorship in all three dimensions is key to reaching the final internal foundations stage. Data in the current study has been coded and analyzed in each of the three dimensions to understand the new professionals' selfauthorship development with greater nuance.

Baxter Magolda's (2001) longitudinal study of self-authorship development among young adults identified a four-phased process of self-authorship development: (a) external formulas, (b) the crossroads, (c) becoming self-authored, and (d) internal foundations. Through this process, the source of knowledge moves from external to internal ways of knowing (Baxter Magolda, 2001). In the first phase young adults define themselves and make decisions based on external formulas. In this phase they rely on experts for decision making and knowledge creation. Young adults often make the assumption that knowledge is certain and imparted by authority figures for them to receive. People in this stage often assume the existence of formulas for success (Magolda, King, Taylor, \& Perez, 2008). Young adults in this stage rely on borrowed prescriptions for understanding and interacting with the world. When they become 
significantly dissatisfied with external formulas, or when they are faced with difficult life challenges, they may become primed for the second phase.

The pivotal second stage, the crossroads, occurs as a result of cognitive dissonance that young adults must reconcile (Daloz Parks, 2000; Baxter Magolda, 2001). Dissonance can help young adults recognize the incongruence between external influences and their internal voice (Baxter Magolda, 2007). When old mental structures are inadequate for problem solving, a period of discomfort and disequilibrium occurs. A more complex level of thinking has the potential to develop as a person tries to restore equilibrium (Brown, 2004). For some, it may take multiple experiences of cognitive dissonance to move from feeling dissatisfied with external definition to experiencing a catalyst that leads them to search for internal definition (Pizzolato, 2005).

Researchers use a variety of terms to describe this critical period of disequilibrium. For example, Baxter Magolda describes crossroads experiences as having two phases, listening to one's inner voice and cultivating the inner voice (Baxter Magolda, 2009). Pizzolato describes provocative moments, which disrupt equilibrium to the point that young adults feel compelled to change their goals and understandings of themselves, either by considering significant changes or committing to new goals or values (Pizzolato, 2005). Daloz Parks's shipwrecks (2000) occur with significant loss, betrayal, or new realizations. In Nash and Murray's choosing myself is scary cycle, students question their deeply-held beliefs, seek meaning, face difficult choices in which their needs and desires conflict with their sense of duty to others, and fear letting down loved ones (Nash \& Murray, 2010). For the purposes of this study, Marcia Baxter 
Magolda's term crossroads will be used to refer to this stage of the process unless specifically referring to another researcher's work. Baxter Magolda has been the most frequently cited researcher on self-authorship for over 25 years and the term crossroads evokes appropriate images of crisis, choices, and the possibility of progression.

The multi-institutional Wabash National Study of Liberal Arts Education identified micro-steps that occur in the crossroads, moving young adults from reliance on others for making meaning to coordinating external influences using one's internal voice (King et al., 2009). Through analysis of interviews with 315 students in their first year, and 228 follow-up interviews in their second year, the study identified four micro-steps within the crossroads: entering the crossroads, standing in the crossroads, moving through the crossroads, and leaving the crossroads: a threshold of self-authorship. The Wabash mixed-methods study will be discussed further in the Methods section.

In the third stage identified in Baxter Magolda's longitudinal study, young adults are becoming self-authored. They begin to explore beliefs, identities, and their relationships with others in a way that simultaneously honors their own internal voice and the perspectives of others (Baxter Magolda, 2001, 2009). Individuals have the capacity to take in others' ideas, but remain critical of them until they see how they align with their own values and ideas. They can make decisions despite others' differing opinions (King et al., 2009).

In the final phase, the internal foundation stage, adults begin to combine their understandings into philosophies that guide their everyday perceptions and choices. In this stage, people have the ability to self-author in each of the three domains: 
epistemological, intrapersonal, and interpersonal (Baxter Magolda, 2001; Kegan, 1994). Adults in the internal foundation stage have internal security in all three dimensions, allowing them to explore a variety of perspectives, engage in authentic and mutual relationships with others, choose values, and construct their identities. Arrival at this phase rarely occurs before age 30 (Baxter Magolda, 2001, 2009).

According to Baxter Magolda's research (2009; Baxter Magolda et al., 2008) selfauthorship requires that young adults develop three capacities, which are built throughout the self-authorship process. First, they must begin trusting their internal voice, which involves the realization that, while no one can control what happens, one can control one's reaction to it. Recognizing the difference between occurrences in the world and one's reaction to them provides the opportunity for individual reflection, agency, and choice. Next, young adults must build an internal foundation that begins to collate their choices into commitments that form a guiding life philosophy. Finally, young people must solidify these philosophies so that they become second nature, which Baxter Magolda terms securing internal commitments (Baxter Magolda, 2009; Baxter Magolda et al., 2008). These often-unconscious roadmaps help young adults navigate life's challenges informed by a strong sense of self. The ability to develop these internal roadmaps has an impact on multiple dimensions of a young adult's experience.

Critics of the stage model of self-authorship development claim that it may be too linear to capture variations and complexities in the developmental process. Research indicates that development happens in a cyclical way, suggesting that one may cycle through self-authored thinking and back to previous stages in the development process 
(Abes et al., 2007). Also, the ability to self-author in one aspect of life does not necessarily correlate with the ability to do so in another. For example, self-authorship development typically occurs in a student's personal domain before he or she applies it to an academic one (Pizzolato, 2008). Similarly, depending on a person's experiences with particular identities (e.g., gender, race, sexual orientation) one may display self-authored thinking in connection with one identity before others (Abes et al., 2007). For example, if a person has had significant struggles around the development of a particular identity (e.g., sexual orientation), they may demonstrate self-authored thinking around that identity before others. For this reason, the interview protocol for this study included questions to identify demonstrations of self-authorship in all three dimensions (epistemological, interpersonal, and intrapersonal). Coding was developed to assess development in all three dimensions, which served as a foundation for identification of the new professional's overall stage of self-authorship. Research on the complexities of individual meaning-making patterns, and in particular contexts, may indicate a need to revise Baxter Magolda's (2001) model to reflect possible variation in self-authorship development in different contexts.

\section{Nuances and Complexities of the Journey Towards Self-Authorship}

A variety of personal and contextual factors influence whether a crossroads experience becomes a transformational experience, moving a young adult towards selfauthorship. Research in this area has begun to identify nuances and complexities of the journey. Exploring the nuances of self-authorship development may identify additional 
strategies that may help advisors better assist students along the path toward selfauthorship.

Jane Pizzolato's research identifies possible personal and contextual factors, such as coping skills and persistence in spite of challenges, associated with provocative moments that promote self-authorship development. Pizzolato describes provocative moments as the culmination of crossroads experiences that ultimately lead to selfauthorship (Pizzolato, 2005). Based on her study of narratives from 613 college students about important decisions they made, Pizzolato found four personal capacities that determine whether a crossroads event is sufficiently "provocative" to achieve selfauthored thinking. They include: (a) recognition of the need to define one's self; (b) volitional efficacy, or the belief in one's ability to persist in goal-oriented behavior despite challenges; (c) behavior regulation (self-regulation) or the degree to which decisions were driven by internal (vs. external) forces; and (d) coping skills (Pizzolato, 2005). For example, the study found several sources of behavior regulation: "(a) others, (b) external circumstances, (c) God, or (d) self" (Pizzolato, 2005, p. 625). This is an important finding because self-authorship, in part, requires the ability to self-regulate rather than rely on external sources of behavior regulation. The study analyzed students' accounts of major decisions in their lives, and found that self-regulation is a necessary but insufficient contributor to self-authorship. Interestingly, the students who demonstrated self-authorship did self-regulate; however, not all students who selfregulated exhibited self-authorship (Pizzolato, 2005). Additionally, a lack of volitional efficacy, or belief in one's ability to persist despite challenges, significantly impeded 
movement from provocative moment to self-authorship (Pizzolato, 2005). Working with students to foster a belief in the student's ability to persist despite challenges (volitional efficacy) may require significant support from mentors and advisors, while working with students on their ability to direct their own decisions may require a more challenging approach. Volitional efficacy and self-regulation were included in the advising strategies coding scheme developed for this study.

Pizzolato's study asked students to describe an important recent decision in their lives. The study found that the purpose of the student's decision also has an impact on whether a potentially provocative moment becomes a catalyst for self-authorship (Pizzolato, 2005). In her study, students who oriented themselves towards their situation in a way that allowed them to see a variety of options for evaluation seemed to demonstrate progress towards self-authorship, unlike students who did not identify multiple options (Pizzolato, 2005). When decisions stemmed from external circumstances, students focused exclusively on external characteristics of the situation (i.e., why they had to make this decision), frequently ignored their volitional efficacy, and did not self-regulate (i.e., they made decisions based on external factors instead of internal ones). If students demonstrated volitional efficacy, or if they self-regulated when making externally-catalyzed decisions, the provocative moment often led to movement toward self-authorship. When processing potentially provocative moments, advisors and mentors can ask probing questions that will help students connect with their volitional efficacy and self-regulation behaviors, and these situations are then more likely to become catalysts for self-authorship. Advising approaches that promote volitional 
efficacy and self-regulation were included in the coding scheme for new professional advising strategies in this study.

In addition to the source of decision making, context also influences the degree to which students display self-authorship. Pizzolato conducted a study in which 90 students from two large public research institutions participated in an interview and completed a short-answer questionnaire regarding their beliefs, goals, and epistemological orientations. The study found that students' epistemological orientations differed significantly in academic and personal contexts, primarily due to differing goals in the two contexts (Pizzolato 2007, 2008). Students chose which epistemology they used based on their perceptions of what is valued in a particular context. For example, most students in her study perceived that professors valued factual knowledge rather than selfauthored thinking; therefore, they were less likely to self-author in an academic context. In contrast, in their personal lives, students in her study more frequently aimed for independence and development of a sense of self (Pizzolato, 2007, 2008). This study found that students are more likely to make progress towards self-authorship outside of the classroom. For student affairs professionals working with students on a personal basis, this finding underscores the developmental opportunities associated with exploring crossroads experiences with students outside of the classroom.

Students' unique experiences in a particular aspect of their lives also influence the degree to which they self-author in a given context. For example, students may have particularly salient experiences around specific aspects of their identity (e.g., race, sexual orientation), and therefore may display self-authored thinking in relation to some of their 
multiple identities before they do so in others. Overall, students with more complex meaning-making capacities were better able to filter the role of contextual influences, such as family background, peer culture, and stereotypes, in their understandings of their multiple identities (Abes et al., 2007). Abes et al. (2007) combined results from Abes and Jones's 2004 study of 10 lesbian college students, which explored the meaningmaking capacity related to the development of participants' multiple identities, with examples of college student meaning making from Baxter Magolda's (2001) longitudinal study. Their findings suggest that students seem to use more complex meaning-making strategies in their understanding of some of their multiple identities than others, depending on the contextual influences they received in relation to a particular identity (Abes et al., 2007). Abes et al. (2007) developed a Reconceptualized Model of Multiple Dimensions of Identity to include a meaning-making filter that more or less finely filters contextual influences based on the student's experiences with a particular identity. Their study underscores the unique intricacies of self-authorship development based on individual experiences, and may point to a need for a more complex model of selfauthorship than Baxter Magolda's four-staged process.

\section{The Role of Student Affairs Professionals in Students' Development of Self-}

\section{Authorship}

Student affairs professionals have the potential to help students sift through the complexity of crossroads experiences in ways that promote movement towards selfauthorship. Because of their frequent and regular contact with students, new student affairs practitioners are in a unique position to seize or create opportunities for 
meaningful self-defining conversations with students, both one-on-one and in group settings. Advising and mentoring relationships have the potential to help a student process a crossroads experience and to promote advancement towards self-authorship (Baxter Magolda, 2001; Daloz Parks, 2000; Pizzolato, 2008). Student affairs staff can invite students into conversations about the reasons behind their interests and choices, who they are, who they want to become, and how they plan to get there. They can serve as allies and facilitators by providing appropriate levels of challenge and support for students as they process their crossroads experiences. Through mentoring and programs, staff can help students identify and assess multiple perspectives, develop their ability to consider competing viewpoints, discover consequences, and weigh their own ideas and values (Daloz Parks, 2000; Nash \& Murray, 2010; Pizzolato, 2005).

Baxter Magolda's 25-year longitudinal study on self-authorship yielded the Learning Partnership Model (LPM), which provides a framework for administrators and faculty interested in creating intentional learning environments that promote progress towards self-authorship. The model is based on three key assumptions and three key principles. The assumptions, which describe the challenges that promote self-authorship, are: (a) knowledge is complex and socially constructed, (b) self is central to knowledge creation, and (c) authority and expertise must be shared. The three key principles describing the supports that foster self-authorship are: (a) validating the learner's capacity to know, (b) situating learning in the learner's experience, and (c) defining learning as mutually constructed (Baxter Magolda, 2001; Baxter Magolda \& King, 2004). 
In the current study, examples of these assumptions and principles from the literature were included in the coding scheme of advising strategies known to promote self-authorship.

The LPM has been used in curricular and co-curricular settings to promote selfauthorship. Criticism of the LPM approach, particularly in an academic setting, includes concerns that course content may be sacrificed, faculty may lose a degree of control over content and learning, and students as partners may not possess the sophistication to maintain rigor (Blimling, 2002). Similar concerns may emerge regarding co-curricular instruction as well. Without the proper challenge and support to push them in their learning and development, students may not develop the ability to reflect and process in the more reflective ways needed to reach self-authorship. To address these concerns, Baxter Magolda contends that educators will need to create transitional cultures for students embedded in absolute thinking. The educator should use his or her own knowledge in a dialectic way, effectively manage conflict, and incorporate multiple ways of making meaning (Baxter Magolda, 1999). Student affairs practitioners and faculty can use the LPM to structure learning experiences and provide developmental advising to students.

The following is one example of the LPM's effectiveness in promoting selfauthorship. The STEP program, an academic advising retention initiative, was developed using the LPM as its foundation (Pizzolato \& Ozaki, 2007). In a study of 18 academically at-risk students at a public Midwestern university who participated in the program, outcomes of the program were examined using semi-structured interviews and 
advisor session taping. Researchers found that while students in the program did not reach self-authorship stage, they did make significant progress towards it. Staff members, who used the LPM model to guide their interactions with students, were able to effectively counsel students toward cognitive interdependence, in which students could successfully manage conflicting expectations in a way that considered their needs and the needs of others. As a result of their consideration of others' viewpoints, students also developed skills that decreased interpersonal dissonance. The program also had an effect on students' epistemic beliefs that they could control outcomes, and that the self is important to knowledge construction and decision making (Pizzolato \& Ozaki, 2007). These changes in skills and attitudes are likely precursors to self-authorship. The study has a number of limitations. The small number of study participants may limit its applicability to other contexts. Also, lacking comparison with a group of students who did not participate in the STEP program, it is possible that the developmental gains experienced by participants may not be a direct result of their participation in the program.

Similarly, a study of a campus student honor council demonstrated the tenets of the LPM. An ethnographic study of 12 students involved in the honor council demonstrated growth on dimensions of self-authorship; however, the structured, functional nature of the council mitigated progression along the self-authorship continuum. While the students made some progress towards self-authorship, the structure of the council did not provide enough opportunities for challenging students in ways that would maximize their development. This research also highlighted the integral 
role of mentorship to support student's journeys towards self-authorship (AppelSilbaugh, 2007). Limitations to this study include the small number of participants and the lack of comparison to students not involved in the honor council.

Other researchers who have conducted studies on college student development have offered additional options for administrators wishing to promote students' development of the self, including: emphasizing action and engagement (Brown, 2004), facilitating interpersonal collaboration and encouraging feedback (Brown, 2004), making intentional learning more visible and accessible for students (Brown, 2004; Daloz Parks, 2000), asking students sufficiently big and complex questions (Brown, 2004; Daloz Parks, 2000; Hodge et al., 2009), and creating mentoring communities (Daloz Parks, 2000). In the current study, advising approaches from this body of research were included in the coding scheme for advising strategies that promote self-authorship.

\section{New Professional Competencies for Promoting Self-Authorship}

As the field of student affairs has increasingly focused on the development of standards and assessment measures, researchers have investigated the professional competencies needed for effective practice in the field (Burkard, Cole, Ott, \& Stoflet, 2005; Loveall \& Kosten, 2000; Waple, 2006; Weiner, Bresciani, Hickmott, \& Felix, 2011). The focus of this study will be the development of competencies among professionals who have the potential to promote self-authorship in students. This study will explore the degree to which new professionals have the capacity to employ these competencies in a way that maximizes developmental opportunity for students. A 
number of researchers have identified competency areas that relate to the facilitation of development of self-authorship among college students.

Loveall and Kosten (2000) analyzed 23 empirically-based studies on student affairs professional competencies, skills, or knowledge bases needed for effective practice in the field. Their meta-analysis categorized the competencies into three areas: skills, knowledge, and personal traits/qualities. Many of the most frequently-identified skills, knowledge areas, and traits include those that have the potential to promote selfauthorship. For example, $78 \%$ of studies examining skills necessary for effective practice in the field included human facilitation (such as counseling skills, interpersonal relationships skills, and communication skills) as a necessary skill for effective successful student affairs practice. The second category of competencies was knowledge. Most frequently cited in this category was student development theory, which is integral in promoting student advancement in self-authorship. The knowledge category also included functional unit responsibilities, organizational development/behavior, and student needs, values and behavior. The third category reported in this meta-analysis was personal traits/qualities which consisted of interactive qualities (such as working cooperatively) and individual traits (such as enthusiasm). Though discussed less frequently than skills and knowledge, personal traits/qualities were discussed in $48 \%$ of the studies analyzed. The skills, knowledge, and traits needed for effective student affairs practice identified in the study are consistent with those described as promoting selfauthorship in students (Baxter Magolda, 2001; Baxter Magolda \& King, 2004; Pizzolato \& Ozaki, 2007). 
One study sought to create consensus among mid- and senior-level student affairs administrators about the requisite responsibilities, skills, and knowledge bases for entrylevel positions in the field (Burkard et al., 2005). The study utilized a Delphi method, which used a series of three surveys to build consensus among the panel of 104 randomly-selected administrators who were members of the National Association of Student Affairs Administrators in Higher Education (NASPA). In this study, many of the top responsibilities of new professionals included those that would put new professionals in positions of advising and mentoring students, and would provide opportunities for promoting self-authorship development among students. Examples included: advising student groups (\#2), advising individual students (\#4), mentoring student leaders (\#6), supervising student employees (\#7) and paraprofessional staff (\#11), developing and providing training for student paraprofessional staff (\#19), facilitating conflict mediation $(\# 20)$, providing crisis intervention (\#22), and providing counseling to individual students (\#23). Of the 32 competency areas identified in the study as essential for new professionals, two emerged as particularly important, both of which are necessary for promoting self-authorship: personal qualities (i.e., critical thinking, analytical skills, problem solving, and communication skills) and human relations skills (i.e., counseling, multi-cultural competency, consultation abilities, and advising). Notably, mid- and senior-level administrators identified Baxter-Magolda's theory of epistemological reflection (self-authorship) as among the most important theories for entry-level professionals. 
The Delphi study also found that mid- and senior-level administrators expected new professionals to have more advanced counseling skills than are typically taught in introductory counseling courses offered in student affairs preparation programs (Burkard et al., 2005). The current study may test the Delphi study findings by comparing advising strategies of those who attended student affairs master's programs (and therefore likely received counseling and/or adult development coursework) and those who did not.

New professionals themselves have also identified advising students and crisis management as essential aspects of their work (Waple, 2006); both of these functions involve interactions around potential crossroads experiences and have the potential to serve as vehicles for self-authorship development (Baxter Magolda, 2001; Pizzolato \& Ozaki, 2007). In one study, 1,237 entry-level professionals who had been in the field for 5 years or less, and who were members of NASPA or ACPA professional associations, were asked to rank 28 competencies based on the degree to which the competencies were necessary for their current job (Waple, 2006). Skills they deemed essential included student development theory, problem solving, advising students and student organizations, and crisis and conflict management (Waple, 2006). New professionals who work with students in advising situations that involve problem solving, crisis and conflict management (potential crossroads experiences) have the opportunity to promote self-authorship through these interactions.

In addition to skill development, new professionals' capacities for self-authorship may also impact their comfort levels with student advising. While mentoring relationships are integral for promoting self-authorship among college students, their 
effectiveness may be mitigated by the developmental capacity of the student affairs mentors. New student affairs professionals may, or may not, be able to identify their own values, beliefs, and identities. Therefore, Baxter Magolda and King (2008) hypothesize that new professionals may feel less comfortable dealing with students' personal issues in a mentoring or advising relationship. Findings from a nationwide longitudinal study of 130 new student affairs professionals support this hypothesis. Respondents in the study often discussed feeling that they lacked advising skills and mentioned frequently having periods when they lacked confidence (Renn \& Jessup-Anger, 2008). Similarly, new professionals who described their first student affairs positions in the book Job One also described having periods where they lacked confidence in their skills and abilities (Magolda and Carnaghi, 2004). New professionals' lack of confidence in their advising skills may impact the kind of advising students receive. The current study explores the degree to which new professionals themselves display evidence of self-authorship, and investigates linkages between development of self-authorship among new professionals and the advising strategies they use with college students.

Not only does the literature discuss the skill set and confidence needed for student affairs professionals to promote student development, a new discussion about the development of self among student affairs professionals themselves has also emerged. Until recently, literature in the area of student affairs competencies included little, if any, discussion about the development of the self among student affairs professionals, which is central to becoming a self-authoring practitioner and to promoting student development. However, in 2010, ACPA and NASPA adopted the recommendations from 
the Joint Task Force on Professional Competencies, which included personal foundations among its 10 core competency areas for student affairs practitioners (ACPA \& NASPA, 2011). The personal foundations competency area includes the ability to maintain holistic wellness, integrity, openness and self-awareness. It also includes the capacity to be self-directed and self-reflective, which are integral to the achievement of selfauthorship in new professionals.

Development of student affairs practitioners' reflective capacities and selfauthored thinking is likely a prerequisite for promoting self-authorship in others (Baxter Magolda, 2007; Baxter Magolda \& King, 2004; Mills \& Strong, 2004). For example, in 2000 the division of Student Affairs at the University of Nevada Las Vegas (UNLV) underwent a major reorganization using Baxter Magolda's Learning Partnership Model (Baxter Magolda \& King, 2004) as a foundation (Mills \& Strong, 2004). The new organizational structure at UNLV intentionally supported the self-authorship development of student affairs staff, and promoted application of the Learning Partnership Model to their work with students. Focusing on the development of selfauthorship among staff resulted in increased emphasis on ways to enhance the psychosocial and cognitive development among the students with whom they work. Programs and services such as tutoring, leadership opportunities and community service projects were redesigned to facilitate development of self-authorship in students. Like the current study, UNLV operated on the assumption that increasing focus on the staff's capacity to self-author would enhance student outcomes. However, the UNLV example did not identify the developmental stage of self-authorship among staff, or the degree to 
which they employed Baxter Magolda and King's (2004) Learning Partnership Model approaches in their mentoring relationships with students. Examining this information through the current study tested the assumption of a link between self-authorship development among staff and the students with whom they work.

Human development theorists have also identified a link between personal development and the capacity to promote development in others, as hypothesized in the UNLV example. Stage theorists such as Kegan (1982, 1994), and Erikson (1959) assume that one has command over earlier developmental stages and continued access to prior patterns of thinking. For example, Kegan's orders of consciousness theory centers on the subject/object relationship (Kegan, 1982). Throughout our development, what was once subject, and controlled us, becomes object and therefore under our control. Put another way, when our tendency to be governed by external expectations becomes object, we can filter those external expectations through the self and gain control over our voice. This may imply that if a new student affairs professional hasn't yet achieved control over her voice, she may not have the capacity to intentionally assist others in doing so.

The core competency literature highlights the centrality of student affairs professionals' knowledge, skills and traits in promoting self-authorship in students. A new discussion in the literature speaks to the importance of the development of new professionals' sense of self, as well (ACPA \& NASPA, 2011). Still unknown is the degree to which new professionals have the ability to employ these competencies in ways that capitalize on the potential for student development of self-authorship. 


\section{Methods}

Self-authorship is typically assessed by analyzing data from semi-structured interviews where participants answer questions, about recent critical decisions, which are most likely to call upon their highest and most complex level of thinking (Baxter Magolda 2001; Perry, 1968/1999; Pizzolato, 2005, 2007). Semi-structured interviews provide consistency among interviews while permitting flexibility to allow for the inclusion of unique content (Baxter Magolda, 1999, 2001, 2007; Pizzolato, 2005). While other researchers have attempted to develop survey instruments and written response methods to assess self-authorship, (Creamer \& Laughlin, 2005; Pizzolato, 2005) the flexibility and ability to ask follow-up questions makes the semi-structured interview the most reliable and commonly-used method for assessing self-authorship. The following paragraphs describe the interview protocols that have been used to assess self-authorship. Most interview protocols assessing self-authorship are loosely based on Robert Kegan's Subject-Object Interview techniques, which explored content areas such as anger, anxiety and change in order to access participants' leading edges of development, rather than their general tendencies (Baxter Magolda, 2007). Marcia Baxter Magolda developed a Measure of Epistemological Reflection (MER), based on Kegan's subjectobject interview protocol (Kegan, 1982). The MER assesses self-authored thinking by asking students to respond to a series of questions covering their most recent major decision about their education, and their perspectives on teaching, the nature of knowledge, and learning (Baxter Magolda, 1999). While the MER assesses the epistemological domain of self-authorship among college students, it does not assess the 
interpersonal and intrapersonal domains. Also, portions of the MER interview are specifically geared to teaching and learning in college and may not be applicable to nonstudent populations.

Similarly, Baxter Magolda's 25-year longitudinal study of self-authorship development began with an open-ended interview that also focused on the epistemological development of college students. As the study continued after participants left college, the nature of the questions expanded to include the intrapersonal and interpersonal domains (Baxter Magolda, 2001). In this post-college version, questions focused on significant decisions participants made in the previous year, which could touch on any of the three domains. The post-college methodology was adapted for use with new student affairs professionals in the current study.

The multi-institutional Wabash National Study of Liberal Arts Education (King et al., 2009) identified micro-steps that occur in the crossroads, moving young adults from reliance on others for making meaning to coordinating external influences using one's internal voice (King et al., 2009). The mixed-methods Wabash National Study of Liberal Arts Education was developed to explore institutional practices and student experiences that affect growth in seven liberal arts learning outcomes, including integration of learning, inclination to inquire and lifelong learning, effective reasoning and problem solving, moral character, intercultural effectiveness, leadership, and well-being (King, Kendall Brown, Lindsay, \& VanHecke, 2007). The interview component of the study was also designed to assess students' meaning-making structures, using the framework of self-authorship and possible intersections between those structures and students' 
experiences. Through analysis of interviews with 315 students in their first year, and 228 follow-up interviews in their second year, the study identified four nuanced micro-stages within the crossroads, which include: entering the crossroads, standing in the crossroads, moving through the crossroads, and leaving the crossroads: a threshold of self-authorship. In consultation with Baxter Magolda, this refined analysis was used as a basis for codes which assessed the development of new professionals in the crossroads stage in the current study. However, after coding in the current study, the stages were collapsed into early, middle, and late stages of self-authorship development.

Jane Pizzolato (2005) developed a method for assessing self-authorship that could be scaled and used to assess self-authorship development with larger populations of students. The Experiences Survey (ES) includes written prompts that approximate those used in a semi-structured interview, asking students about an important decision they have made, other than the decision to apply to college (Pizzolato, 2005). While this approach allows distribution and assessment on a larger scale because it does not require one-on-one interviews and transcription, it does not allow for the follow-up questioning in semi-structured interviews that can be valuable in exploring responses in more depth. Pizzolato (2007) also developed The Self-Authorship Scale (SAS), a 24-item survey designed to assess self-authoring abilities, which is recommended for use in conjunction with the Experience Survey as an alternative to semi-structured interviews. While the SAS appears to be a reliable and statistically-sound measure of self-authorship, the open-ended questions on the Experience Survey allow for additional insights into young adults' reasoning and action not captured by the SAS alone. The scale also 
assesses self-perception of tendencies rather than particular examples of decision making. Asking about particular instances may yield more typical (and accurate) responses, rather than those participants perceive as optimal (Creamer \& Laughlin, 2005). Therefore, for the purposes of this study, I have chosen to use semi-structured interviews rather than the SAS and ES.

\section{Summary}

Based on the body of constructivist developmental work, Robert Kegan identified self-authorship as an integrated internal identity that provides individuals with the capacity to coordinate and act upon internal values and beliefs. Marcia Baxter Magolda's longitudinal research has applied this theory to college students and young adults. Baxter Magolda's four-stage process provides a framework for understanding the process of self-authorship development. Subsequent research has identified increasingly more nuanced stages of self-authorship development (King et al., 2009), though critics of Baxter Magolda's self-authorship process argue that a stage theory may be too simplistic for the fluid nature of self-authorship development.

Self-authorship typically occurs after young adults leave the supportive college environment and face more life challenges (Baxter Magolda, 2001). However, research shows that development of self-authorship in college is possible (Baxter Magolda, 2001, 2003; Daloz Parks, 2000; Hodge et al., 2009; Pizzolato, 2005). Self-authorship is also linked to student achievement of higher education learning outcomes (Abes et al., 2007; Appel-Silbaugh, 2007; Baxter Magolda, 2001; Baxter Magolda \& King, 2004; Kegan, 1994; Pizzolato, 2008; Pizzolato \& Ozaki, 2007; Taylor, 2008). Furthermore, research 
has identified advising strategies that may promote self-authorship development in college students (Brown, 2004; Baxter Magolda, 2001; Daloz Parks, 2000; Pizzolato, 2008; Pizzolato \& Ozaki, 2007). These strategies were included in the coding scheme for the current study to identify the degree to which new student affairs professionals utilize advising approaches that promote self-authorship in college students.

Many competency areas for new student affairs professionals identified in the research identify proficiencies required for effective practice; these areas dovetail with competencies needed for development of advising strategies that promote self-authorship. In this literature review, competencies were discussed that link qualities of effective student affairs practice with qualities needed to promote self-authorship in college students. Recent research on competency areas has begun to identify the need for development of the self among professionals in the field (ACPA \& NASPA, 2011). A hypothesis has emerged in the literature that development of self-authorship may be a prerequisite for advising college students in ways that promote self-authorship. This study explores that assumption.

Finally, several methods have been used to assess self-authorship, including semistructured interviews (Baxter Magolda, 2001; Kegan, 1982; King et al., 2009), mixed methods (Creamer \& Laughlin; Pizzolato, 2005), and survey instruments (Creamer \& Laughlin, 2005; Pizzolato, 2005). The most effective strategies have been semistructured interviews that ask participants about recent critical events or decisions that would call on their most sophisticated ways of knowing. This study employed the most commonly used semi-structured interview methodology. 


\section{CHAPTER THREE}

\section{METHODOLOGY}

\section{Methodological Overview}

The purpose of this study was to explore the degree to which new student affairs professionals display evidence of self-authored thinking, and to ascertain if they advise students using strategies known to promote self-authorship in undergraduate students. The study also examined differences in advising approaches used by new professionals depending on their stage of self-authorship development, age, gender, and education. Using qualitative methods, this study attempted to answer the following research questions:

RQ \#1: To what degree do new student affairs professionals demonstrate evidence of self-authorship? What common characteristics and trends emerge among new professionals in different stages of self-authorship development?

RQ \#2: In what ways, if any, do new student affairs professionals use strategies and approaches that facilitate self-authorship with undergraduate students?

a. What are the differences in advising approaches used by new student affairs professionals based on characteristics such as gender, age, education, and their own demonstrated stage of self-authorship development?

This study was designed to develop rich descriptions that expand possible understandings of new professionals' development in ways that may inform the way we educate and supervise them. For this reason, this study employed qualitative methods, 
specifically within-case and cross-case analysis in order to develop the most complete picture of the self-authorship development and advising practices of new student affairs professionals in the study. Qualitative methods are appropriate for this study because understanding the complexities of epistemological, interpersonal, and intrapersonal development of new professionals requires a research method that is flexible enough to explore nuances of complex patterns of thinking. Qualitative research methods are responsive to new data as it emerges (Charmaz, 2006; Glaser \& Strauss, 1967).

Qualitative research methods are ideal for developing theory based on thick descriptions (Geertz, 1973), which provide rich, in-depth, specific descriptions from which readers may draw their own conclusions.

Constructivist grounded theory methodology is the most commonly used approach to assess self-authorship because it captures the nuances of the complex meaning participants make of their experiences and how they arrive at their current understandings (Baxter Magolda, 2001; Creamer \& Laughlin; 2005; Kegan, 1982, 1994; Pizzolato, 2005). Constructivists study how or why participants construct meaning in some aspect of their lives (Charmaz, 2006). As opposed to methodology based on objectivist grounded theory, which seeks to gather concrete information about timelines, events, and behaviors, constructivist grounded theory methodologies focus on the ways people make meaning of their experiences, their assumptions, and their mental models (Charmaz, 2006). This approach involves sampling to build a theory, rather than sampling to be representative of the population (Charmaz, 2006). Constructivism identifies data and analysis as stemming from shared experiences with participants, and 
views the resulting theory as an interpretation of the data (Charmaz, 2006). For example, Baxter Magolda (1999) used constructivist grounded theory to analyze interviews, course documents, and field notes to develop a theory about the epistemological development of undergraduate students. In this study, constructivist grounded theory was not used, since the intention was not to construct a theory, but to identify developmental stages and patterns across cases. However, grounded theory coding (open, axial, and selective coding) was used to identify themes and nuances among new professionals' narratives, and within-case and cross-case analysis was used to analyze the data.

While other researchers have developed survey instruments that attempted to assess self-authorship development (Creamer \& Laughlin, 2005; Pizzolato, 2007), these methodologies lacked the capacity to delve deeply into participants' lived experiences, which are central to this study. Because the focus of this study is to explore the demonstrations of self-authorship and advising styles of new professionals, the use of grounded theory coding allowed for the discovery of patterns of thinking that illustrate the stages of self-authorship development, and nuances of approaches to advising college students with a level of depth that survey instruments cannot.

In order to achieve a rich understanding of the self-authorship development and advising strategies of new professionals in the study, I collected data from multiple sources: interviews, journal entries, and researcher notes. Semi-structured interviews were conducted with 12 new student affairs professionals working at one of three fouryear institutions in southern California. Additionally, for a 2-week period following the interview, participants were asked to submit online journal entries about their advising 
approaches after meeting with students. A total of 40 journal entries were received, with an average of three entries per participant. Finally, I took researcher notes after each interview and throughout the data analysis process. These notes recorded observations, possible themes and initial analysis of participants in the study.

To gather a rich understanding of the nuances of new professional meaning making and its relationship to existing research, within-case and cross-case analysis were used to analyze data from the interviews, journal entries, and researcher notes. Constructivist grounded theory advocates the use of inductive reasoning in research, developing theories from research data rather than deducing testable hypotheses from existing theories (Charmaz, 2006; Glasier \& Strauss, 1967). In this study, the inductive process of grounded theory coding, or open, axial, and selective coding, was used initially to explore the uniqueness of self-authorship development within a sample of new professionals. This was followed by a deductive process of coding, using codes from the literature to explore the ways in which new professionals' development and advising strategies may relate to themes identified in the literature.

First, since self-authorship development has not been studied in new professionals, a grounded theory coding process was used, first to analyze advising approaches, and then to understand the histories and self-authorship development of individual participants. "Grounded theory methods consist of systematic, yet flexible guidelines for collecting and analyzing qualitative data to construct theories 'grounded' in the data themselves" (Charmaz, 2006, p. 2). Grounded theory is both a way to study a phenomenon, and a way to develop theories for understanding it (Charmaz, 2006). This 
theory builds on the work of Glaser and Strauss' (1967) conception of traditional grounded theory, expanding it within a constructivist perspective, which describes the process as interpretive, and assumes that researchers' experiences, perspectives, histories, assumptions, values, social standing, ideologies, decisions, identities and prior knowledge can shape the emerging theory and findings (Charmaz, 2006). In this study, grounded theory coding was used initially to explore the nuances of the experiences of new professionals in the study, a population not yet studied from a self-authorship perspective. This was followed by coding from the literature and within-case and cross-case analysis.

To compare the data in this study with data from prior research, after grounded theory coding the data was coded a second time using a coding scheme consisting of advising strategies described in the literature as promoting self-authorship and stages of self-authorship development. The data included in the pre-existing codes was discussed in depth in chapter 2. Similar to the grounded theory coding, to prevent bias from knowledge of self-authorship, new professionals' advising strategies were coded prior to assessing the stage of self-authorship identified in participant narratives.

Finally, within-case and cross-case analysis was used to identify common themes. Analysis explored characteristics such as age, gender, education, and identified stage of self-authorship. Using cross-case analysis, differences in characteristics and advising styles among new student affairs professionals were explored to identify patterns and themes that may ultimately improve the quality of advising to undergraduate students.

\section{Data Collection Methods}


Twelve new student affairs professionals currently working at 4-year institutions in southern California participated in a single interview lasting approximately 60-90 minutes. Through semi-structured interviews, which provide a degree of consistency among interviews while permitting flexibility to follow unique conversational threads (Patton, 2002), I was able to obtain rich descriptions of the experiences and advising styles of new student affairs professionals. Rich descriptions are detailed, focused on a specific phenomenon, and thoroughly fleshed-out (Charmaz, 2006). This allowed for emergence of a full picture of the levels of self-authorship and advising practices of the participants.

The interview protocol was divided into two parts. Part 1 asked about participants' background and questions about a recent important decision in the new professional's life, along with other experiences as a new professional, to assess displays of self-authorship. Part 1 of the interview protocol, which was designed to gather background data and identify the stage of self-authorship development, was modified from Baxter Magolda's Measure of Epistemological Reflection and the protocol for the multi-institutional Wabash study (Appendix A), both of which were discussed in depth in chapter 2 . These instruments were designed to assess self-authorship development in undergraduate students. Changes were made to the interview guide in consultation with Baxter Magolda in an attempt to stay true to the original protocol, yet provide appropriate adaptations for use with student affairs professionals.

Part 2 asked about a particular advising experience with a student who spoke with the new professional about an important decision in the student's life. Interview 
questions delved deeply into one advising experience with a student who came to the new professional about an important decision because, during these potential crossroads experiences, advisors would likely utilize their most complex set of advising strategies with students. Participants were also asked to write journal entries in which they recorded descriptions of, and personal reflections about, advising meetings with students for a 2-week period following the interview. Information from part 2 of the interview was combined with data from these post-interview journal entries to identify participants' advising approaches.

Participant Selection

Twelve new professionals working at one of three institutions in southern California were selected for the study. Each had worked full-time in the field of student affairs for approximately 2 years or less. The purpose of seeking participants with just two years of experience is that these new professionals often have the most contact with undergraduate students. Participants were recruited by sending emails to senior student affairs professionals at various institutions and sending invitations via student affairs listserves at each institution. New professionals/potential participants who responded to email and listserve announcements were asked to fill out a brief initial questionnaire containing questions about advisor characteristics such as number of years as a student affairs professional, gender, age, current position in student affairs, education, and whether the new professional had formal or informal mentoring relationships with students (Appendix B). This information was later used to analyze advising strategies 
and themes among participants with different demonstrated stages of self-authorship and advising strategies.

Initially, the goal was to select participants based on responses to the questionnaire using Patton's (2002) purposeful sample framework to attain the highest possible variation and diversity within the pool that fit the criteria. The intention was to gather a sample representative of the variety of new student affairs professionals from a range of roles within student affairs, at an array of 4-year institutions (e.g., public, private, faith-based). Participants were to be selected into the study until data saturation was reached and, if applicable, until the levels of self-authorship of new professionals formed clusters to make cases. In actuality, a diverse sample was achieved because those who selected to participate had a variety of positions, backgrounds, and demographics. New student affairs professionals who matched the criteria were identified initially through listserve announcements and through colleague recommendations using a snowball sampling technique (Patton, 2002). New professionals also referred eligible colleagues from various parts of campus; therefore, snowball sampling yielded a diverse set of participants from a variety of positions in student affairs. Participant demographics and characteristics are discussed further in chapter 4.

Eligible participants were those who worked at a 4-year institution participating in the study, and who indicated in the initial questionnaire that they had worked in the field of student affairs for approximately 2 years or less and had a formal or informal mentoring relationship with students (Appendix B). Ultimately, 15 people responded to the email announcement, and 12 were eligible for the study. Of the three who were 
ineligible, one did not work at an institution participating in the study, another was no longer considered a new professional due to the number of years he had worked in the field, and the third had minimal contact with students. Each of the 12 participants eligible for the study completed all study requirements, which included the interview and online journal entries.

All aspects of the study, including procedures for gaining access, were subject to review by the Institutional Review Board at my home institution, and letters of support were obtained by the other participating institutions. The appropriate student affairs administrator at each institution also approved the listserve announcements.

\section{Interview Procedures}

Participants selected for the study took part in a 60 - to 90 -minute interview. An interview guide was used to assure the same basic lines of questioning for all participants, while maintaining a level of flexibility for further exploration of unique issues for each participant (Charmaz, 2006; Patton, 2002). Interviews took place in a private room on the participant's home campus. Interviews were recorded and transcribed verbatim.

\section{Interview Approach}

For this study, I assessed self-authorship and advising approaches using the most common method, semi-structured interviews. During the creation of the interview protocol, I consulted with Marcia Baxter Magolda, who provided ideas, resources, and feedback on questions and coding schemes.

Part 1 of the interview assessed $R Q \# 1$, the degree to which new student affairs professionals demonstrate self-authorship (see Appendix A). Questions in part 1 
explored the level of self-authorship in three dimensions (epistemological, intrapersonal, interpersonal). Similar to both Baxter Magolda's Measure of Epistemological Reflection (MER; 1999) and Pizzolato's Experiences Survey (2005), the interview questions that assess the epistemological dimension of self-authorship include open-ended questions about a recent important decision. People most likely display their most complex ways of knowing when making an important decision; therefore, this is considered to be the best indicator of a person's ability to self-author (Pizzolato, 2005).

To assess the epistemological dimension of new professionals' self-authorship development, interview questions from Baxter Magolda's Measure of Epistemological Reflection (1999) were modified to apply to a post-college context. Originally developed to assess college students' perceptions about the nature, certainty, and limits of knowledge, the MER became the basis for assessing epistemological development of participants in Baxter Magolda's 25-year longitudinal study of self-authorship development (Baxter Magolda, 1999). Additional questions have been added to the instrument for this study to assess the interpersonal and intrapersonal domains, based on the Wabash Study questions that promote self-authorship development in advising situations (Magolda et al., 2008).

Part 2 of the interview was designed to determine the degree to which new student affairs professionals use advising techniques known to promote self-authorship in college students, and the characteristics and advising strategies common to those with differing stages of self-authorship, age groups, educational backgrounds, and gender. Part 2 investigated the possible relationship between these characteristics and the degree to 
which new professionals may be assisting college students in their progress towards selfauthorship (RQ \#2).

In this section, participants were asked to share a particular example of a time when an undergraduate student consulted with them about a significant decision in his or her life (a possible crossroads experience). The advising strategies used during a crossroads experience have the potential to create what Pizzolato described as a "provocative moment" (Pizzolato, 2005), a sufficiently impactful experience prompting movement towards self-authorship. Follow-up questions explored in detail the specific approaches and strategies used by the new professional as he or she worked with the student. This provided insight into the degree to which the participant utilized the approaches identified in the Learning-Partnerships Model (Baxter Magolda \& King, 2004) and other research known to promote self-authorship among students. Additional advising strategies that may promote self-authorship were identified in the course of the study through grounded theory coding of interviews and journal entries. These included challenging students to identify their own desires, validating student experiences, and active listening to promote student reflection.

\section{Post-Interview Process}

Post-interview researcher memos were completed at the conclusion of each interview to record observations and the ways in which the new data may have caused me to rethink assumptions, identify or refine my theories and frameworks, and ask new questions (Baxter Magolda, 1999; Charmaz, 2006; Glaser \& Strauss, 1967). After each interview, verbatim transcripts were sent to participants for member check to ensure 
accuracy. Participants received the transcripts approximately 1 month after the interview, after they had completed their online journal entries.

Additionally, during a 2-week period following the interview, each participant was asked to complete online journal entries after advising sessions with students (Appendix C). Participants were asked to describe their advising approaches and strategies and to reflect on the advising experience and their advising style. In addition to providing additional data, online journals also provide an opportunity for participants to practice reflective inquiry and self-authored thinking. This additional source of data was designed to enhance the credibility and trustworthiness of the data and to allow for deeper understanding of participants' advising experiences in multiple situations (Patton, 2002). Electronic journal entries were coded using both grounded theory coding and the coding scheme derived from the literature, and were analyzed alongside interview data about advising strategies.

\section{Data Analysis}

Throughout the analysis process, I completed researcher notes describing how I refined my interpretations of the data, describing my initial categories and codes, and noting any theoretical frameworks that informed the analysis (Baxter Magolda, 1999; Charmaz, 2006; Glaser \& Strauss, 1967). Using observations recorded in researcher notes after each interview and throughout the data analysis process, I identified patterns and themes about the development and advising methods of the new student affairs professionals. Themes were continually revised and interview questions modified as new 
patterns emerged (Charmaz, 2006). Thus the analysis was dynamic, flexible and continually refined.

Self-authorship development has not been studied in new professionals; therefore I coded each interview using grounded theory coding prior to coding a second time using the coding scheme from the literature. Starting with grounded theory coding allowed influences and patterns to emerge directly from the data prior to layering and evaluating it through the lens of prior research. To prevent bias based on perceived attributes of participants in particular stages of self-authorship development, I also fully coded part 2 of the interview (which investigated advising strategies and approaches) using grounded theory coding and pre-existing codes prior to identifying stage of self-authorship development displayed by the new professional. Codes for analysis of part 2 were developed based on Baxter Magolda's Learning Partnership Model and additional research on approaches known to promote self-authorship (Baxter Magolda, 1999; Brown, 2004; Daloz Parks, 2000; Hodge et al., 2009; Pizzolato, 2005).

While remaining aware of prior research that has been done on the topic of selfauthorship development, I designed the study in a way that kept coding open, adding and revising codes as necessary throughout the process (Charmaz, 2006). I also took a slightly skeptical or critical stance with respect to earlier research on self-authorship development and advising styles that promote it, allowing prior research to enter my study only through patterns in my data (Charmaz, 2006).

In order to respond to $R Q \# 1$, the degree to which new professionals demonstrate evidence of self-authorship, I again began with grounded theory coding to explore 
participant histories and influences, and then used the coding scheme developed for this study to identify the stage of self-authorship demonstrated in participant narratives. Participants' development in each of the three self-authorship domains (interpersonal, intrapersonal, epistemological) was coded based on responses to the targeted questions in each area. Coding for overall stage of self-authorship development was based on analysis of development across the three domains.

Codes for assessing levels of self-authorship were based on those developed for use in the Wabash National Study of Liberal Arts Education (Baxter Magolda et al., 2008; King et al., 2009; see examples of codes in Appendix A). The Wabash study was designed to identify how students' characteristics, such as their epistemological, intrapersonal, and interpersonal development, influenced their engagement in educational experiences. This coding scheme was selected due to its nuanced assessment of the crossroads stage of self-authorship development. In the current study, after the full coding was complete, the six stages of self-authorship from the coding scheme were collapsed into three: early, middle, and late stages of self-authorship development, which allowed the 12 participants to be grouped into cases.

After participants' advising styles were analyzed individually and recorded in researcher notes, individual participants were grouped into cases with others at similar stages of self-authorship development (early, mid, late); education; age; and gender. These six cases served as units of comparison for within-case and cross-case analysis for RQ \#2a. RQ \#2a, which sought to identify themes in advising strategies based on advisor characteristics. Once the cases were determined, I reexamined the data to identify trends 
in advising approaches to see which categories and themes emerged within and across cases. I also created concept maps for each person to help identify influences, advising strategies, self-authorship development, and other unique factors to compare and contrast the cases and note themes and trends within and across cases.

In order to refine the interview guide, ensure question clarity, and check data analysis procedures, I conducted a pilot interview in early November, 2011 with a participant who had significant advising experiences through graduate assistantships, yet was ineligible for the study because she had not yet worked full-time in the field. The pilot participant also completed journal entries about her advising experiences. Data were analyzed using the study procedures described above. For inter-rater reliability, a colleague familiar with the self-authorship literature also analyzed the data using the same procedures and coding schemes. We met to discuss our analyses and addressed discrepancies in interpretation until they were resolved. Through our discussion, we identified themes in the pilot participant's self-authorship development and agreed on the overall assessment of the participant's stage of self-authorship development. This analysis validated the reliability of the coding schemes and provided new perspectives on data analysis.

In addition, after completing the coding process for all of the data, I consulted with another colleague familiar with self-authorship to check my categorization of grounded theory codes for advising strategies that promote self-authorship. After discussion, and revisiting the data where appropriate, I made a few minor revisions to code names to make them more specific. A list of codes is provided in Table 1. The full 
coding scheme containing the literature, examples, and references is available in Appendix A. 
Table 1

Advising Codes

Coding from pre-existing literature

Knowledge is complex and socially constructed

Prompts student to compare alternatives

Prompts students to explore multiple frameworks or lenses

Explores assumptions about knowledge as universal

Encourages critique of existing theories

Encourages taking a stand on an issue or topic

Encourages feedback

Asks students sufficiently big and complex questions

Self is central to knowledge construction

Asks reflective questions

Asks student to identify his/her perspective

Asks student to reflect on his/her personal values

Encourages student to reflect on his/her level of satisfaction with relying on External definitions/sources for decision-making

Asks clarifying questions about whether the student's decisions were driven by internal or external forces (promotes behavior regulation/self-regulation)

Asks students to distinguish and weigh internal vs. external factors for decision making and behavior regulation

Expertise and authority are mutually shared among peers in knowledge construction

Promotes confidence by validating student's voice

Encourages discussion with peers with diverse perspectives

Advisor gives student authority to make his/her own decisions.

Facilitates interpersonal collaboration

Counsels students toward cognitive interdependence in which students could successfully manage conflicting expectations in a way that considered their needs and the needs of others

Validate learner's capacity to know

Promotes confidence by validating student's voice

Prompts student to identify their own viewpoints, values and worldview

Asks student to expand on their initial view of an experience

Situate learning in learner's experience

Redirects conversation toward learner's experience

Encourages student to apply what he/she learned in this situation to another Situation

Encourages student to apply what they learned in another situation to this Situation

Encourages the student to make sense of their experience rather than the educator making sense of it for them

Mutually construct meaning with the learner

Displays curiosity

Reflects on their own assumptions vs. expert, guide, authority role

Promote volitional efficacy, or belief in one's ability to persist in goal-oriented behavior despite challenges 
Table 1 (continued)

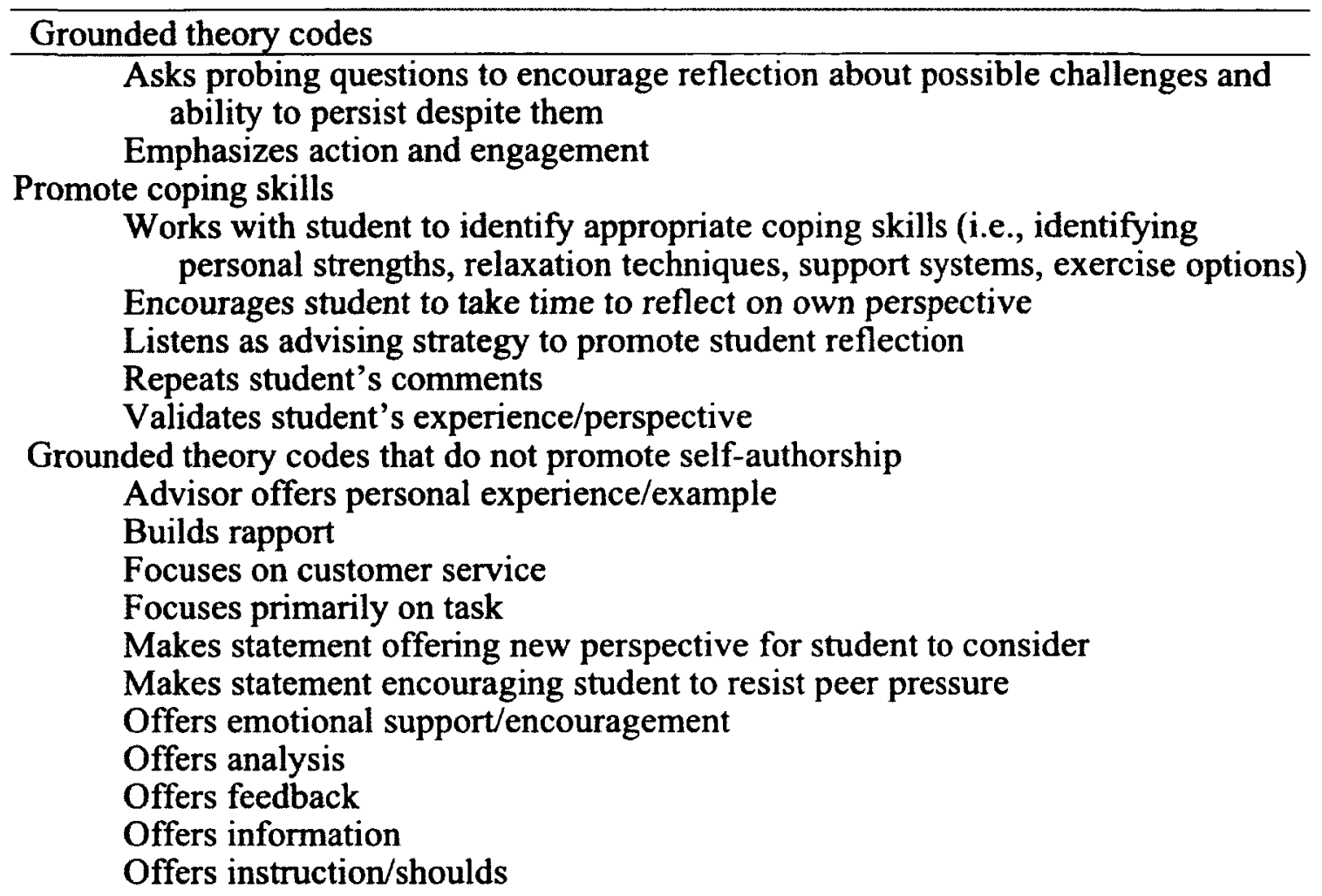

\section{Delimitations and Limitations}

There are a number of limitations to this study. The data was based on participants' self-reports of advising experiences and will not be compared with observational data. Observing personal conversations between student affairs advisors and students could have felt like a violation of the trust built within the advising relationship, and may have altered the information shared or the advising approaches used. To mitigate this, participants were asked to recall particular instances and examples of important decisions in their lives and advising conversations with students, rather than to describe general tendencies. In prior research, asking participants to recall particular instances of decision making yielded more accurate results than asking about 
general tendencies. This may be because participants, when responding to questions about tendencies, may indicate perceived optimal rather than typical ways of knowing (Creamer \& Laughlin, 2005). While assessment of displays of self-authorship were based on an analysis of single events, exploring participants' recent significantly challenging experiences is likely to call upon their most complex level of thinking (Pizzolato, 2005). If a person has the capacity to self-author, they will most likely do so during a significantly challenging experience.

While responses are not representative of the entire population of new student affairs professionals, this study provides an opportunity to explore applications of selfauthorship among new student affairs professionals in some depth, and offers a range of new possible understandings about their development.

The working hypothesis that emerges is not assumed to extend to new professionals in other contexts. However, the working hypothesis from the study may be transferrable at the judgment of the reader based on the rich descriptions' applicability to other contexts. By selecting new professionals from three different types of 4-year campuses, a large public, a small faith-based private, and a large research institution, the research may inform hypotheses at a range of other institutions.

The researcher in this study is a student affairs professional with 10 years of experience advising students and supervising new professionals in the field. While this may be an asset that helped me identify additional nuances and patterns in the data, there may be a possibility of researcher bias given my entrenchment in the field. I attempted to mitigate this by comparing the findings of a pilot study with another researcher familiar 
with self-authorship literature, comparing coding lists with another researcher familiar with self-authorship literature, keeping and analyzing researcher notes, member checking, and comparing themes from my data with existing research in the field through open coding.

Additionally, this study investigates self-authorship development in new student affairs professionals only. The degree to which more seasoned professionals and graduate assistants, who may also work directly with students, may self-author and promote self-authorship in students may be an area for further research. 


\section{CHAPTER FOUR}

\section{FINDINGS}

After a brief overview of the study's purpose and research questions, this chapter describes findings that emerged from the 12 participants' narratives, 40 journal entries, and researcher notes from this study. Participant demographics are presented, followed by a description of the overarching stages of self-authorship development described in participant narratives, and the themes that emerged that contributed to the development of self-authorship among new professionals. A discussion follows which explores themes that emerged within and across cases with respect to participants' advising strategies that may promote self-authorship development in college students. This section investigates the relationship between participant characteristics such as age, gender, education, and the advisor's stage of self-authorship development, and the advising strategies new professionals use with college students. Themes are presented in relation to each of the study's research questions.

\section{Review of Study Purpose and Research Questions}

The purpose of this study is to explore the degree to which new student affairs professionals use advising strategies that promote self-authorship development among the undergraduate students they advise. The relationships between advising strategies and characteristics such as age, gender, education, and new professional's stage of selfauthorship development are explored. By identifying themes and trends in new professionals' development and their advising strategies, I hope to illuminate ways graduate preparation programs, mentors and supervisors of new professionals may 
provide supports that enhance the development of new professionals and the students they advise.

The following overarching research questions guided this study:

RQ \#1: To what degree do new student affairs professionals demonstrate evidence of self-authorship? What common characteristics and trends emerge among new professionals in different stages of self-authorship development?

$R Q \# 2$ : In what ways, if any, do new student affairs professionals use strategies and approaches that facilitate self-authorship with undergraduate students?

a. What are the differences in advising approaches used by new student affairs professionals based on characteristics such as gender, age, education, and their own demonstrated stage of self-authorship development?

\section{Participant Demographics}

Table 2 provides demographic information for the new professionals who participated in this study. As described in chapter 3, those eligible for the study had worked in student affairs for approximately 2 years or less and worked at one of three 4year institutions in southern California (large research, large public, and small faith-based private). Of the 15 people who responded to the email announcements, all 12 who were eligible participated in the study. While participants represented a cross section of entrylevel positions in student affairs, no eligible participants came forth from residential life. 
Table 2

Participant Demographics

\begin{tabular}{|c|c|c|c|}
\hline Demographic & Number & Demographic & Number \\
\hline Age & & Time in Student Affairs & \\
\hline $23-25$ years & 6 & $<6$ months & 2 \\
\hline $26-28$ years & 4 & $7-12$ months & 1 \\
\hline $29-31$ years & 0 & 13-18 months & 5 \\
\hline $32-34$ years & 1 & 19-24 months & 2 \\
\hline $35-37$ years & 1 & $25-30$ months & 2 \\
\hline Gender & & Primary Functional Area & \\
\hline Male & 3 & Academic advising and & 1 \\
\hline Female & 9 & support & \\
\hline Transgender & 0 & Admissions & 2 \\
\hline Intersex & 0 & Career development & 1 \\
\hline Education & & Greek life & 2 \\
\hline Student Affairs master's & 8 & Judicial affairs & 1 \\
\hline preparation program & & LGBT campus resources & 1 \\
\hline No Student Affairs & 4 & Sexual assault prevention & 1 \\
\hline $\begin{array}{l}\text { master's preparation } \\
\text { program }\end{array}$ & & Student activities & 3 \\
\hline \multicolumn{4}{|l|}{ Institution type } \\
\hline Large 4-year public & 3 & & \\
\hline $\begin{array}{l}\text { Large 4-year public } \\
\text { research }\end{array}$ & 6 & & \\
\hline $\begin{array}{l}\text { Small 4-year faith-based } \\
\text { Private }\end{array}$ & 3 & & \\
\hline
\end{tabular}

\section{Data Analysis of New Professional Interviews and Journal Entries}

RQ \#1 asked the degree to which new professionals display evidence of selfauthorship. This question was answered by analyzing data obtained in part 1 of the interview, which assessed stage of self-authorship using a protocol and coding scheme adapted for this purpose (see chapter 3 for more details). Trends were analyzed through within-case and cross-case analysis of interview transcripts, journal entries, and 
researcher notes. The protocol included a series of questions about new professionals' development in each of the three domains of self-authorship: intrapersonal, interpersonal, and epistemological. The interview included questions that asked new professionals to delve deeply into a recent important decision in their own lives, which would likely call on their most complex level of thinking. New professionals' overarching stages of selfauthorship were originally coded into six micro-stages (described in chapter 3), and were later clustered in three categories, those in early, middle, and late stages of selfauthorship development. Pseudonyms are used to protect participant identities.

\section{Early Stage of Self-Authorship Development}

Five of the 12 participants displayed evidence of being in the early stage of selfauthorship development. While no participants exhibited evidence of being in the firmly external stage, in which young adults uncritically adopt beliefs from authority figures (Baxter Magolda et al., 2008), one participant was primarily in entering the crossroads, and four were in standing in the crossroads. One participant in this stage was in her early 30 s and the other four were in their early 20 s.

Those in the early stage of self-authorship tended to rely heavily on others for decision making and understanding. Several participants talked about making education and career decisions based on others' advice. For example, Amy is a former executive assistant in graduate admissions in her early 20 s, and she is also currently enrolled in a student affairs master's preparation program. When her supervisor accepted a new position, Amy became the interim director of the department, a transition that caused her significant stress and anxiety. She talked about her decision to apply to a graduate 
program based on her prior supervisor's recommendation to do so. "He was the one that really pushed me to go into my grad program. He was the one that really said, 'You know, you should apply and at least try it out' because I wasn't really sure.“

Similarly, Faith, who had recently decided to apply for a graduate program in student affairs, took a full-time interim position in Greek Life based on strong recommendations from others.

So I guess I kind of just made the decision because . . . based on advice from others. Called my mom, called Shana who was kind of my mentor, called my cousin who's my best friend and who was just like, "OK, you start praying about this. I'm going to start praying about this."

Lily, a project coordinator, recently graduated from the institution where she now works full-time. Her story highlights reliance on others, illustrating how new professionals in early stages of self-authorship development navigate the establishment of a professional identity. She discussed her struggles identifying appropriate boundaries with friends who still attend the University, one of whom she now supervises.

I got a lot of input from my co-workers and supervisors, because they are really cognizant. We have interns who I had been working with and, all of a sudden, I'm their supervisor. So we had a lot of conversations on "How do I interact with at least the people working in my office" because I had been friends with them. I'd invite them out to my things, I told them about my love life, like that kind of stuff. So, at least in our office, we had conversations about 'This is how we need you to supervise them.'

Another participant story from Cheryl demonstrates reliance on others for validation. While those in the early stages of self-authorship could often articulate the importance of developing their internal voice, they were still in the process of identifying their own values, beliefs, and sense of internal validation. Cheryl, a former teacher in her early 30 s, switched to a career in student affairs when she realized that she wasn't happy 
in the teaching profession. Cheryl is currently working in student activities. Her sister works in student affairs and has given her significant career advice, which she readily follows. She mentioned that her sister "tells me what to do, and I do it." When asked how she'll know she's been successful in her role, her comments spoke to her desire for external validation from others. While she also described a sense of knowing she's done a good job, the desire for validation and the self-doubt characteristic of those in the early stages of self-authorship was prominent for her.

When I get positive feedback from my supervisor or the dean, I feel that I've been successful in the profession. And it's just that intrinsic feeling that, wow, I did a great job. Because I know when I don't do a great job I kind of, I question myself a lot.

Clarissa, who is also in her early 20 s and also works in student activities,

illustrates another theme among those in the early stages of self-authorship development. Participants often discussed feeling a lack of confidence to act on their own judgment. When expectations of others conflicted with their own desires, they frequently expressed frustration, though they often continued to do what others expected of them. Clarissa, for example, felt significant angst upon receiving strong dissenting comments from colleagues about a previous decision she had made about admission parameters for an event she had planned. She mentioned that she would likely defer to her colleagues' recommendations if a conflict arose again, regardless of her thoughts and opinions on the matter.

... I think it's hard because, even though it's my event, people feel like they have the right to sort of tell me how to do it. So ... I don't know. I don't know what will happen in this next conversation, but I do see myself sort of maybe letting go a little bit and sort of being more appeasing, I guess, to whatever the group thinks is best, then that's sort of what we'll go with .... 
All participants in the early phases of self-authorship relied heavily on the thoughts, validation, and recommendations of others as they made decisions, and they often let others guide their decision-making processes.

Middle Stage of Self-Authorship Development

Four participants were in the moving through the crossroads stage, which, for the purposes of this study, serves as the middle stage of self-authorship development among new professionals in the study. In this stage participants began trusting and using their internal voice. One participant in this stage was in her early 20 s and three were in their mid- to upper 20 s.

Participants in this stage began feeling more comfortable expressing their needs to others, though external influences remained strong and continued to create internal tension. For example, Cara, a Greek Advisor in her mid 20s, had become dissatisfied with her social network. She had launched a "major life overhaul" the week prior to our interview in an attempt to live a more social and balanced life. She had recently made a decision to give her dog to her father so she would be more available to attend social events after work. She discussed her decision with family and friends, some of whom did not agree with her choice, and she experienced inner turmoil about her decision.

I tell my presidents every semester, "You're going to hit a wall at some point in time, so find what makes you happy so you don't get to that wall." And I think I'm finally getting to that wall where I have to do ... I have to make my own personal decision. Some people may not like it-they might not understand it. And so, you just have to get over it and do it yourself.

Participants in this stage continued to rely heavily on external support as they progressed towards their own internal definition. They began to identify their own next 
steps based their own and others' experiences. Nina, a new professional in her mid-20s had started a new position as a judicial officer several weeks before our interview. Prior to this position she worked in another office in student affairs, an environment she did not feel was supportive and healthy for her. She relied heavily on advice and support from her mentors, calling them up on multiple occasions saying, "Convince me not to quit!" Despite others' advice to stay, after 6 months she decided to leave the position and find another job.

In this stage participants were able to make their own decisions, often with significant input and support from others. Cecelia, an academic advisor in social sciences and culturally based academic programs in her early 20 s, had worked in academic advising as an undergraduate student and transitioned to full-time work after graduation. After a period of time, she decided to move to New York with friends to explore a new life and career. She described her decision to move back to southern California and reenter a career in Student Affairs.

That decision came to me in dreams, which sounds really kind of odd, but I had dreams. I have a sister ... and I had dreams where I kept on losing her. I think my family's what pushed me to make the decision to come back to San Diego, or come back to California. And then, when I decided I wanted to come back to California, I was just, "I had a sweet setup in Sociology. I'm going to go back to that."

Robert also made a significant decision with a lot of consultation with his family. Robert is in his mid-20s and attended graduate school for K-12 counseling, his "original passion." He described a recent decision in which he'd been offered two jobs, one in school counseling and one in student affairs advising student organizations. His decision-making process was highly collaborative, with heavy influence from his family 
and his fiancée. He ultimately decided to take the position in student affairs, saying, “... they all had their own opinions, and I think a lot of them ... I think at one point they all wanted me to take the other one, but they all knew that this was a better decision."

Participants in this stage were able to acknowledge their own needs and interests, though they often found it challenging to consistently use their internal voice with others.

\section{Late Stage of Self-Authorship Development}

Three participants were in the later stages of self-authorship, one was in leaving the crossroads: threshold of self-authorship and two were in the final internal foundation stage. They demonstrated the capacity to remain open to multiple viewpoints, critique others' points of view, and decide the degree to which external influences impacted their perspectives. Participants in the late stages of development had a range of ages, one in her early $20 \mathrm{~s}$, one in his late $20 \mathrm{~s}$, and another in his mid-30s.

All of the participants in this stage engaged in deep introspection and often made decisions despite others' objections, based on a sense of their own internal needs, values, and perspectives. For example, Enrique, an admissions counselor in his late 20 s, made difficult decisions based on his values. Enrique turned down a job in residential life without another offer, in a tough economy, in order to stay true to his values and interest in college admissions and access.

I had applied to housing positions because that's what I had done the last two years, and then outreach and admissions positions because that's what I really wanted to go into. And I interviewed and was offered a position ... [as] a hall coordinator, and that's kind of when that whole piece about being authentic and being able to feel like I was going to be able to put in genuine work and passion and motivation in that position. ... Sometimes I would feel like I'm inadequate because I'm still job searching, and it's five months after graduating, you know? 
It was important to get a job out of grad school, but I wasn't going to compromise my beliefs and my motivation.

Aaron, a career counselor in his mid 30 s, had recently changed fields after a dissatisfying career as an IT engineer, despite his family's strong preference for him to continue a career in a STEM field. He described his reasons for making the decision:

[My previous work] made me feel very miserable because I feel that I'm not contributing to anything I believe in, but rather I'm selling myself out to do something that I strongly disbelieve in. . . . And so I would say that the most important factor for me to decide on the career, was that it has to be something very meaningful, and . . . a cause I can identify with.

Marcia also made a decision based on deep reflection about her internal priorities. Marcia is in her early 20 s and works at a campus LGBT center. She knew she wanted to pursue a career in student affairs when she graduated with her undergraduate degree. She discussed the choice to accept a full-time job rather than apply immediately to a graduate preparation program. Despite advice from a dean and other colleagues to pursue her education, she chose full-time work after paying attention to her "energy" around the decision.

But yeah, I think most people say, "Go through [go to grad school]." And when they say "Go through" it's in this mentality of . . . "or you'll never do it" or "you're going to be too tired." And when I thought about it, I'm like, "Is that a good reason to do anything?" . . So I looked at certain schools. I was excited, but when I thought about jobs I was more excited, so I really looked at my energy and I said, "Well, whatever I decide, my energy's going to carry me forward."

Participants in the late stage of development had identified a set of foundational beliefs and priorities that served as a basis for their lives. New professionals in the late stages of self-authorship discussed making difficult personal decisions in order to remain consistent with their internal interests and values. 


\section{Influences and Trends in New Professional Self-Authorship Development}

This section will explore factors that seemed to influence the development of selfauthorship in new professionals. For this section, I reviewed the concept maps and researcher notes for each participant and compared them with interview and journal data. Information in this section is presented according to themes, which include the role of life challenges, student affairs master's degree programs, mentoring, family, and feedback.

\section{Life Challenges}

Stage of self-authorship development was more highly correlated with provocative moments and life challenges than with age. Age was loosely correlated with self-authorship in the early and middle stages, though participants in later stages were a variety of ages and seemed to have other characteristics in common. While participants in early stages of self-authorship tended to be in their early 20 s, one participant in the early stage was in her early 30 s. Those in the middle stage tended to be in their mid-20s; however, participants in the late stages included one person in her early $20 \mathrm{~s}$, one in his late 20s, and one in his mid-30s. All of those in the late stage of self-authorship were people of color who had faced significant challenges in their lives. Marcia described herself as a "Black queer woman," and the other two, Enrique, a Latino male, and Aaron, an Asian male, were first-generation college students. As mentioned in the previous section, all participants in the late stage of self-authorship described a significant provocative moment. 


\section{Student Affairs Master's Degree Programs}

Participants in this study who had attended or were currently attending student affairs master's degree programs were no more likely to self-author than those who did not. The student affairs master's degree programs attended by study participants included courses that covered college student development. Four of the five new professionals in the early self-authorship stage have attended student affairs master's preparation programs, and one of the three in late stages of self-authorship had not attended. Therefore, there seemed to be little correlation in this study between studying student development theory and one's own developmental stage.

\section{Mentoring}

The vast majority of participants described the significant roles mentors had played in their personal and professional development. Four participants expressed a desire for more mentoring and support. Mentors included graduate professors, colleagues, supervisors, and former mentors in student affairs from their undergraduate careers. These mentors supported new professionals through a variety of challenges, including: job choices, transitioning roles from student to staff, boundary management, building rapport with students and colleagues, navigating in a political environment, and personal decisions.

While mentors often provided emotional support, career advice, job-specific direction, feedback, guidance in conducting and presenting research, and served as personal sounding boards, there were some variations in the ways new professionals utilized their mentors, based on level of self-authorship. For example, Faith, who is in 
the early stages of self-authorship, describes her relationship with a mentor who is also a friend in the field. Faith relies on this mentor to listen and provide feedback.

I consider Shana one of my best friends but, at the same time, she's the person I go to whenever something does come up professionally or when I am struggling. A lot of times, she was the one I would vent to, whatever, and she'd say, "Well, now you're a professional and you need to get it together."

Nina, in the middle stage of self-authorship, relied heavily on her mentors for emotional support and career advice.

I think I first went to them with a lot of personal issues, since we developed a big trust. It really sometimes becomes a counseling type of relationship, of saying, "Oh, this is what I would do" or "What are your thoughts on that? What are your feelings on that?" ... I really used my mentors a lot when it came to the job search right after grad school. I was really struggling.

Nina's reliance on mentors for emotional support was typical of those in the middle stages of self-authorship, when participants were seeking support as they developed and tested their internal voice. Nina also described her hope that supervisors may be able to provide direct advice in response to her questions: "I definitely came up to some supervisors and was like, 'Just make this decision for me' or 'Which decision is right? Just tell me and then I can learn.' And they're like, 'No. This isn't how you learn. You don't just mimic."' Nina's comment reflects the pull for new professionals to rely on supervisors and mentors for answers, while her supervisor's response to challenge her to think through the decision is likely to encourage self-authored thinking.

Aaron, a career counselor in the late stages of development, described staying in touch with the director of career services at another institution and his former professors.

I've met with him for lunch from time to time, and just to learn about what's going on with the staff, or the other mentors' recent career moves. So they're kind of like my go-to people. I sometimes choose to, not necessarily ask for any 
direct advice, but just to reflect on where I've been the past two years, and what I'm going to do next.

Aaron's description is indicative of those in the later stages of self-authorship. He does not describe seeking direct advice from his mentors, but instead uses them to learn about their career paths and reflect on his own next steps. Enrique, also in the late stages of self-authorship, discussed his supervisor's role in "Just being honest, and having someone that can give me .. . challenge me to do certain things, and just let me do it." He emphasizes the role of his mentor's challenge and the importance of letting him try his assignments independently.

Several participants described using advising strategies with students that their mentors had used with them. I encountered a variety of mentor roles and noticed patterns in the advising strategies used by participants' mentors. For example, Lily, who is in the early stages of self-authorship, describes role-playing conversations she had with her supervisor to learn best practices in working with students.

We've had a lot of conversations on "What is the best way to talk to a student?" So, if my supervisor was out of town and I'm handling a case, we'll start talking and I'll start writing down what she's saying. And then she'll realize ... I'll say it back to her, whatever I needed to say to the student.

Lily's description of writing down her supervisor's words is characteristic of those in the early stages of self-authorship who rely heavily on experts and prefer scripts to follow.

Nina and Marcia both describe using strategies their mentors had used with them. Nina, who is in the middle stages of self-authorship development, mentioned employing the same decision making strategy with a student that had been used by her mentor:

I remember my mentor, I was in her office crying of, "I have to tell them by four o'clock if I'm accepting a job at Cal Poly SLO, and I don't want it" and she's 
literally sitting there making a pros and cons list. And so that's one of the things I did with my student Roxanne, in saying, "OK, this has helped me. Let's try doing a pros and cons list for each institution and see where the right place is."

In addition to replicating advising strategies her mentors used with her, Marcia, who is in the late stages of self-authorship development, also describes paying attention to her needs and voice. "I think with that, also thinking about mentors and colleagues and how they listen to my problems, or what I'd like to hear back from them. I think it formed me, and how I'm able to relate to students." Marcia's ability to synthesize her own voice with those of others is characteristic of new professionals who self-authored.

\section{Family and Culture}

Family was also a common influence on new professional development. Enrique, a first-generation college student, described family support as important to him: “. . f family is always a support system, but they don't really know what I do. I just work at a college but they support me." Similar to others who were the first members of their family to go to college, his family provided emotional support, but he tended to rely on mentors in the field for career-oriented advice.

Robert and Lily both demonstrate the centrality of family in decision making. For example, the researcher notes taken after Robert's interview indicate that it was difficult for me (and for Robert) to determine the degree to which his many discussions with his family influenced his decision to take a job in student affairs over a school counseling position. His descriptions of the decision-making process frequently referenced "we." Similarly, Lily described the importance of considering the relationship between family, culture, and self-authored decision making. 
I really hesitate to ever say, "Your parents are wrong. Your family is wrong about you needing to be a doctor," that kind of thing because, for some people, for me, family is really important and taking in that . . . being respectful and taking in that opinion is really important. So, how can you best negotiate what you want and what others want, because I think it can't be just a what-you-want question. I think it's really easy to say that, but for most people it's not going to be that conversation. It will be: How do all of these people who will be affected by your decision ... how do we kind of - not please everyone - but come up with a decision that will make you feel comfortable?

After her interview had ended, Lily and I continued our conversation for several

minutes. Lily talked about the role of both culture and family in decision making, which

I discussed in the researcher notes I took after my interview.

Lily talked about the importance of including family in decision making for some people, that decisions are joint decisions in some cultures. Though it appears that heavy influence from family may prevent students from identifying their own perspectives [which is necessary for self-authorship development], it may not prevent it from occurring. The ability to self-author is predicated on the ability to coordinate perspectives from multiple sources, including one's own and others. Family relationships add a level of complexity to advising for self-authorship development.

Lily's description of negotiating "what you want and what others want" indicates an understanding of the importance of a basic tenet of self-authorship. While taking family perspectives into consideration is important, it is also important for the student to identify their own desires in order to come to a workable solution. The ability to recognize and coordinate one's own perspectives and those of others is a hallmark of selfauthorship.

As these notes suggest, family influence and a collective mentality can make it difficult to identify the degree to which someone may be making a self-authored decision. While this may add a level of complexity to advising situations with students making decisions using a collective approach, the model of self-authorship can still be applied in 
such scenarios. The ability to self-author does not imply a lack of outside influence in decision making, but rather an ability to recognize and coordinate internal and external influences.

\section{Feedback}

Clarissa, Lily, Cheryl, and Cara discussed the role of feedback in refining their professional practice. Cara, a Greek advisor in the middle stages of self-authorship, provides an example of nuances in the development of self-authorship associated with receiving and integrating feedback. Typically, those in early and middle stages of selfauthorship development struggle to identify their own perspectives and rely heavily on external sources for support, meaning making, and decision making. The researcher notes taken after Cara's interview describe the opposite dynamic, where Cara was able to identify and vocalize her own thoughts, but needed to learn to integrate others' perspectives.

One thing I noticed is that Cara's first instinct is to strongly state her opinion, which would seem like self-authoring behavior. However, she sometimes struggled to integrate external perspectives into her opinions, which doesn't reflect self-authoring behavior. She gave an example of an IFC board, which held private meetings without her present because her advising style wasn't connecting with them. She then realized she needed to step back, reflect, and adjust her approach with the next council, which demonstrates that she was able to develop an ability to synthesize internal and external perspectives. However, selfauthorship literature seems to assume that the challenge is to find one's internal voice. In this case, she had the ability to strongly state her opinions, but had not fully developed the practice of integrating external sources. The coding matrix doesn't account for this well.

Ultimately, the ability to self-author involves the ability to coordinate internal and external influences and internally define one's own beliefs, identity, and relationships (Baxter Magolda, 2001). Self-authorship occurs in the interpersonal, intrapersonal, and 
epistemological domains. Feedback from the IFC board provided an opportunity for Cara to incorporate greater coordination in the interpersonal realm. While the greatest challenge in the self-authorship process tends to involve identifying one's own thoughts and beliefs, for some, a greater challenge may be to remain open to and coordinate external influences.

RQ \#1 investigated the degree to which new student affairs professionals demonstrated evidence of self-authoring. In the previous section, the range of stages of development and influences on new professional development were explored. The next section will address RQ \#2 and RQ \#2a.

\section{New Professionals' Use of Advising Strategies That Promote Self-Authorship} Among College Students

RQ \#2 asked about the degree to which new professionals use advising strategies known to promote self-authorship in undergraduate students. While all new professionals used some strategies that promote self-authorship among students, some new professionals used significantly more than others. A range of advising strategies was found among new professionals in connection with participant characteristics. The major themes that emerged will be explored in discussion of RQ \#2a below.

To answer RQ \#2a, data about advising strategies that promote self-authorship were sorted and analyzed by a number of characteristics, including age, education, gender, and stage of self-authorship. Key findings are discussed below. 


\section{Advisors in Early Self-Authorship Offered More Direction}

To analyze advising styles, I looked at the predominant advising styles and the range of advising approaches used by each participant. The research showed that new professionals in earlier stages of self-authorship tended to offer more direction, instructions, and prescriptions for success than those in later stages. These advising approaches provide too much direction and not enough challenge to encourage complex self-authored thinking in students (Baxter Magolda \& King, 2004). Most participants in the early stage of self-authorship development frequently used directive approaches with students, while those in the late stage rarely offered prescriptions for success.

Faith, a new advisor in Greek Life, is in the early stages of self-authorship development. Her advice to a council president overwhelmed by responsibilities tended to focus on efficiency.

She felt forced into her role on MGC, and some of her regrets about it, and I think once she got them out she realized it was OK to have those kinds of thoughts, and to have those regrets. But you still have to make something of the role, and you still have to get things done. We just talked about ways to be a little bit more efficient, checking emails. Yeah, we talked a lot about how to make a meeting more efficient, how to create a schedule and a meeting agenda, and how to answer emails ....

Faith's focus on meeting efficiency and the logistics required by the position reflects a tangible, hands-on advising style and is not likely to challenge the students enough to identify their own thoughts, feelings, and values in ways that promote selfauthored thinking. Faith later describes advising students about the fraternity recruitment 
process. This description illustrates how an advisor's conception of the nature of knowledge may influence advising styles in early stages of self-authorship development. ... with some of the other groups that had been doing their own thing for so long, and don't want direction. Showing them that there's a better way, and then having actual facts to back it up. So, saying like, "This isn't how you should be recruiting, this is how you should be recruiting."

Faith's description of her role as "showing the students a better way, and then having the facts to back it up" may also reflect her own perception of knowledge as fixed, external, and providing prescriptions for success, which is characteristic of those in early stages of self-authorship development.

In a journal entry, Faith recounts an advising session with a sorority member in a judicial role with her peers, who was handling her first crisis. Faith made an effort to get to know the student, provide her with emotional support, and offer her direction about next steps. Her attempts to support the student may have prevented the student from learning to navigate delicate situations that may have occurred if Faith had offered more challenge.

She is very quiet and shy and so I wanted to make sure she realized that she could do this job and hold girls two years older than her accountable. I made sure she knew how and where to find the information she needed to do her job well. I wanted her to have all the tools ... Her role is judicial ... and she had a major problem with a member she was dealing with, so we had to finish that as well as get to know each other. I kept things simple and went over the basics. I supported her and made a challenging phone call for her, but then made her draft a challenging email that she needed to do.

Faith, who is currently in a master's program in student affairs, had recently learned about the concept of providing appropriate levels of challenge and support for students. While Faith attempted to provide a balance of challenge and support by lifting 
some of the burden from the student, her efforts may not have provided enough challenge to the student to foster student growth. In an effort to support the student, Faith made a challenging phone call for her. To better support her self-authorship development, Faith might have worked with the student to prepare her to make the difficult phone call herself. As in this example, Faith described multiple instances where she expressed wanting to be seen as an advocate for the students she advised, which seemed to prevent her from taking full advantage of opportunities for student learning. Seeking approval from others is also characteristic of those in early stages of self-authorship.

In part, Faith's example demonstrates a theme of those in early self-authorship development who long to provide support and definitive answers for students. This more directive approach is often well received by students, who often welcome relief from the uncertainly and struggles associated with big "crossroads" decisions. In the following example, Nina, a new professional in student affairs in the middle stages of her selfauthorship development, describes her advising approach with a student who was deciding whether to attend a private graduate program connected to her faith after attending a secular public undergraduate institution. This example demonstrates advising strategies of those in the middle stages of self-authorship development, and students' desire for the advisor to make decisions on their behalf. Nina describes her conversation with the student:

"Well, these are some of the changes that you might see there. Is this going to be too much of a shock for you at once? Is this something that you just really want to immerse yourself in and try it?" And we had a lot of really good conversations, at some point she even came to tears of, "I just don't know. I'm just so frustrated." And she joked around, she's like, "Can't you just make a decision for me? Nina, you make a decision." And I had another conversation with her of, "I 
can make the decision, but it's not my life. You need to be satisfied with what it is, and you also need to be OK with, if you make the decision, to stick with it whether it's right or wrong, because you have the personality that you can be satisfied no matter where you are. You just need to decide that this is the right decision, and go whole-heartedly with it."

Nina, who is in the middle stages of self-authorship development, uses a combination of assertions, such as "These are some of the changes you might see" and probing questions, such as "Is this going to be too much of a shock for you all at once?" and "Is this something that you just really want to immerse yourself in and try it?" While she does recognize that the student needs to make the decision herself, and she engages students in critical questions, the comments and questions may indicate that the student may be able to identify the advisor's perspective.

While the student in the previous example joked about wanting Nina to make the decision for her, Aaron, a career counselor, described this phenomenon as common among undergraduates who come to ask for career advice. In contrast to those participants in early self-authorship, his description of his intentional resistance to providing direction to students serves as an example of advising by someone in the late stages of self-authorship development.

Oftentimes I feel that students come to the Career Services Center . . . they're like just some survivor of a shipwreck just wandering in the sea-they just want to hold onto something, so we give them direction. They just want a direct answer to tell them what to do, and if you give them that kind of answer, oftentimes they will just follow that answer. Like, a career assessment result: you should be soand-so, and that makes me ... I'm very worried about giving direct advice like that, because that's such a responsibility that no one else can make besides the student, him or herself.

Aaron then describes the advising strategies he uses when students come to him wanting him to offer specific career advice. 
It is very often that students who come to me to seek for a particular career advice turn out to have many other underlying issues related to the situation. The particular questions that the students ask are often just the tip of an iceberg. Instead of giving direct advice on the specific question, I often encourage the students to elaborate their thoughts and feelings about the situation. It is particularly important to maintain neutral and nonjudgmental, because otherwise students may hesitate to reveal their true opinions for the fear of being criticized or scrutinized.

Aaron's use of probing and reflective questions challenges students to identify their own perspectives, needs and values. His intentional nonjudgmental approach provides a "holding environment" (Kegan, 1994) that supports the student's growth. These strategies, while often uncomfortable for students, offer them an opportunity to practice self-authored thinking.

\section{Advisors in Late Self-Authorship Use More Strategies That Promote}

\section{Self-Authorship}

For this section, I looked at the number and breadth of advising strategies described in participant interviews and journal entries which are known to promote selfauthorship. Advisors in the late stages of self-authorship development use a greater number and greater breadth of advising strategies that promote self-authorship among students than those in earlier stages. New professionals early in the stages of selfauthorship tended to use fewer total advising strategies and described using strategies that promote self-authorship fewer times than those in late stages of self-authorship. For example, participants in early self-authorship described using an average of 11 strategies that promote self-authorship and an average of 23 of these strategies in their interviews and journal entries. Similarly, those in the middle stages of self-authorship averaged 9 strategies that promote self-authorship, averaging 18 total descriptions of strategies in 
their narratives. However, those in the late stages of self-authorship described significantly more strategies, an average of 20 per participant, and an average of 69 occurrences in their narratives. This trend was consistent across all participants in early and late stages of development, and is demonstrated in participants' examples.

Amy, an interim director of admissions in her early 20 s who is in the early stages of self-authorship development, described using 10 different advising strategies that promote self-authorship, with 20 examples of these strategies mentioned in the interview and journal entries. Amy described her advising approach in working with students interested in admission to the department where she works.

I usually say a little bit about, "This is sort of the philosophy of this program. This is the philosophy of that one. Which do you think is a better fit with you, and why?" And we'll sort of talk through that ... . Since she was fairly unfocused, I started by asking her a bit about her background and what she hoped to do in the future. From there, I explained what the intentions and outcomes of several of our programs are, and asked her what seemed to fit her goals the best. She identified the programs that seemed like her best fit, and we discussed the application process. At that point I relied mostly on her questions to fuel the conversation and let her take the lead.

In this example, Amy describes several advising strategies that promote selfauthorship, including prompting the student to compare alternatives, redirecting the conversation to the learner's experience, and asking the student to identify her perspective.

Enrique, also an admissions counselor, is in later stages of self-authorship. He described using 15 different advising strategies promoting self-authorship, which were coded a total of 35 times in his narrative. While Enrique and Amy have similar roles 
with prospective students, Enrique's description of his advising approach includes additional strategies and approaches.

... one of the things that I kind of think about is "should I intervene on their behalf, or should I help them gain self-efficacy?" because it's kind of like that "give them a fish, teach them how to fish." I could tell you, "Go here, or do this. Or let's talk about how you can figure out what your issue is, how you can resolve your issue, and what you need to do to kind of resolve your issue." And so, I think it would be that: is to help them build their helping strategies, coping strategies, or just kind of problem-solving strategies. I always think the listening aspect, kind of, just listening twice as much as you speak. Let them be heard, let them feel like whatever issue they're coming to you with is validated, and then try to find interventions.

Enrique describes giving the student the authority to make her own decision, emphasizing action and engagement, identifying coping strategies, listening as an advising strategy to promote reflection, and validating the student's perspective. Enrique also expands beyond the student's immediate question and describes his intentional approach to help the student gain self-efficacy. Such intentional advising approaches were mentioned more frequently by those in the later stage of self-authorship development.

Marcia, also in the late stages of self-authorship, illustrates the expanded number and breadth of advising approaches, which seem predicated on her own capacity for selfauthored thinking. Marcia, who works in an LGBT center, described 25 different advising strategies promoting self-authorship. A total of 79 occurrences were identified in her interview and journal entries. In her interview, Marcia described a conversation with a student who was witness to an incident involving potential sexual harassment.

Whenever students come to me with issues, I try to think about what's said and what's not said. So sometimes it's less about the problem, and more about their reaction to the problem. In this situation, it was this feeling of silence, and 
anxiety around that. In other situations, it's other stuff, so I think the way I've been trained is to really listen and try and hear what the student's not necessarily saying ... Throughout the conversation, I was listening to the student, and also myself with my own reactions and being uncomfortable, and figuring out what to do about this. I was faced with this. And so I think I chose those things because, in my head, I remembered the trainings that we've done. I said, "OK, this is the next step that we've explicitly said." But then I thought ... I listened to the student really actively, and I heard how difficult it was to even name that. So I said, "Well, this must be difficult, so let's talk about that." And in that way, it was a validating experience for them.

Her description demonstrates a complex multi-layered advising approach in which she listens deeply to the student, identifies what other factors may be contributing to the situation, and pays attention to her own internal reactions. The capacity to coordinate internal and external influences is a hallmark of self-authorship (Baxter Magolda, 2001). Unlike those early in self-authorship development, who are dependent on external formulas, Marcia was able to combine factors, including her own thoughts and feelings, her training, and the situational characteristics to chart a path forward with the student that was different from the training she received. Coordinating multiple influences, including one's own perspective, was more typical among those in later stages of self-authorship development in this study.

\section{Transactional versus Developmental Advising Approaches}

This section explores the degree to which new professionals seized opportunities to have developmental conversations with students. Some advisors viewed their roles with students as primarily transactional, while others used tasks as entry points for developmental conversations. Participants in this study viewed their roles with students in a variety of ways. First, those advisors who seemed to view their roles as primarily transactional will be discussed, followed by an example of an advisor who seems to be 
learning to expand her advising portfolio to provide more developmental conversations with students, and finally an example of someone who uses transactions to create transformational conversations with students will be examined.

Multiple participants seemed to view their advising roles with students as either primarily or completely task oriented or transactional in nature. Those who tended to focus on transaction and providing information tended to provide fewer examples of advising strategies that promote self-authorship. For example, Robert described his advising style with student organizations as "friendly, yet factual." In addition to his interview, he provided three journal entries, all of which were focused on the task or transaction presented by the student. His interview and journal entries showed his propensity to be of service to the students, instead of examples of advising strategies that promote self-authorship.

Whatever it is you need help with, I'm going to advise you on that aspect, and then I'm also going to give you the tools if you need to talk to this person about this, or "Here is this person's phone number, here's my phone number if you need anything. Don't hesitate to give me a call." ... It's usually something that, "I couldn't get this room" or "We had this issue, we had this problem. What can you do? Can you help?" . . That's just the profession that we're in, that's just the nature of it . . . And I also come from a customer service background, too, so I'm big on customer service and being that person like, if you say you're going to do something, just do it.

Similarly, Cecelia described her academic advising sessions with students using transactional terms as well. She described her advising experiences in multiple journal experiences as "cut and dry academic advising," "all academic," "strictly academic," "a quick run-down [of the requirements]," and "short and sweet." Though she also described an example in her interview of counseling a student who wanted to change 
majors and was concerned about his family's reaction, she seemed to generally approach advising with students and others who come to see her with the purpose of meeting their transactional needs.

Interestingly, neither Cecelia nor Robert attended a student affairs master's preparation program. This may partially explain the heavy task orientation to their roles, since they may not fully comprehend the accompanying developmental purposes of student affairs work. However, as will be discussed later in this chapter, the participants in this study who completed master's preparation programs in student affairs were not more likely to use advising strategies that have been shown to promote self-authorship in undergraduate students. Nevertheless, those with heavy task orientation also used fewer advising strategies that promote self-authorship than those who viewed their roles as developmental.

Cara seemed to be learning to adjust her advising style to offer more in-depth conversations with students. Cara, a Greek advisor who describes herself as an introvert, says it takes her a while to build relationships. Her job seemed to demand that she gain a level of comfort with advising students outside of a task structure. She described frequently starting conversations with students around a task to be completed, though several times in her journal entries she discussed starting a meeting focused on a task and recognizing that the student may need to talk about something else. She describes one example below:

He was given a list of tasks to accomplish before our next meeting in which he needs to bring different materials for the binder. The reason I moved from the normal "check items off the list" approach is due to the fact I noticed his body language change and he started to hold back his answers more because he did not 
have the answer. I like to start these meetings with the task that needs to be accomplished but sometimes it has to change when a student is not prepared to go that way. Once I changed my approach he began to unload a lot of his frustrations and really begin to work on a plan for the future.

Cara also described having learned that different groups she advises required different relationship-building strategies to open them up to a broader range of advising conversations.

Because with the women, I have to kind of get onto their level faster, and it's hard because I have to open up to them really quickly, because if I don't open myself up emotionally, they're never going to come to me .... And then my cultural groups, a lot of them it's about family and power. So in their meetings, I let them talk and then I'll wait till it's my turn, and then I'll tell them different things .... And then my guys are, "You've got to get straight to it. What's the point?"

Cara exemplifies a new professional who is learning how to build rapport with students to engage them in advising conversations in broader developmental contexts than the task before them.

Aaron, a career advisor, demonstrates how advisors can use transactions as prompts for more developmental conversations.

[A] resume advising session is often a "gateway" visit to the career services. It often leads to the discussions about other issues .... In a resume advising session, I always ask the students about the purpose of the resume and learn a little bit of background information about students' job search. While the technical part of this advising session (resume) was very straightforward, it raised my concern when the student told me that she would avoid using family connections to find a job. I invited her to elaborate more about this statement and learned that she regarded family connections as nepotism and she preferred to rely on her own efforts to find jobs.

Aaron's probing questions uncovered a more sustentative conversation with the student. 
I also noticed that the advising journals seemed to include more transactional approaches and have fewer examples of advising that promotes self-authorship than those described in the interviews. This may be because in the interviews I asked participants to recall a student who came to them asking about a significant decision in the students' lives, while the journal entries focused on typical advising experiences. Advisors probably use their most sophisticated advising strategies when a student is confiding in them about a particularly important crossroads experience. Nevertheless, advisors like Aaron took advantage of everyday advising experiences to promote self-authorship in students.

\section{Student Affairs Master's Programs and Advising Strategies}

Student affairs master's degree preparation programs typically require coursework in student development and/or counseling. In this study, those who had attended or were attending student affairs master's programs were, overall, no more likely to use advising strategies that promote self-authorship than those who did not attend. There were, however, differences in the types of strategies they used. Those who did not attend master's degree programs were more likely to use supportive advising strategies known to promote self-authorship that validated students' experiences and perspectives. Those who attended master's preparation programs were more likely to use strategies that promote self-authorship that challenged students to identify their own perspectives, prompted students to compare alternatives, emphasized action and engagement and asked students to reflect on their personal values. 
For example, Lily, a project coordinator in an office that provides sexual assault support services, recently graduated from her undergraduate institution and has not attended a student affairs master's program. Lily submitted a journal entry about a conversation with a student intern who reports to her. The intern had expressed feeling "stagnant" and wanting more challenge in her work at the office. Lily reflected on her advising approach with the student:

I noticed I was better at affirming her choices and giving her positive reinforcement: both in the fact that she spoke up and the idea that she wanted to be better and learn more at work. I also gave her positive feedback at how she knows herself so well. There weren't any concerns with her working style, as she has been very efficient and responsible. However, we did talk about time management and how she can improve there.

Lily's supportive approach typifies those who had not attended a master's degree program. She validated the student's perspective, asked reflective questions, and promoted confidence by validating the student's experience. Robert, a student organizations advisor who had a master's degree in counseling, but not in student affairs, described the supportive approach he used with a fraternity which was under sanctions for several disciplinary infractions. He described providing a supportive ear for their concerns.

... so when they came in, my advising approach was that I just wanted to be more an ear that they can ... some way that they can feel confident that they can vent to, and that they can talk to about, but that I wasn't going to go and tell somebody else, or tell them what they confided in me.

Clarissa and Nina's advising approaches, on the other hand, illustrate the more challenging approaches used by those who attended master's programs in student affairs. Clarissa worked in student activities and was approached by a student who came to her 
having made a decision to resign from his role on student council because of disagreements and personality conflicts over his "very strict, rigid and professional" leadership style. In her interview, Clarissa described her challenging advising approach with him.

I tried to help give my insight and sort of tell him not to be as mean, but in a nice way, you know? And I really tried to use examples, because he said that he was really successful at his internship, and he really liked his supervisor there. So, when he said that, I was like, "OK, well tell me why you liked your supervisor, and what did your supervisor say or do that made you want to work for him or her?" ... . Yeah, so I tried to share and give examples to him so that he could sort of hear the differences, and sort of recognize that. And then I really tried to get him to articulate his own experiences, and why he thought certain things weren't working, and things like that. So I was really trying to just help him process through certain things....

Nina, who also attended a graduate program, describes asking challenging and reflective questions to a student who met with her as she confirmed her decision to pursue a career in student affairs and choose a graduate program.

I walked her through the graduate school process, really helped her apply, and then when it came back to her actually getting her acceptances, she's like, "Oh. OK, now I actually am going. I need to decide $100 \%$, 'Is this something that's right for me? Was I doing it just because everyone was telling me it's the right decision for me?' and also 'Which institution do I want to go to?"' And so, for me, it's really important not to ever feed my decision to a student, but much more help them come to that decision on their own. So the majority of what I did was just ask questions of, "OK, what makes you want to go into student affairs? What makes you want to stay in California for student affairs? What are the pros and cons to a lot of these schools? Let's physically write a list down of pros and cons."

Unlike those who did not attend master's programs, who validated students' experiences, both Clarissa and Nina demonstrate approaches that challenged students to identify their own perspectives, values, and beliefs and encouraged the student to make sense of their own experiences. 
Notably, two participants mentioned wanting more training in advising approaches. One had attended a master's program, the other had not. In a journal entry, Marcia, who had not attended a master's program, reflected on an advising situation with an introverted intern who reports to her. She wrote "I need to take a supervision class or talk with others about how to navigate moments that seem awkward when people aren't sure what to say." Clarissa, who had attended a master's program, wanted more concrete advising resources than she received in her coursework.

I feel, like in grad school when you learn about these things, they don't tell you what to say exactly. Like "Ask "what do you mean by that?" or "What's the verbage you actually need to use when you're sitting in a one-on-one meeting?" There's no readings on that. And "How, exactly, do you challenge and support someone?" .. I asked my supervisor about that, too and she gave me some reading about it ... It was a reading about "What's your advising style?" And I remember, at the time, I didn't really find it helpful, because ... I wanted something more tangible.

Clarissa's need for exact language to use when advising students may also reflect her own stage of development. Clarissa is in the early stages of self-authorship development, in which young adults rely heavily on formulas for success. Nonetheless, Marcia and Clarissa expressed interest in more opportunities to improve their advising skills. While attendance in student affairs master's degree programs was linked to greater use of challenging advising approaches, both new professionals who attended and those who did not expressed interest in further advising training to perform their roles.

\section{Gender and Advising Strategies}

Both men and women in my sample used strategies that promote self-authorship. Both were likely to ask probing and reflective questions of the students they advised, though there were differences in the use of other advising strategies that promote self- 
authorship, based on gender. Women tended to use advising strategies that validate the student's perspective and promote collaboration, while men used strategies that challenged students to identify their values and perspectives, and emphasized action and engagement. For this section, I identified advising strategies that had a marked difference in usage among women and men.

Women in the study were more likely to validate the student's experiences and perspectives, redirect the conversation to the learner's experience, challenge the student to identify their own perspective, facilitate interpersonal collaboration, and promote discussion with peers who have diverse perspectives. Men, on the other hand, were more likely to emphasize action and engagement, prompt students to compare alternatives, give students the authority to make their own decision, ask students to expand on their initial view of the experience, encourage students to make sense of the experience themselves rather than make sense of it for the student, and prompt students to identify their own viewpoints, values, and world views.

Marcia describes using supportive strategies as she advised a couple of students who had been affected by an incident of sexual harassment.

I validated their experiences, because they experienced it, and so there was that. There was ... I provided the student with space to be able to name it and to talk about what that meant to feel so much silence around it. And then we talked about next steps, and visited those next steps ... I learned that it was about the community - we've had other instances of harassment and our people feeling uncomfortable and unsafe - it was about, "So, what resources do you think that person needs, and how can I support you in such ways to build you up so that you can then support your friend who was affected by it." Then I had to think about confidentiality and what that means for me, and connecting with the director, and connecting with offices to better support the student, and actually walking them over to get that support. 
Marcia's approach demonstrated several supportive strategies, including listening to promote student reflection and validating the students' experiences prior to taking action.

Cheryl demonstrates a number of advising strategies typical of women in the study, particularly those approaches involving validation and collaboration. In this case, Cheryl, who coordinates student activities, works closely with a student who is considering a career in student affairs despite her parents' desire for her to pursue a career in medicine.

The student was a student worker in our office and I believe her major was premed. But she enjoyed planning events and working alongside of me, doing anything I told her to do. And then she would just tell me that she's not doing well in her classes, it's just not interesting to her, it's too difficult . . . And so I told her, "Have you seen the Career Services Center? You can take an assessment of your interests, like there is an Interest Inventory to take, and even talking with a career counselor" . . . But then, one of her things was like, "Well, my parents will be upset because they think I'm going to be pre-med and they're financially supporting me, but I'm just not happy in what I'm doing."

Cheryl then prompts the student to further explore her career path of interest

despite her parents' desire for her to pursue a career in medicine.

And so I just told her, "If you think you're interested in doing it, why don't you job shadow somebody in the area that you'd be interested in doing? Conduct some informational interviews with the dean of the college, because you know her. See what her journey was." I pretty much just told what she needed to do and she did really well. She's very organized, loved working with students, so I knew that this field would be good for her, but I just wanted to make sure that she did some homework on her own so that she could determine if this is the thing that she wanted to do.

Her advice illustrates a number of advising strategies common among women in the study. Her advising approaches validate the student's experiences and perspectives, encourage her to consider her needs and the needs of others, and challenge her to identify 
her own perspective. Cheryl also encourages interpersonal collaboration by encouraging informational interviews with the college dean and later sets her up with a mentor in the field.

Aaron's example illustrates a number of advising strategies more frequently used by men in this study. Aaron describes his approaches to working with a student who was deciding between a career as a medical doctor or a veterinarian. In the conversation, Aaron asked the student a number of questions about factors that were important to her in a future career.

During the conversation I caught myself-several times, I sort of slipped toward that direction [giving direct advice], but I had to remind myself it's not my decision to make. I have to help her to understand the pros and cons. So basically I listened, and without making any direct suggestions. I gave her a lot of links, resources to basically research different kinds of lifestyles, different kinds of work, and the educational requirements of that, to get a more realistic picture about being a vet doctor and being a medical doctor.

Aaron later reflected upon his advising approach with the student.

But now I've started to think about if she had come to me in the first session, and I had told her that, "Forget about medical doctor-do vet" or say I told her that, "No, maybe the doctor probably has more job security and more pay. If that's important to you, why don't you go for that route?" If I actually started giving direct advice ... I'm very worried about giving direct advice like that, because that's such a responsibility that no one else can make besides the student, him or herself ... If I give that student any direct advice, the student probably won't come back for the second, and tell me about she figured everything out herself. So I think that's probably one of the most rewarding experiences I've had, not necessarily giving a direct answer ... but ask her all the questions that may be related to this decision. Have her talk, and apparently she was thinking while she was talking how to clarify her thoughts, and eventually come out to her decision.

Aaron's intentional focus on probing questions helped her to identify her own viewpoints and values, allowed her to expand on her initial view of the decision, and gave her the opportunity to make sense of the experience herself rather than him making 
sense of it for her. His offer of resources prompted her to compare alternatives and gave the student the authority to make her own decision.

Similarly, Enrique counseled a student worker after he learned she had a severe eating disorder.

... the coaching was, "Well, you're in a position where you're helping first-year students find academic success but, again, you're not helping yourself right now, and you're not taking care of yourself." It's kind of: how can you help others when you don't make yourself a priority? So kind of just talking about that, where you always need to take care of yourself first, so you can helpful to others. And then, just kind of providing her resources to help....

In addition to referring the student to campus resources to help her address the issue, Enrique's approach challenged the student to expand on her initial view of the experience and apply her values for helping others to her current situation.

While men and women both employed strategies that promote self-authorship, they tended to use different strategies to achieve it. Women were more likely to promote expertise and authority as mutually-shared among peers in knowledge construction (Baxter Magolda and King, 2004). Men were more likely to promote knowledge as complex and socially-constructed (Baxter Magolda \& King, 2004) volitional efficacy (Brown, 2004; Pizzolato 2005), and coping skills (Pizzolato, 2005). Women were more likely to use strategies that provide support to students, while men were more likely to challenge them.

\section{Summary of Findings}

The findings in this study provide insight into the self-authorship development and advising experiences of new student affairs professionals. Participants early in the stages of self-authorship development tended to defer to others as they made decisions. 
Those in the middle stage felt more comfortable using their voice with others, though they tended to rely heavily on others for support. Those in the late stage of selfauthorship tended to engage in deep reflection and often made decisions based on their personal beliefs and values.

A number of themes emerged in relation to self-authorship development of new professionals, including the role of life challenges, master's degree preparation programs, family, feedback, and mentoring. Participants' life challenges that served as significantly provocative moments were more predictive of self-authorship development than age in the late stage of development. There seemed to be little connection between studying student development in a graduate preparation program and a participant's stage of selfauthorship development. Family played an integral role in decision making for some participants, in some cases it was difficult to tell the degree to which a decision was made by family or the participant. Feedback from students and others became a catalyst for change for some participants. Finally, the types of relationships people had with their mentors differed based on the new professional's level of self-authorship. Those in the early and middle stages of self-authorship tended to rely heavily on mentors for support, validation, direction, and decision making, while those in late self-authorship tended to use mentors as sounding boards for their own reflection.

Additional themes emerged around new professionals' advising strategies related to advisor characteristics. New professionals in the late stage of self-authorship development used a greater number and broader range of strategies promoting selfauthorship, and those in earlier stages of self-authorship development gave more concrete 
direction and instruction to students. Some advisors viewed their roles with students as primarily transactional, while others used tasks as entry points for developmental conversations. Those who attended student affairs master's programs used more challenging advising approaches than those who did not. Finally, women tended to use more supportive advising strategies, while men tended to use more challenging approaches. These findings may inform the ways supervisors, graduate preparation programs, and mentors support the development of new professionals and the college students with whom they work. Implications for practice and areas for future research will be discussed in chapter 5 . 


\section{CHAPTER FIVE}

\section{DISCUSSION}

Following a brief overview of the study and a summary of the study findings, this chapter provides a discussion of linkages between the results of this study and the selfauthorship literature. It concludes with implications for the field of student affairs and areas for future research, a brief discussion of limitations, and a final conclusion.

\section{Justification for Study}

Colleges and universities are increasingly being called upon to demonstrate their effectiveness in meeting student learning and developmental outcomes. Unfortunately, research indicates that institutions of higher education are not adequately preparing students to handle the complexities of their adult lives after graduation. Employers indicate the need for campuses to increase focus on analytical and problem-solving skills to prepare students for the workforce (AACU, 2007; National Association of Colleges and Employers, 2010). Similarly, one research study suggested that many students aren't making statistically-significant increases in critical thinking, complex reasoning, and writing skills in college (Anum \& Roska, 2010). Such gains in learning require educators to place focus on both intellectual and developmental outcomes (Keeling, 2004).

Self-authorship, a concept developed by Robert Kegan (1982) and applied to college students by Marcia Baxter Magolda (1999), combines cognitive and psychological development through the meaning-making structures people use to make sense of their lives. Self-authorship is the development of an internal voice and the ability to identify others' expectations as separate from us, and under our control (Kegan, 
1982). Self-authorship is the ability to internally define one's own beliefs, identity, and relationships (Baxter Magolda, 2001). The theory of self-authorship focuses on the process of advancing to more complex meaning-making structures in the cognitive, identity, and relationship domains. This holistic approach to development is linked to advancement of key college learning outcomes in all three domains. The capacity to selfauthor is crucial in the development of complex reasoning skills, healthy relationships, and sense of identity described in higher education learning outcomes.

Self-authorship can result from adults' attempts to resolve feelings of disequilibrium caused by cognitive dissonance between external and internal voices (Baxter Magolda, 2001; Kegan, 1982; Pizzolato, 2005). Experiences of cognitive dissonance, which Baxter Magolda terms crossroads experiences, occur in college and have the potential to help college students identify their own internal voice, values and belief systems. However, Baxter Magolda's 25-year longitudinal research indicates that the majority of young adults in college are not self-authoring and are not successfully resolving their feelings of dissonance in ways that advance their capacity for selfauthorship (Baxter Magolda, 2001). Achievement of self-authored thinking typically does not occur until after college, when young adults have fewer support systems and face increased challenges (Baxter Magolda, 2001).

Fortunately, research shows that it is possible to promote the development of selfauthorship in college. Mentoring and advising relationships between students and campus administrators can serve as primary vehicles for processing students' crossroads experiences and promoting development of self-authored thinking in college (Baxter 
Magolda, 2001; Daloz Parks, 2000; Hodge et al., 2009; Pizzolato, 2005; Pizzolato \& Ozaki, 2007). This study explores the advising strategies used by new student affairs professionals, who often have the most direct contact with students. The study examined the degree to which new professionals advise students in ways that promote selfauthorship, and the relationships between several advisor characteristics and the advising strategies they use.

\section{Overview of Purpose of the Study and Findings}

The purpose of this study was to identify the degree to which new professionals use advising strategies that promote the development of self-authorship in undergraduate students. The study identified whether the new professionals demonstrated evidence of self-authoring, and explored the degree to which these new student affairs professionals use advising strategies that promote self-authorship in undergraduate students. The relationship between new professionals' advising strategies and characteristics, such as education, gender, age, and stage of self-authorship, were also explored.

The following research questions guided this study:

RQ \#1: To what degree do new student affairs professionals demonstrate evidence of self-authorship? What common characteristics and trends emerge among new professionals in different stages of self-authorship development?

RQ \#2: In what ways, if any, do new student affairs professionals use strategies and approaches that facilitate self-authorship with undergraduate students? 
a. What are the differences in advising approaches used by new student affairs professionals based on characteristics such as gender, age, education, and their own demonstrated stage of self-authorship development?

\section{Summary of Methods Used in the Study}

Data for the study were gathered from a variety of sources, including participant interviews, participant journal entries, and researcher notes. First, 12 new professionals working in student affairs at four-year institutions in Southern California each participated in one 60 - to 90 -minute interview. Interview questions were designed to elicit responses about participants' backgrounds, stage of self-authorship development, and the advising approaches they use with students. For a 2-week period following the interviews, participants submitted electronic journal entries describing and reflecting on their advising experiences with students. Participants were asked to submit one journal entry for each advising interaction on the day of an advising session. Participants submitted an average of three entries each and a total of 40 journal entries were received. After each interview and throughout the coding process, I took researcher notes for each participant to record my observations, perceptions, and emerging theories. The three data sources were analyzed to identify the study findings.

Self-authorship development and advising strategies have not been studied in new student affairs professionals; therefore, interviews and journal entries were analyzed first using grounded theory coding (open, axial, and selective coding). This allowed codes and trends to emerge directly from the data for this population. To determine the degree 
to which the experiences of new professionals match codes derived from the literature on self-authorship and advising strategies that promote self-authorship, the data was coded a second time using a coding scheme derived from the literature. Finally, themes and findings were identified using within-case and cross-case analysis.

To establish inter-rater reliability and to test the study protocol, I conducted a pilot study before the study began. A colleague familiar with the self-authorship literature and I individually analyzed the results and then met to discuss our analysis. Our collective findings supported the reliability of the coding schemes and facilitated fine-tuning of the analysis process. Similarly, to establish a definitive list of advising strategies that promote self-authorship from the grounded theory codes, I discussed my categorizations with another colleague familiar with the self-authorship literature. As a result of this conversation, and after reviewing the data associated with particular codes, a few of the code names were modified for clarity.

\section{Summary of Study Findings}

Participants in the current study demonstrated varying stages of self-authorship development. Five of the 12 participants were in the early stages of self-authorship, four were in the middle stage, and three were in the late stages of development. Those in the early stages tended to rely heavily on others for decision making, making sense of their experiences, and validation. People in this stage frequently expressed a lack of confidence to act on their own thoughts and perceptions. Those in the middle stage of self-authorship development were more likely to trust their internal voice, expressing their needs and opinions to others (thought not always consistently), and they often relied 
heavily on others for emotional support. Participants in the late stages of self-authorship development were able to coordinate influences from multiple sources and integrate them with their own thoughts and feelings. In this stage, participants made decisions based on deep introspection about their own needs, values and perspectives, often in spite of others' advice to the contrary. The analysis uncovered a number of factors that influenced new professional development, such as the role of life challenges, student affairs master's degree preparation programs, mentoring relationships, family, and feedback.

Participants used a variety of advising strategies with the undergraduate students. These strategies differed based on advisor characteristics such as age, gender, education, and the advisor's own stage of self-authorship development. After conducting withincase and cross-case analysis based on a number of advisor characteristics, five overarching themes emerged around advisors' stage of self-authorship, advising interactions, education, and gender.

Two themes emerged related to the participant's level of self-authorship. Those in earlier stages of self-authorship development tended to offer more specific direction, instructions, and recipes for success than participants in the late stages of development. Also, those in late stages of development used an increased number and a greater breadth of advising strategies that promote self-authorship than those in the middle and early stages of self-authorship development.

Another theme emerged around the types of interactions advisors had with students. Some advisors seemed to focus their interactions with students on completing 
tasks or handling transactions, while others used tasks as "gateways" to developmental conversations with students. Those who displayed more task orientations tended to be those who did not attend student affairs master's degree preparation programs, and who therefore may not understand the developmental potential in advising conversations.

Attending a student affairs master's degree program was linked with other advising differences as well. While there were no significant differences in the numbers of strategies promoting self-authorship participants used based on attendance at master's programs, there were differences in the types of strategies used. Those who attended master's preparation programs were more likely to use strategies that challenged students to identify their own perspectives, prompted students to compare alternatives, emphasized action and engagement, and asked students to reflect on their personal values. Participants who did not attend master's degree programs were more likely to use supportive advising strategies that validated students' experiences and perspectives. While each of these strategies support the development of self-authored thinking, those who attended master's degree programs were more likely to provide greater challenge to students, while those who did not used more supportive approaches.

Finally, gender was also associated with differences in advising strategies. Women tended to use more supportive and validating advising strategies, while men used approaches that challenged students to think about their values and take action on their situations. While promoting self-authorship requires both supportive and challenging approaches, significant challenge is critical to achieving the level of cognitive dissonance required for self-authored thinking (Baxter Magolda, 2001). 


\section{Interpretation of the Findings}

The study findings contribute to the literature on self-authorship development in a number of ways. In the following section, findings about new professionals' stage of self-authorship and their advising styles are discussed in relation to the literature on selfauthorship development.

\section{Development of Self-Authorship Among New Professionals}

Nine of the 12 new professionals in this study were in the early and middle stages of self-authorship development. Those in the early and middle stages relied heavily on others for decision making and support, and therefore would most likely have reached Kegan's third order of consciousness, which is characterized by exploring mutual relationships, identification with shared values, and reliance on the perceptions of others. Arrival at Kegan's fourth order of consciousness is characterized by the ability to engage in mutual relationships and the ability to self-author (Kegan, 1982). Kegan's third order of consciousness is the most common developmental stage among college students (Abes et al., 2007; Baxter Magolda, 2001). The majority of adults are between Kegan's third and fourth orders of consciousness (Debold, 2002; Kegan, 1994). It is therefore not surprising that many of the new professionals in the study were still on the developmental path to self-authorship.

Participants in the study described a number of challenges that have the potential to serve as crossroads experiences, and which may move them along the self-authorship developmental process. Participants described struggling with the following types of 
challenges: boundary management, building rapport with students and coworkers, meeting friends, managing their emotions, lack of mentors and guidance, demonstrating their effectiveness, job choices, encountering diverse perspectives, feeling inexperienced, managing conflict, navigating workplace politics, identifying differences between their values and those of the institution, work-life balance and managing job pressures. Participants expressed significant struggles in these areas, and many participants reached out to supervisors and mentors for help in resolving and managing them. Mentoring new professionals as they gain confidence and experience managing challenging situations can serve as a vehicle for gaining core competencies in the field. For example, core competencies identified in a survey of 1,237 entry-level professionals in a nationwide study included problem solving, student advising, and crisis and conflict management (Waple, 2006). New professionals often reached out to supervisors, mentors, and even former graduate advisors for advice as they worked through difficult issues, providing opportunities for advising and mentoring in ways that promote self-authored thinking and competency development.

For example, Cara described contacting a mentor for advice about challenges she faced with student advising. When asked if she has a mentor in student affairs, she said:

Yeah, I do within Greek life, but I don't have a general one just yet. The ... Greek advisor [from another campus] has always been there ... I've known her since my sophomore year of college. She had interviewed for the position and we just stayed in touch around Greek stuff and conferences. And so, she's the one I call [if I have a] total breakdown. "What do I with these students? They're never going to get it." She's always been there for me. 
Enrique talked about the multiple roles his graduate advisor has played in his development, which include: providing professional guidance, offering personal support, and serving as a mentor of color:

Support system? Definitely my faculty advisor from graduate school. He's ... beyond graduate I mean, in the program, as a student, graduated, job searching. Even now I'm working on a presentation for a conference in May ... And he was the first person I went to for support ... And so, he's been a support system, not only for work but just kind of personal, as well ... He's also a professional of color, so I look for support to him.

Nina relied heavily on her mentors for personal support and job advice during a

stressful time when she started a job that didn't feel like a good fit for her.

I think the one that most stands out in my mind right now is making the decision that I was going to turn in my two-week notice at the other position. . . Probably about three weeks in [to my job] I already started to realize that it wasn't necessarily the right place for me. And I remember literally one day calling one of my mentors and saying, "Convince me not to quit. Convince me that this is the position that I need to be in, that it's just tough at the beginning and it will get better."

These stories demonstrate the important roles of supervisors and mentors in the development of new professionals. Specifically, supervisors and mentors of new professionals have the relationships, trust, and roles that would make it possible to promote self-authored thinking during these potential crossroads experiences.

Development of intercultural competencies is also linked to self-authorship (Baxter Magolda, 2003). In this study, participants like Lily and Robert discussed the roles of culture and family relationships in their decision making. It is important for advisors to take into account such differences as they work with students from various backgrounds. Development of self-authorship involves the ability to coordinate internal and external influences on their decision making. Collective decision making common in 
some cultures may make it more difficult for advisors to determine whether a decision was made using self-authored thinking. For example, Robert's collective decisionmaking process about which of two job offers to take was based on numerous conversations with his parents and his fiancé. Both Robert and I found it difficult to identify the degree to which his family influenced his decision. Similarly, Lily discussed the importance of considering family needs in decision making in Asian cultures. Collective decision making and cultural dynamics may make it difficult to determine whether a student is using self-authored thinking. However, self-authorship does not imply lack of influence from others; rather, that the individual has the ability to consider others' opinions and integrate them with their own. Advisors may be able to help students from various backgrounds to ferret out their own perspective from those of others, without judgment about the relative weights of those perspectives on students' decisions. Advising strategies that promote self-authorship, such as asking students to weigh internal versus external perspectives, will be particularly important for students from backgrounds with significant family influence on decision making.

In Kegan's theory, age is roughly correlated with development until the stages typically occurring in adulthood (Kegan, 1982). Adults can remain in Kegan's third order of consciousness throughout their adult lives, without ever advancing to the fourth order. In this study, age generally correlated with stage of self-authorship development of new professionals in the early and middle stages; however, age was not a significant predictor among those who were in the late stages of self-authorship. Participants in the later stages represented a variety of ages from their early 20 s to the late 30 s. Participants 
in the late stages, however, had other common characteristics. Each had experienced significant life challenges including being first generation college students, and struggles with gender and racial identity development. Research in this area suggests that some college students have had to struggle to make meaning around their identities because of a lack of formulas to follow when they were visible minorities in communities (Creamer \& Laughlin, 2005; Pizzolato, 2005). The similar struggles faced by participants in the current study were likely to have provided sufficient challenge to promote self-authored thinking.

\section{Advisors in Early Self-Authorship Offered More Direction}

New professionals in the study tended to advise in ways characteristic of their own stage of development. For example, those in early stages of self-authorship development tended to advise in more directive ways. People in these stages also tended to seek out more direction, instructions and prescriptions for success from their supervisors, advisors, and mentors. For example, Clarissa, who is in the early stages of self-authorship, sought out concrete instructions about how to advise students. Clarissa mentioned that in her graduate courses, "they don't tell you what to say, exactly ... What's the verbiage you actually need to use when you're sitting in a one-on-one meeting?" After reading an article about advising styles given by her supervisor, she said “I didn't really find it helpful, because .. . I wanted something more tangible." Clarissa's search for tangible instructions for advising students is characteristic of the desire for formulas for success in early self-authorship development (Baxter Magolda, 2001, King 
et al., 2009). Similarly, her interview transcript describes some direct instruction and feedback she provided to a student who was struggling with his leadership style.

I was also trying to give him some feedback about how he can be better as a leader, instead of just sort of mandating people to help him out with posters and signs. Like he needs to sort of say it in a nicer way, and it's hard to tell a student that, you know? And so I said a lot, like "Look, I'm really on your side. I want you to succeed, and I'm only telling you this because I really want to help you."

Clarissa's desire for concrete direction (e.g., wanting exact language to use with students) and the directive advice she provided the student she advised (e.g., how to get people to help with tasks, how to speak in a nicer way) may illustrate a relationship between new professionals own stage of development and their advising approaches with students. The majority of participants in the early stage of self-authorship development frequently used directive approaches with students, while those in the late stages rarely offered prescriptions for success, and often in conjunction with more challenging questions that promote self-authorship. Prior to this study, several researchers had hypothesized a relationship between new professional's stage of self-authorship development and advising to promote self-authorship (Abes et al., 2007; Baxter Magolda, 2007; Baxter Magolda \& King, 2004; Mills \& Strong, 2004). For example, the University of Nevada Las Vegas included a focus on staff development of self-authorship as it underwent a restructuring and programmatic overhaul, with the assumption that doing so would improve student outcomes (Mills \& Strong, 2004). Similarly, the authors of a Reconceptualized Model of Dimensions of Identity conjecture that the development of those working with students is a prerequisite for assisting students in their identity development (Abes et al., 2007). The results of this study identify a link between the 
advisor's stage of self-authorship development and the use of advising strategies that promote self-authorship in students. These results lend credence to the existence of the relationship between self-authorship development of advisors and the students with whom they work. 


\section{Advisors in Late Self-Authorship Used More Strategies That Promote}

\section{Self-Authorship}

In this study, all three of the advisors in the late stages of self-authorship development described using a greater number of strategies that promote self-authorship, and used a broader set of strategies that promote self-authorship, than the participants in the early and middle stages. Participants in early self-authorship described using an average of 11 strategies that promote self-authorship, and an average of 23 of these strategies were described in their interviews and journal entries. Similarly, those in the middle stages of self-authorship averaged 9 strategies that promote self-authorship, and 18 total descriptions of strategies in their narratives. However, those in the late stages of self-authorship described significantly more strategies, an average of 20 per participant, and an average of 69 occurrences were identified in their narratives. Two areas in the literature may help to explain this trend. Literature on the development of self-authorship indicates that those who self-author demonstrate increases in cognitive complexity, critical thinking and problem solving, (Baxter Magolda, 2001; Pizzolato, 2008; Pizzolato \& Ozaki, 2007). Greater aptitude in these areas may indicate that new professionals in the later stages of self-authorship development have increased capacity to advise students in more nuanced ways, to consider situational nuance, and to respond to specific student needs in the moment.

Also, like Erikson (1959) and others, Kegan's model of development argues that as a person advances to more complex stages of development, they have access to ways 
of thinking from previous developmental stages (Kegan, 1982). In this study, those in the late stage of self-authorship tended to use a greater breadth of advising strategies than those in earlier stages. The expanded repertoire of advising strategies in the late stage could indicate the adoption of new advising approaches as one progresses to later developmental stages. Those in the late stage of self-authorship development in this study may have access to previous patterns of thinking in addition to their new, more complex, ways of self-authored thinking. New professionals' expanded advising repertoire may consist of new strategies beyond those they used in their previous stages of development.

\section{Transactional versus Developmental Advising Approaches}

Some new professionals in the study saw the primary purpose of their advising as transactional, while others saw it as transformational. Among study participants, this seemed primarily connected to whether or not a new professional had attended a student affairs master's preparation program. Student affairs preparation programs typically offer counseling and/or student development courses that would help new professionals understand their developmental roles with students.

Even with training provided in master's programs, several new professionals struggled to bridge theory with practice. For example, Clarissa and Nina both described finding it difficult to apply student development theory taught in their graduate programs into their everyday practice. Clarissa sought more concrete advising strategies and advice from other sources, such as colleagues and articles, while Nina decided to rely on examples from others and her own instincts. After describing her self-doubt about being 
able to master student development theory in graduate school, Nina describes her advising approaches by saying:

I think, for me, a lot of what I do with the students is much more intuitive. Again, I would love to say that I have theory that backs up everything, but I still really trust that gut feeling for a lot of things. I use a lot of my intuition of "What would I have wanted someone to tell me when I was deciding for grad school?" or "What did somebody tell me that made me feel fulfilled or made me come to a better decision when I was trying to decide where I wanted to work, and I was turning down jobs and applying for jobs?"

Challenges of new professionals in this study paralleled those noted in Job One:

Experiences of New Professionals in Student Affairs (Magolda \& Carnaghi, 2004). New professionals both in the book and in this study struggled to bridge theory and practice, develop their professional identities, and explore expectations. New professionals in this study and in Job One exhibited struggles towards self-authorship development in each of the three domains - intrapersonal, interpersonal, and epistemological - underscoring the work domain as a place for potential crossroads experiences and opportunities for holistic growth (Magolda \& Carnaghi, 2004).

\section{Student Affairs Master's Programs and Advising Strategies}

The current study found no difference in the number of advising strategies used between those who had studied student affairs master's programs and those who did not; however, there were differences in the types of strategies they used. Those who attended master's preparation programs were more likely to use strategies that challenged students, such as challenging students to identify their own perspectives (Baxter Magolda \& King, 2004), prompting students to compare alternatives (Baxter Magolda \& King, 2004), and emphasizing action and engagement (Brown, 2004). Those who did not attend master's 
programs used more supportive advising, such as validating the student's experiences and perspectives (Baxter Magolda \& King, 2004).

Kegan's model is predicated on the notion that movement to a new stage of development requires a sufficient level of cognitive dissonance for which one's existing mental models are inadequate (Baxter Magolda, 2001; Kegan, 1982; Perry, 1968/1999). Baxter Magolda's research indicates that students may not be reaching self-authored thinking because they are receiving too much support and too little challenge (Baxter Magolda, 2001). This may imply that, while a combination of challenge and support are needed to support student growth, advising strategies that challenge students may have a primary role in encouraging the dissonance necessary to promote transition to selfauthored thinking. While supportive advising strategies may help build rapport and validate students' voices, use of advising strategies that challenge students to identify their own perspectives is likely essential for promoting self-authored thinking. This study found that new professionals who have studied in a student affairs preparation program may be more adequately prepared to challenge students in advising and mentoring relationships than those who have not studied in a student affairs program.

Interestingly, 8 of the 12 new professionals in the study expressed interest in increased training or mentoring in advising and counseling students, regardless of whether they attended master's degree programs. Marcia, who did not attend a master's degree program, reflected on her need to "take a supervision class or talk with others about how to navigate moments that seem awkward when people aren't sure what to say." Lily, who also did not attend a master's program, role-played advising scenarios 
with her supervisor. Similarly, Cara and Nina, who attended master's programs, sought advising advice from mentors and Clarissa, who also attended a master's degree program, expressed interest in more applied learning than she received in her graduate program. The new professionals' desire for more training and support as they learn to advise students may suggest room for improvement in graduate preparation program curricula. The Delphi study conducted of mid- and senior-level administrators about the needs of new professionals corroborated this assertion (discussed further in chapter 2). Mid- and senior-level professionals expected new professionals to have more advanced counseling skills than are typically taught in introductory counseling courses in student affairs graduate programs (Burkard et al., 2005). The Delphi study's finding is consistent with the reports from new professionals in the current study which indicated that participants did not feel adequately prepared for their advising conversations with students.

\section{Gender and Advising Strategies}

The study found gender differences in advising strategies used. Specifically, women tended to use more supportive strategies, such as validating the student's experiences and perspectives, redirecting the conversation to the learner's experience, and facilitating interpersonal collaboration. Men, on the other hand, used approaches that tended to challenge students to expand on their initial view of the experience, identify their own viewpoints, values, and worldviews, and make sense of the experience themselves rather than having the advisor make sense of it for them. Baxter Magolda's (1992) longitudinal research on gender patterns in ways of knowing and reasoning in college identified similar findings. As in the current study, women exhibited 
relationship-oriented and collaborative approaches, while men used more challenging and action-oriented approaches. In her study of ways of knowing, Baxter Magolda found that women tended to use a relational approach to knowing, which involved receiving, interpersonal and interindividual ways of knowing, while men used an abstract approach involving mastery, impersonal, and individual ways of knowing. Students (primarily women), who focused on interpersonal ways of knowing, also emphasized relationships and expanding knowledge through sharing perspectives. They tended to care about their classmates' perspectives, wanted to get to know their peers, and hoped that instructors cared about them. Without a sense of caring, teaching was ineffective. Those who preferred impersonal patterns (primarily men) focused on challenge and individual learning were as primary focus. Similarly, in the current study, female advisors were more likely to use advising strategies that have been shown to support students, while male advisors were more likely to challenge students and promote action and engagement with the problem. This may suggest two things. First, a relational learning style may imply preference for a relational advising style. In this study, new professionals often replicated successful approaches their mentors and supervisors have used with them. New professionals may replicate advising styles that have worked with their own learning style; therefore, they may either intuitively or intentionally advise others in ways they prefer to be advised.

This may also suggest that male and female students may need different types of advising to achieve self-authored thinking. Female students may need a more relational approach to connect with their advisors. They may require more back and forth 
exchange, more sharing, and a sense that their advisor cares for them. Male students may need a more impersonal, challenging advising approach to make movement towards selfauthorship. Of course, there is great variation among males and females and advising approaches would need to be tailored to the unique needs of the individual student.

\section{Implications for Student Affairs Practice}

This study investigated the degree to which new student affairs professionals used strategies that promote self-authorship development among the students they advised. Factors associated with the development of self-authorship among new professionals included family relationships, mentoring relationships, and student affairs graduate preparation programs. Characteristics that influenced advising strategies that promote self-authorship included age, gender, education, and the level of self-authorship development. The findings from this study indicate that new professionals may benefit from opportunities to practice self-authored thinking and examples of concrete strategies that encourage development among students. Implications for student affairs practice are discussed below.

Promoting Self-Authorship Development Among New Professionals Through Student Affairs Graduate Preparation Programs

The study found that new professionals who attended graduate preparation programs used approximately the same number of strategies that promote self-authorship as those who did not. However, those who attended graduate preparation programs were more likely to use strategies that challenge students, while those who did not attend graduate preparation programs were more likely to use supportive strategies that 
validated students perspectives. The use of more challenging strategies by participants who attended graduate preparation programs may indicate that graduate curricula may be exposing them to the developmental benefits of challenging advising approaches.

However, 8 of the 12 new professionals in the study, including those who attended graduate preparation programs, expressed their desire for more training to adequately take up their advising roles with students. Study participants expressed a need for more counseling and development training, and a study of mid- and upper-level administrators support this need (Burkard et al., 2005). A Delphi study of 104 randomly selected mid- and senior-level administrators found that administrators expected new professionals to have more advanced counseling skills than are typically taught in introductory counseling courses offered in student affairs preparation programs (Burkard et al., 2005). New professionals in this study expressed interest in more training in advising students, which may support assertion that additional coursework in counseling may be needed in graduate curricula.

Graduate programs use a variety of curricula for teaching advising and counseling skills, and I did not differentiate the teaching approach used in the graduate programs attended by study participants; however, participants in the study attended a variety of programs. The number of participants expressing a desire for more training suggests a need to review and possibly revamp curricula in graduate preparation programs in student affairs to meet the developmental and training needs of new professionals. Programs could increase counseling requirements and increase assignments and class time to promote application of theory to real-world practice. Programs could increase reflective 
assignments in which new professionals discuss and analyze their own advising approaches. The input from participants in the current study, such as Lily, who mentioned role-playing advising scenarios with her supervisor, underscores the importance of real-world application and practice.

Also, a number of advising strategies may point to the particular benefits of peer group work around advising styles. For example, encouraging discussion with peers with diverse perspectives, encouraging feedback, and facilitating interpersonal collaboration are strategies that promote self-authored thinking, and they can be employed in a classroom setting. Given the range of self-authorship development among new professionals, it may be helpful to have other members of the class provide feedback to fellow students on their advising approaches and provide opportunities for new professionals to practice, reflect, and debrief in groups.

Faculty members who advise graduate students can also utilize strategies that promote self-authorship among students in the program. Advisors can employ many of the strategies described in the study, such as prompting students to identify their own viewpoints, values and worldviews, prompting students to explore multiple frameworks or lenses, asking clarifying questions about whether a decision was driven by internal or external forces, and asking sufficiently "big" questions. Similarly, graduate advisors can be explicit about expectations for reflection, and both personal and professional development with those they advise. 


\section{Supervising and Mentoring New Professionals to Promote Self-Authorship Development}

Supervisors, also, can utilize strategies to promote new professional development. Similar to those described for advisors in graduate preparation programs, supervisors can use advising strategies in one-on-one and team interactions. In subsequent supervisory meetings, supervisors can check-in with the new professionals about advising strategies and struggles. In this study, Robert, a student organizations advisor, and Cecelia, an academic advisor, seemed to consider their primary role with students to be transactional in nature. To avoid a scenario where a new professional is simply not aware of the potential to turn transactional conversations into transformational discussions, supervisors could set expectations for new professionals to focus on developmental conversations with students who meet with them. Supervisors can set the expectations for more in-depth conversations with new professionals when they begin their new positions. The key is to expand the view of the job beyond a transaction focus and to encourage the knowledge, skills, abilities, and capacity to promote self-authorship.

Supervisors can also help new professionals identify opportunities to use more developmental strategies with students. In this study, a list of strategies that do not directly promote self-authorship emerged from the grounded theory coding. Examples of those that do not explicitly promote self-authorship included: providing information, focusing primarily on task, offering analysis, and offering instructions or "shoulds." Use of these strategies may be necessary at times and may not be detrimental to student 
development. For example, an academic advisor may need to convey information about the procedures for declaring a major. Other strategies that do not promote development, such as offering analysis, could be replaced with more developmentally-oriented approaches, such as asking the student questions to help him or her reflect on his or her values. Supervisors can help new professionals identify opportunities to have more developmental conversations with students.

Marcia, Clarissa, Cara, and Lily were among the new professionals in the study who discussed their struggles to find their advising styles and to find ways to encourage students to open up to them. Marcia expressed interest in taking a class or talking with others about how to get shy students to open up. Clarissa sought out readings and advice to explain "how exactly do you challenge and support someone?" Cara discussed ways to improve her advising approaches with her mentor, and Lily role-played advising conversations with her supervisor. Despite the fact that two of these participants had attended master's degree preparation programs, they expressed the need for additional training. Ongoing professional development opportunities would help new professionals identify and improve their advising approaches to maximize student development and self-authorship.

New professionals may also want to consider the skill development they will need throughout their career. Tools such as the Professional Competency Areas for Student Affairs Practitioners (ACPA \& NASPA, 2011) can help new professionals identify areas of growth and develop an intentional plan for personal and skill development throughout their career. In addition to advising and helping, the document, adopted by ACPA- 
College Student Educators International and NASPA-Student Affairs Administrators in Higher Education, includes a personal foundations section, which includes outcomes related to the development of the self. New professionals can review the competencies and make individual action plans to advance their skills in particular areas, or they can use them as talking points with supervisors and mentors. An assessment of new professional skills, traits, and competencies may also help new professionals identify areas for improvement, particularly in the area of advising strategies. Jane Pizzolato (2007) developed the Self-Authorship Scale survey to identify self-authorship development among undergraduate students. It is recommended for use in combination with qualitative assessment measures (Pizzolato, 2005). A similar approach could be considered to help new professionals identify their own developmental stages and possibilities. In the case of new professionals, a survey could be used in combination with observational data from supervisors. Similarly, a 360-degree feedback instrument could be developed in which perceptions from students, colleagues, and supervisors could be combined with self-reports to identify strengths and areas for growth.

Developing Mentoring Communities to Promote Development of Self-Authorship in

\section{Undergraduate Students}

Jane Pizzolato describes the content of programs that could promote selfauthorship. These conversations could take place one-on-one with students or in coordinated programs that encourage development of self-authorship.

Conversations about the reasons behind students' interests, the implications of choosing particular majors, and clarifying students' understanding of who they are, who they want to become, and how to get from one to the other may prove particularly helpful in creating provocative moments ... Programs to help 
students identify and evaluate multiple perspectives . . may facilitate provocation and help students develop their ability to balance competing ideas, long-term benefits and consequences, and their own desires and principles. (Pizzolato, 2005, p. 638)

In addition to one-on-one mentoring and advising relationships, student affairs professionals can promote the capacity for self-authorship by providing an environment that consistently promotes students' development of the self, fosters growth and student reflection, raises complex questions, introduces students to the tools to respond to them, and offers tailored programs and services that increase in challenge over time and provide appropriate levels of support (Baxter Magolda, 2001; Daloz-Parks, 2000; Hodge et al., 2009; Pizzolato \& Ozaki, 2007). Through revamping programs and services, campuses could provide fewer prescriptions for success, and instead help students identify their values, beliefs, and goals, and the steps needed to take action on them (Baxter Magolda, 2001; Pizzolato \& Ozaki, 2007). The goal is to surround students throughout their campus experiences with challenging and developmental conversations and opportunities for self-reflection, in a variety of settings and formats. This can happen in a number of campus settings, such as in mentoring relationships, mentoring communities, experiential learning opportunities, and orientation programming, to name a few.

According to Daloz Parks (2000), mentoring environments have the potential to "provide an initiation into ... suffering and wonder." When this is done, "then contradiction and dissonance proliferate, raising big questions and activating the imagination in its search for meaning and faith" (p. 149). Student affairs administrators have the opportunity to create mentoring communities that will respond to students' desires for mentoring in which they have the opportunity to examine issues in their 
everyday lives and discuss questions of meaning and purpose. Through intentionally designed programs and services, campuses have the potential to provide mentoring communities that foster growth and meaning making throughout students' engagement with the institution. In addition, students who seek mentors can create their own communities of multiple mentors. As previously mentioned, curricular and co-curricular experiences have the potential to become places of mentoring, exploration and engagement with "big questions" (Daloz Parks, 2000; Nash \& Murray, 2010).

Community standards enforcement offers another venue for promoting selfauthorship (Baxter Magolda, 2003). Campuses would be better able to promote self authorship by moving from a system of rule enforcement and control to one in which students play an important role in developing, implementing, and assessing standards. Baxter Magolda (2003) offers an example that involves students developing and holding each other accountable for community standards in a residential environment. This model involved three phases, establishing a foundation for community, community problem solving, and accountability to the community. Again the role of mentorship is key, as ideally throughout the process, students would receive consistent messages and feedback about who they are becoming and their proactive role in getting there, and this study identified the need for new professionals to be equipped to advise students in this way.

Another example of creating a mentoring community involves structuring of services offered by academic counselors. Virginia Polytechnic Institute and State University developed a student advising model that includes progressively more 
responsibility on the part of students over time. Advising initially focuses on the academic requirements, policies, and formulas for college success, as most first year students are following external formulas. Despite the initial focus on formulas, advisors also send the message that students must make decisions and take actions based on their individual interests. Each year, the advising becomes progressively more studentdirected. By the students' final year, the students and advisors define their own relationships (Baxter Magolda, 2003). This type of progressive model may be applicable in other arenas, such as student organizations advising.

Other opportunities ripe for mentoring to promote self-authorship include experiential learning experiences, such as leadership opportunities, community service, service learning, campus student employment (Baxter Magolda, 2001), and resident advisor training (Pizzolato, 2005). Through advising conversations that encourage reflection, each of these experiences has the potential to require students to identify values and beliefs and process complex challenges, multiple perspectives, and encounters with others that can help students practice self-authored thinking.

New student orientation may be an opportune time to discuss the developmental changes that occur in college and to prepare students and parents for the process of selfauthorship. Providing a framework for the developmental changes that take place, what it will look like, and where students are heading may help students become more directed in their development. Miami University offers instruction to parents during orientation that helps parents understand ways to adjust their role to promote student development and decision making (Hodge et al., 2009). Enlisting parents as partners in learning may 
be a contributing factor in providing adequate challenge to promote self-authorship during crossroads experiences.

Mentoring communities can promote deep and expansive learning for undergraduate students by creating a sense of belonging, asking "big enough" questions, promoting encounters with "otherness" that can encourage the disequilibrium necessary for growth, creating space for dialogue, critical thinking, synthesis, and exploration of imaginative dreams, and exposure to examples of quests for truth, transformation, emerging selves, and wholeness (Daloz Parks, 2000). The current study found that new professionals took up the role of asking "big enough questions" in varying degrees. In order for mentoring communities to be effective, mentors must have the skills and ability to pose challenging and deep questions in ways that promote students' development. This study identified the need for supervisors, mentors, and graduate preparation programs to build the capacities of new professionals necessary to facilitate self-authored thinking among students, either in one-on-one or group experiences.

\section{Professional Development Opportunities for New Professionals}

The findings in the current study of one-on-one advising relationships could also apply to new professionals who facilitate mentoring communities such as those described above; they will also likely benefit from a simultaneous focus on the development of selfauthorship among staff as well as students. A number of recommended practices could build capacity among new professionals. Many of the same practices mentioned earlier for supervisors, mentors and graduate preparation programs can prepare new professionals to work with students in both one-on-one relationships and in group 
settings. These include supervising, mentoring, and advising new professionals in ways that promote the new professional's development of self-authorship, and structuring graduate preparation curricula in ways that encourage self-authored thinking.

Creating opportunities for partnerships with more advanced practitioners may foster learning and create opportunities for mentoring relationships. For example, new professionals could partner with more seasoned professionals to develop co-curricula that promote self-authorship, which can also create more developmental mentoring relationships for the staff across age and, potentially, developmental levels. Partnering on program development would create opportunities for new professionals to discuss student developmental needs and program design with experienced professionals who could also serve a mentoring role.

In addition to creating mentoring communities for undergraduate students, developing formal or informal mentoring communities for new professionals could better prepare them for creating developmental opportunities for undergraduate students. Campus administrators could also structure roundtable professional development discussions, possibly around the NASPA/ACPA adopted Professional Competency Areas for Student Affairs Practitioners (2011), which include the areas of personal foundations and advising and helping. In the current study, new professionals represented a range of developmental stages, so formal or informal roundtable discussions could create opportunities for reflection and sharing across developmental levels. Such discussions would ideally be facilitated by someone skilled in asking the types of probing and 
challenging questions that could promote self-authored thinking and provide opportunities for group learning.

\section{Implications for Further Research}

The study found linkages between characteristics of new student affairs professionals and the advising strategies they use with students. To expand on this study, research could be conducted with students to identify the degree to which new professionals with different characteristics actually make a difference in the development of self-authorship among the students they advise. For example, Pizzolato and Ozaki (2007) conducted a study of college students participating in a program designed to promote self-authorship based on Baxter Magolda's Learning Partnership Model. Participants in the study agreed to have their advising sessions taped, and participated in two semi-structured interviews. A similar study could be conducted to identify the influence of particular advising styles on student learning and development. Expanding the study by interviewing students may also yield information about the effectiveness and utilization of particular advising practices. A study might, for example, ask students about a recent time when they discussed a significant life experience with a student affairs advisor. The study could identify advising strategies used and identify which approaches were most effective with students.

Many of the new professionals in the early stages of self-authorship tended to use more directive and instructional language with students and provide more direct advice about what the student should do. They often sought more concrete examples of advising strategies and frequently relied on formulas for success in their work and personal lives. 
They often relied heavily on supervisors, mentors, family, and friends for direction and decision making. A longitudinal study of new professional development may illuminate additional factors that may influence new professionals movement along the selfauthorship continuum, and successful interventions that promote new professional development in the workplace.

This study identified possible correlations between advising strategies that promote self-authorship and advisor characteristics (age, gender, education, and advisor's stage of self-authorship development). Additional characteristics such as ethnicity or sexual orientation may also influence advising styles. Additionally, it may be helpful to identify factors beyond advisor characteristics that contribute to the advising approaches used by new professionals. For example, an advisor may have time constraints that limit the amount of time available to expand beyond meeting the transactional needs of the student. Also, students may feel less comfortable disclosing personal information if their advisor's office is located in a cubicle or a similar location lacking privacy.

Research indicates that promoting self-authorship in undergraduate students requires the use of challenging and supportive advising strategies (Baxter Magolda \& King, 2004). However, one hypothesis is that students may not be self-authoring in college because they have too much support and not enough challenge to encourage a sufficient cognitive dissonance from occurring (Baxter Magolda, 2001). A follow-up study could distinguish the advising strategies that yield the most developmental benefit and determine whether supportive advising strategies alone are necessary but insufficient for promoting self-authorship. 
This study found that men were more likely to use advising strategies that challenge students, while women used more supportive strategies. The field of student affairs is comprised primarily of women; therefore, the proportion of men to women in the field could be contributing to the lack of sufficient challenge in college to promote self-authorship development. A larger scale study of advising strategies by gender could explore this possibility further.

Gender may have other implications as well. Studies that explore the effectiveness of particular strategies on men and women may illuminate whether female and male students may need differing advising approaches to achieve self-authored thinking. Similarly, supervisors and mentors may also need to employ differing advisory styles based on gender, to promote self-authorship among new professionals. It could also be interesting to identify whether new professionals use different strategies when advising male and female students.

The role of family and culture in decision making emerged as a theme for two participants in this study. Specifically, these participants articulated the importance of collaborative decision making in some cultures and incorporating family perspectives. The theory of self-authorship does not imply making independent decisions, but rather the ability to identify one's own perspective and coordinate it with the perspectives of others. Despite the fact that decision making was more individualistic for some participants and more collective for others, the theory of self-authorship remains relevant. A larger sample size may have yielded other themes about the role of culture on the 
development of self-authorship of new professionals. Therefore, a future study could investigate the applicability of the tenets of self-authorship across cultures.

It may be helpful to identify how new professionals expand their repertoire of professional advising strategies over time. What advising approaches do new professionals use as they begin their careers, and what prompts them to develop new advising strategies? This may be helpful in learning how supervisors, mentors, and graduate preparation programs can encourage greater use of advising strategies that promote self-authorship among students.

Finally, the findings of this study identify a relationship between the development of self-authorship in new professionals and new professionals' capacity to advise students in ways that promote student development. This may suggest that new professional selfauthorship development may also correlate with the capacity to fulfill other core competencies in the field beyond student advising, such as student learning and development, or leadership (ACPA \& NASPA, 2011). Similar to advising, these competencies may include a developmental component. A study similar to the current study could be conducted to identify possible relationships between new professional self-authorship and other core competencies in the field.

\section{Limitations}

There are a number of limitations to this study. The data were based on participants' self-reports of advising experiences and was not compared with observational data. Observational data would have intruded on the trust and privacy established in student-advisor relationships, and the presence of an observer or camera 
may have changed the nature of the discussion. This study was based on interviews and journal entries from 12 new professionals in southern California. While responses may not be representative of the entire population of new student affairs professionals, this study provided an opportunity to explore applications of self-authorship among new student affairs professionals in some depth, and provided a range of new possible understandings about their development and advising strategies. This study is not generalizable to other contexts. However, the working hypotheses from the study may be transferrable at the judgment of the reader, based on the rich descriptions' applicability to other contexts. Finally, the researcher in this study is a student affairs professional with 10 years of experience in advising students and supervising new professionals in the field. This may be an asset that helped me identify additional nuances and patterns in the data, but there is also the possibility of researcher bias given my experiences in the field of student affairs. To mitigate the potential bias, I compared data analysis of a pilot study with another researcher, compared coding lists with a colleague familiar with selfauthorship literature, kept ongoing researcher notes, conducted member checks, and compared results with existing research in the field.

\section{Conclusion}

This study suggests that there is a range of advising approaches used by new professionals in student affairs, and that new professionals with some characteristics are more likely to use advising strategies that promote self-authorship among college students than others. The study found that new professionals use strategies that promote self-authorship to varying degrees. Those who are themselves in the later stages of self- 
authorship development are more likely to use a greater number and broader range of strategies promoting self-authorship. Those earlier in their own self-authorship development were more likely to give concrete direction and instruction to students, which is less likely to promote self-authorship. New professionals who tended to view their roles as transactional were less likely to use advising strategies that promote selfauthorship than those who saw their role as developmental. Women tended to use more supportive advising strategies, while men tended to use more challenging approaches. Those who attended master's degree programs in student affairs were more likely to use more challenging advising approaches than those who did not. With this information, we are better able to understand, and therefore support, the development of new professionals and the college students with whom they work.

While this study included a limited number of participants, its findings suggest several particularly notable trends that may warrant further investigation. In this study, the types of advising strategies used by new professionals differed based on the advisor's gender, age, stage of self-authorship development, and education. Male advisors and those who attended master's degree programs in student affairs tended to use more challenging advising approaches than female advisors and those who did not attend student affairs programs. Identifying the balance of challenging and supportive strategies and identifying the advising approaches that have the most developmental impact may be particularly useful for graduate preparation programs and supervisors who work with new student affairs professionals. 
New professionals in the late stages of development tended to use a greater number and broader range of advising strategies that promote self-authorship. The data from this study supports the claim that self-authorship is a prerequisite for promoting its development in others. The results of this study underscore the need for graduate preparation programs, supervisors, and mentors to increase their focus on both the personal and professional development of new student affairs professionals. By placing added emphasis on the development of self-authorship in new professionals, this study suggests that we may increase new professionals' effectiveness in promoting selfauthorship among students.

The role of gender in advising strategies also warrants further investigation. Men tended to use more challenging approaches, while women used more supportive advising strategies. Research on gender differences in college students' ways of knowing suggests that students who focused on interpersonal, relationship-oriented ways of knowing (primarily women) needed to have a sense that their instructor cared about them, while students who preferred impersonal ways of knowing (primarily men) focused on challenge and individual learning (Baxter Magolda, 1992). College students' preferences for particular teaching styles based on gender may indicate similar preferences for advising styles. An area of further research may be the degree to which particular advising approaches may be more effective in promoting self-authorship with male or female students.

In this study, the role of culture and family relationships played an integral role in decision making for some new professionals. When Robert was choosing which of two 
jobs to take, the decision-making process was so collaborative it was difficult for him and for me to tease out the degree to which his family influenced his ultimate decision. Similarly, Lily talked about the importance of taking family considerations into account in particular cultures. While the sample size in this study was small, the role of culture and the role of family in the development and expression of self-authorship may be an important area for further research.

College campuses have tremendous potential to serve as mentoring environments that help students achieve significant learning and developmental outcomes. As traditional students move from adolescence to adulthood, student affairs professionals have the opportunity, through advising and mentoring relationships, to surround students with developmental conversations that encourage their growth, stretch their capacities, assist them in identifying a sense of self, help them identify their values, and prepare them for the complexities of their adult lives. By understanding the factors that contribute to new professional advising approaches, we may better support the development of new professionals and, ultimately, the students with whom they work. 


\section{References}

Abes, E. S., Jones, S. R., \& McEwen, M. K. (2007). Reconceptualizing the Model of Multiple Dimensions of Identity: The role of meaning-making capacity in the construction of multiple identities. Journal of College Student Development, $48(1), 1-22$.

American College Personnel Association \& National Association of Student Personnel Administrators. (2011). Professional competency areas for student affairs practitioners. Washington, DC: Author.

Appel-Silbaugh, C. (2007). Acting out integrity and honor: Student Honor Council cultural influence on members' development (Doctoral dissertation, University of Maryland). Retrieved from Dissertations \& Theses: Full Text. (Publication No. AAT 3287725)

Arnett, J. J. (2004). Emerging adulthood The winding road from the late teens through the twenties. New York, NY: Oxford University Press.

Arum, R., \& Roska, J. (2011). Academically adrift: Limited learning on college campuses. Chicago: The University of Chicago Press.

Association of American Colleges and Universities (2007). College learning for the new global century. Washington, DC: Author.

Astin, A. W. (1993). What matters in college? Four critical years revisited. San Fransisco. CA: Jossey-Bass. 
Baxter Magolda, M.B. (1992). Knowing and reasoning in college: Gender-related patterns in students' intellectual development. San Francisco, CA: Jossey-Bass.

Baxter Magolda, M. (1999). Creating contexts for learning and self-authorship:

Constructive-developmental pedagogy. Vanderbilt Issues in Higher Education. Nashville, TN: Vanderbilt.

Baxter Magolda, M. (2001). Making their own way: Narratives for transforming higher education to promote self-development. Sterling, VA: Stylus Publishing.

Baxter Magolda, M. (2003). Identity and learning: Student affairs' role in transforming higher education. Journal of College Student Development, 44(2), 231-247.

Baxter Magolda, M. (2007). Self-authorship: The foundation for twenty-first-century education. New Directions for Teaching and Learning, 109, 69-83.

Baxter Magolda, M. (2009). The activity of meaning making: A holistic perspective on college student development. Journal of College Student Development, 50(6), 621-639.

Baxter Magolda, M., \& King, P. (2007). Interview strategies for assessing selfauthorship: Constructing conversations to assess meaning making. Journal of College Student Development, 48(5), 491-508.

Baxter Magolda, M., \& King, P. (2008). Toward reflective conversations: An advising approach that promotes self-authorship. Peer Review, 10(11), 8-11.

Baxter Magolda, M., \& King, P. (Eds.). (2004). Learning partnerships: Theory and models of practice to educate for self-authorship. Sterling, VA: Stylus. 
Baxter Magolda, M., King, P., Taylor, K., \& Perez, R. (2008, November).

Developmental steps within external meaning making. Paper presented at the Annual Meeting of the Association for the Study of Higher Education, Jacksonville, FL.

Blimling, G. S. (2002). Review of Creating contexts for learning and self-authorship. Journal of Higher Education, 73(2), 307-309.

Brown, S. C. (2004). Learning across the campus: How college facilitates the development of wisdom. Journal of College Student Development, 45(2), 134148.

Burkard, A., Cole, D. C., Ott, M., \& Stoflet, T. (2005) Entry level competencies of new student affairs professionals: A delphi study. NASPA Journal, 42(3), 283-309.

Charmaz, K. (2006). Constructing grounded theory: A practical guide through qualitative analysis. Thousand Oaks, CA: Sage.

Council for the Advancement of Standards in Higher Education. (2006). CAS professional standards for higher education (6th ed.). Washington, DC: Author.

Creamer, E. G., \& Laughlin, A. (2005). Self-authorship and women's career decision making. Journal of College Student Development, 46(1), 13-27.

Daloz Parks, S. (2000). Big questions, worthy dreams: Mentoring young adults in their search for meaning, purpose, and faith. San Francisco, CA: Jossey-Bass. 
Debold, E. (2002). Epistemology, fourth order consciousness, and the subject-object relationship: or . . How the self evolves with Robert Kegan. What Is Enlightenment, no. 22, 143-154.

DeWitz, S. J., Woolsey, M. L., \& Walsh, W. B. (2009). College student retention: An exploration of the relationship between self-efficacy beliefs and purpose in life among college students. Journal of College Student Development, 50(1), 19-34.

Erikson, E. (1959). Identity and the life cycle. New York, NY: W.W. Norton \& Company, Inc.

Evans, N., Forney, D. S., Guido, F. M., Patton, L. D., \& Renn, K. A. (2010). Student development in college: Theory, research, and practice. San Francisco, CA: Jossey-Bass.

Geertz, C. (1973). The interpretation of cultures: Selected essays by Clifford Geertz. Analysis, 25(3), 299-302.

Glaser, B., \& Strauss, A. (1967). The discovery of grounded theory: Strategies for qualitative research. Piscataway, NJ: AldineTransaction.

Harper, S. R., \& Quaye, S. J. (2009). Student engagement in higher education: Theoretical perspectives and practical approaches for diverse populations. New York, NY: Routledge.

Hodge, D. C., Baxter Magolda, M. B., \& Haynes, C. A. (2009). Engaged learning: Enabling self-authorship and effective practice. Liberal Education, 95(4), 16-23.

Keeling, R. P. (2006). Learning reconsidered 2: A practical guide to implementing a campus-wide focus on the student experience. Washington, DC: NASPA. 
Kegan, R. (1982). The evolving self: Problem and process in human development. Cambridge, MA: Harvard University Press.

Kegan, R. (1994). In over our heads: The mental demands of modern life. Cambridge, MA: Harvard University Press.

King, P., Baxter Magolda, M., Perez, R., \& Taylor, K. (2009, November). Refining the journey towards self-authorship: Developmental steps within the crossroads. Paper presented at the Annual Meeting of the Association for the Study of Higher Education, Vancouver, British Columbia.

King, P. M., Kendall Brown, M., Lindsay, N. K., \& VanHecke, J. R. (2007). Liberal arts student learning outcomes: An integrated approach. About Campus, 12(4), 2-9. doi:10.1002/abc.222

Kuh, G. D., Kinzie, J., Schuh, J. H., Whitt, E. J., \& Associates, A. (2005). Student success in college: Creating conditions that matter. San Francisco, CA: JosseyBass.

Kuh, G. D., Schuh, J. H., Whitt, E. J., \& Associates. (1991). Involving colleges: Successful approaches to fostering student learning and development outside the classroom. San Francisco, CA: Jossey-Bass.

Loveall, C. D., \& Kosten, L. (2000). Skills, knowledge, and personal traits for success as a student affairs administrators: A meta-analysis of thirty years of research. NASPA Journal 37(4), 553-572. 
Magolda, P. M., \& Carnaghi, J. E. (Eds.). (2004). Job one: Experiences of new professionals in student affairs. Lanham, MD: American College Personnel Association.

Magolda, M. B. \& King, P. M. (2008). Toward reflective conversations: An advising approach that promotes self-authorship. Peer Review, 10(1), 8-11.

Magolda, M. B., King, P. M., Taylor, K., \& Perez, R. J. (2008, November). Developmental steps within external meaning making Paper presented at the Annual Meeting of the Association for the Study of Higher Education, Jacksonville, FL.

Meszaros, P. (2007). The journey of self-authorship: Why is it necessary? New Directions for Teaching and Learning, 109, 5-14.

Mills, R., \& Strong, K. (2004). Organizing for learning in a division of student affairs. In M. Baxter Magolda \& P. King (Eds.), Learning partnerships: Theory and models of practice to educate for self-authorship (pp. 269-302). Sterling, VA: Stylus.

Nash, R., \& Murray, M. (2010). Helping college students find purpose: The campus guide to meaning-making. San Francisco, CA: Jossey-Bass.

National Association of Colleges and Employers. (2010). Job outlook 2011: November 2010. Bethlehem, PA: NACE Research.

Pascarella, E. T., \& Terenzini, P. T. (2005). How college affects students (Vol. 2). San Francisco, CA: Jossey-Bass. 
Patton, M. Q. (2002). Qualitative research \& evaluation methods. Thousand Oaks, CA: Sage. 
Perez-Pena, R. (2012, April 7). Trying to find a measure for how well colleges do. The New York Times. Retrieved from http://www.nytimes.com/2012/04/08/education /trying-to-find-a-measure-for-how-well-colleges-do.html?_r=1\&scp=1\&sq $=$ how $\% 20$ to\% 20 measure $\& s t=c s e$

Perry, W. G. (1968/1999). Forms of ethical and intellectual development in the college years: A scheme. San Francisco, CA: Jossey-Bass.

Pizzolato, J. (2005). Creating crossroads for self-authorship: Investigating the provocative moment. Journal of College Student Development, 46(6), 624-641.

Pizzolato, J. (2007). Assessing self-authorship. New Directions for Teaching and Learning, 109, 31-42.

Pizzolato, J. (2008). Meaning making inside and outside the academic arena: Investigating the contextuality of epistemological development in college students. Journal of General Education, 56(3-4), 228-251.

Pizzolato, J., \& Ozaki, C. (2007). Moving toward self-authorship: Investigating outcomes of learning partnerships. Journal of College Student Development, 48(2), 196-214.

Renn, K. A., \& Jessup-Anger, E. R. (2008). Preparing new professionals: Lessons for graduate preparation programs from the National study of new professionals in student affairs. Journal of College Student Development. 49(4), 319-335.

Settersten, R., \& Ray, B. E (2010). Not quite adults: Why 20-somethings are choosing a slower path to adulthood, and why it's good for everyone. New York, NY: 
Bantam.

Taylor, K. (2008). Mapping the intricacies of young adults' developmental journey from socially prescribed to internally defined identities, relationships, and beliefs. Journal of College Student Development, 49(3), 215-234.

Waple, J (2006). An assessment of skills and competencies necessary for entry-level student affairs work. NASPA Journal, 23(1), 1-18.

Weiner, L., \& Bresciani, M. J., Hickmott, J., \& Felix, E (2011). Developing and implementing learning goals for student affairs practitioners. The Colorado State University Journal of College Student Affairs, 20, 86-93. 
Appendix A

Interview Protocol and Coding Matrixes 
Pre-interview questionnaire:

Name

Email address

Phone number

Age

Gender (Male, female, transgender, intersex)

Length of time you have worked full-time in the field of student affairs

Job Title/Position in Student Affairs

Institution

Have you been in a formal or informal advising/mentoring role with students during your full-time work in student affairs?

Education

Did you attend a student affairs master's degree program? $(\mathrm{Y} / \mathrm{N})$

If Yes, what part of the country? (Southern California, Northern California, Midwest, Northeast East, Southwest, Other.

Interview Protocol

Section 1: New Professional's level of self-authorship

Rapport building questions

Tell me a little about your background and what brought you to the field of student affairs? (adapted from Baxter Magolda \& King, 2008).

Tell me about aspects of your campus experience that have brought you the most joy or satisfaction. Follow up: Why do you think this is the case? (adapted from Baxter Magolda \& King, 2008). 
Are there aspects of your work that you find stressful or challenging? If so, tell me about them. Follow-up: what are the common threads of the aspects you find stressful? (adapted from Baxter Magolda \& King, 2008).

\section{Intrapersonal dimension}

How do you think your work in student affairs has affected who you are and the way you see yourself? Follow-up question: What experiences have led you to that perspective? (adapted from Baxter Magolda \& King, 2008 and BM email communication).

How do you think your experience might have affected your beliefs or values? (adapted from Baxter Magolda \& King, 2008).

\section{Interpersonal dimension}

Working on a college campus often exposes you to multiple perspectives-encountering people who grew up differently than you, people who hold different beliefs than you. Have you encountered new perspectives? Tell me about them. Follow-up: How did that experience affect the way you see things? (adapted from Baxter Magolda \& King, 2008).

What kinds of support systems do you have? Follow-up questions: What role have they played in your experience so far? (adapted from Baxter Magolda \& King, 2008, also included in BM email communication)

Do you have someone you consider a mentor in the field? Tell me more about the roles he/she has played in your development as a professional in the field and as a person (Characteristics and assessment of self-authorship).

\section{Epistemological Dimension}

Think about the last time you had to make a major decision in which you had a number of alternatives (for example, a career decision, a decision in your job, a relationship decision, a decision about what you believe...) What was the nature of the decision? Follow-up question: What was that like for you? (Adapted from Baxter Magolda's MER) 
What alternatives were available to you? (Baxter Magolda's MER)

How did you feel about these alternatives? (Baxter Magolda's MER)

How did you go about choosing from the alternatives? (Baxter Magolda's MER)

What things were the most important considerations in your choice? Please give details. (Baxter Magolda's MER)

Why did you make the decision you made?

How did this experience change/shape your thinking (about your self, your role...)? Did this experience make you see your self differently? If so, please explain. (Intrapersonal dimension) (adapted from Baxter Magolda \& King, 2008).

\section{Wrap-up meaning making questions}

It sounds like you've had a range of experiences so far. In what ways do you see yourself as the same as when you started your work in student affairs? In what ways do you see yourself as different than when you started? (adapted from Baxter Magolda \& King, 2008).

How will you know you've been successful in your role in student affairs? (developed from Baxter Magolda, 2001, p. 81).

\section{Section 2: Approaches to advising students}

If you could give advice to anyone about how best to work with college students who are making important decisions in their lives what kind of advice would you give them? Talk about what YOU believe is the key to effectively advising students. (Adapted from Baxter Magolda's MER) 
Describe a situation in your recent student affairs career in which a college student came to you to talk about a significant decision in his or her life. What was the nature of the decision? (Adapted from Baxter Magolda's MER)

Describe in as much detail as possible your conversation with the student.

Describe your approach to working with the student.

Why did you choose that approach?

What kind of guidance did you offer the student (please provide as many details as possible)? (Baxter Magolda, email communication)

In the example you gave me, were these strategies you typically use with students? In other words, did you intentionally decide to use that strategy with the student or was it a less conscious more intuitive approach to the conversation? (Dissertation committee)

Where did you first see/learn about the strategies you used? What informed the choice to use your strategy with the student? (Dissertation committee)

Do you think that was the most effective strategy and why? (Dissertation committee)

\section{Follow-up/probing questions:}

What does that mean for you?

What do you mean when you say that?

How did that perspective come about?

What are the experiences that led you to that idea? 
Part 1: Coding for New Professional Self Authorship Section

\begin{tabular}{|c|c|c|}
\hline Milestones & General Description & Examples \\
\hline $\begin{array}{l}\text { E } \\
\text { Firmly } \\
\text { External }\end{array}$ & $\begin{array}{l}\text { - Uncritically adopt beliefs from faculty, } \\
\text { staff, parents, clergy or anyone they } \\
\text { perceive to be an authority. } \\
\text { - Follow formulas derived from external } \\
\text { sources because they do not yet have } \\
\text { an internal authority upon which to } \\
\text { base their beliefs, identity, and } \\
\text { relationships. } \\
\text { - The majority of the transcript suggests } \\
\text { reliance on external sources for } \\
\text { knowledge, self-definition, and social } \\
\text { relations. } \\
\text { Cognitive } \\
\text { Once young adults recognize that } \\
\text { authorities' views can differ, they look } \\
\text { for authority's guidance in resolving } \\
\text { these discrepancies. } \\
\text { Intrapersonal } \\
\text { They define their identities through } \\
\text { what they think others want from them } \\
\text { and focus in relationships on acquiring } \\
\text { others' approval. } \\
\text { When peers' expectations differ, } \\
\text { students struggle to maintain approval } \\
\text { in multiple relationships. } \\
\text { Interpersonal } \\
\text { Any seeds of internal voice that may } \\
\text { be present are not sufficient to take } \\
\text { note of. While there may be } \\
\text { LANGUAGE that sounds internal, the } \\
\text { overall structure is clearly external. } \\
\text { Note that a person can rely on external } \\
\text { to varying degrees. } \\
\text { (Baxter Magolda et. al., 2008) }\end{array}$ & $\begin{array}{l}\text { "It's important for me to } \\
\text { have mentor figures who I } \\
\text { trust and who I believe in } \\
\text { give me their opinions in } \\
\text { terms of black and white } \\
\text { instead of gray." } \\
\text { "I get in so many } \\
\text { conversations with people } \\
\text { talking about whether it's a } \\
\text { just war or like good or bad } \\
\text { or whether they're for it or } \\
\text { against it and I've heard so } \\
\text { many good points, but I've } \\
\text { gone from being for it to } \\
\text { against it to back in the } \\
\text { middle and so some things } \\
\text { I just kind of give up on. I } \\
\text { know that I'll never know } \\
\text { everything about that } \\
\text { situation. There's just no } \\
\text { way and so I'm not going } \\
\text { to pretend to make an } \\
\text { opinion about it, so there's } \\
\text { some things that I just try } \\
\text { to leave alone." } \\
\text { (Baxter Magolda et. al., } \\
\text { 2008) }\end{array}$ \\
\hline $\begin{array}{l}\text { E (I) } \\
\text { Entering } \\
\text { the } \\
\text { Crossroads }\end{array}$ & $\begin{array}{l}\text { Outside forces continue to be strong } \\
\text { (even overwhelming) influences. } \\
\text { - Continue to rely on external sources } \\
\text { yet start to see the importance of } \\
\text { developing their internal voice. }\end{array}$ & $\begin{array}{l}\text { "[My professor has] talked } \\
\text { about everything from the } \\
\text { war in Iraq to euthanasia to } \\
\text { gay and lesbian marriages } \\
\text { and everybody has a }\end{array}$ \\
\hline
\end{tabular}




\begin{tabular}{|c|c|c|}
\hline & $\begin{array}{l}\text { Begin to differentiate between their } \\
\text { own constructions of their identity, } \\
\text { relationships, and beliefs and those of } \\
\text { others } \\
\text { Can often see discrepancies between } \\
\text { what others want for them and what } \\
\text { they want for themselves, but they lack } \\
\text { the confidence in and clarity about } \\
\text { their beliefs and values necessary to } \\
\text { act upon what they want for } \\
\text { themselves. } \\
\text { Cognitive } \\
\text { Cognitively, recognize the need to } \\
\text { make decisions based on a set of } \\
\text { internally constructed values and } \\
\text { beliefs. } \\
\text { May recognize a distinction between } \\
\text { viewpoints adopted from others and } \\
\text { own viewpoints, actively working to } \\
\text { sort out which viewpoints are his/her } \\
\text { own. } \\
\text { Intrapersonal } \\
\text { Still in the process of discovering what } \\
\text { they value and how they form beliefs } \\
\text { They define their identities through } \\
\text { what they think others want from them } \\
\text { and focus in relationships on acquiring } \\
\text { others' approval. } \\
\text { When peers' expectations differ, } \\
\text { students struggle to maintain approval } \\
\text { in multiple relationships } \\
\text { Interpersonal } \\
\text { Can identify how external sources such } \\
\text { as their friends' and family members' } \\
\text { emotions influence them, though they } \\
\text { are not yet able to overcome or } \\
\text { coordinate these influences. } \\
\text { (King, et. al., 2009) }\end{array}$ & $\begin{array}{l}\text { different viewpoint. But to } \\
\text { have to articulate that } \\
\text { makes you think through, } \\
\text { "Why do I think this? Is it } \\
\text { just because my teachers } \\
\text { told me this in high school? } \\
\text { Is it just because I learned } \\
\text { this from my peers? Is it } \\
\text { just because that's what } \\
\text { everybody thinks, that's the } \\
\text { most widely accepted } \\
\text { view? Or is it because } \\
\text { that's what I really think } \\
\text { and I can back it up?" } \\
\text { (King, et. al., 2009) }\end{array}$ \\
\hline $\begin{array}{l}\text { E-I } \\
\text { Standing in } \\
\text { the } \\
\text { Crossroads }\end{array}$ & $\begin{array}{l}\text { Not only see the need for an internal } \\
\text { voice but also to start cultivating and } \\
\text { using one's internal voice } \\
\text { External sources may still be } \\
\text { predominant }\end{array}$ & $\begin{array}{l}\text { "I started hanging out with } \\
\text { [my boyfriend] all the time, } \\
\text { and I kind of replaced [my } \\
\text { roommates], so maybe they } \\
\text { think that they were }\end{array}$ \\
\hline
\end{tabular}




\begin{tabular}{|c|c|c|}
\hline & $\begin{array}{l}\text { Cognitive } \\
\text { Working to develop internal voice to } \\
\text { construct beliefs } \\
\text { - Recognizes that multiple complex } \\
\text { perspectives exist } \\
\text { Intrapersonal } \\
\text { - Working to develop internal voice to } \\
\text { construct identity } \\
\text { - Begins to make purposeful decisions } \\
\text { about how to develop identities } \\
\text { Interpersonal } \\
\text { Working to develop internal voice to } \\
\text { construct relationships } \\
\text { Individuals may continue to do what } \\
\text { others expect of them yet may } \\
\text { experience frustration or regret when } \\
\text { what others want and what they want } \\
\text { conflict. } \\
\text { Lacks confidence in and experience } \\
\text { with using her internal voice amidst } \\
\text { external pressures } \\
\text { (King, et. al., 2009) }\end{array}$ & $\begin{array}{l}\text { replaced or that I like him } \\
\text { better... they're getting all } \\
\text { upset, but I guess I have to } \\
\text { do what makes me happy... } \\
\text { They [my roommates] } \\
\text { would complain that my } \\
\text { boyfriend was over too } \\
\text { much, so I pretty much told } \\
\text { him to stop coming over, so } \\
\text { he hasn't been over really } \\
\text { in a few weeks. And } \\
\text { they're still giving me these } \\
\text { looks and I don't know. I } \\
\text { just can't win. So I pretty } \\
\text { much can't win unless [my } \\
\text { boyfriend and I] broke up } \\
\text { and I devoted all my time } \\
\text { to them because the second } \\
\text { roommate pretty much - } \\
\text { she devotes all of her time } \\
\text { to the first roommate, and } \\
\text { she just does whatever she } \\
\text { says. So I don't know. I } \\
\text { don't really want to be that } \\
\text { way where somebody's } \\
\text { telling me what to do and } \\
\text { planning everything for } \\
\text { me." } \\
\text { (King, et. al., 2009) }\end{array}$ \\
\hline $\begin{array}{l}\text { I-E } \\
\text { Moving } \\
\text { through the } \\
\text { Crossroads }\end{array}$ & $\begin{array}{l}\text { Increasing trust in using their internal } \\
\text { voice } \\
\text { Presence of both external and internal } \\
\text { voices; yet at this level, the internal } \\
\text { voice is strong enough to edge out } \\
\text { external voices } \\
\text { Internal voice dominant in meaning } \\
\text { making, however external voices } \\
\text { remain present and create tension } \\
\text { when they do not align with the } \\
\text { internal voice } \\
\text { Enough confidence in her internal } \\
\text { voice to later express her perspective } \\
\text { and the reason for it with others } \\
\text { - Finding her own strategies, taking into }\end{array}$ & $\begin{array}{l}\text { "One of my friends and me, } \\
\text { we had some tension, and } \\
\text { then she started yelling at } \\
\text { me, like, "You always need } \\
\text { to sleep." I'm like, "Yeah, } \\
\text { but that was the agreement } \\
\text { if I lived with [you]." } \\
\text { They're my best friends. } \\
\text { I'm like, "I told you this } \\
\text { semester I was going to } \\
\text { need to sleep these days, } \\
\text { and you guys said you } \\
\text { wouldn't have parties, and } \\
\text { here you are having parties. } \\
\text { We made this deal that you }\end{array}$ \\
\hline
\end{tabular}




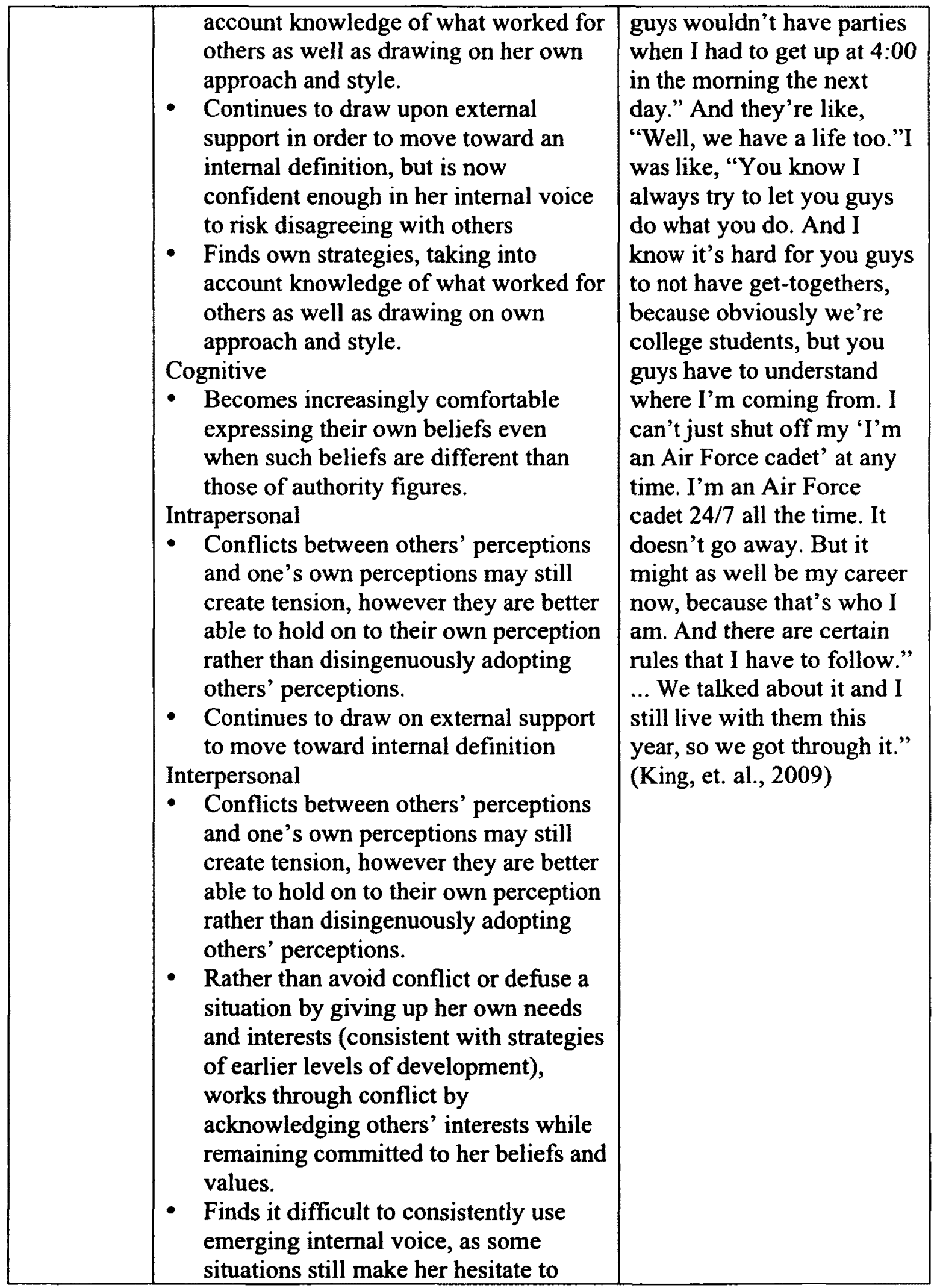




\begin{tabular}{|c|c|c|}
\hline & $\begin{array}{l}\text { fully express her perspective. } \\
\text { (King, et. al., 2009) }\end{array}$ & \\
\hline $\begin{array}{l}\text { I }(E)- \\
\text { Leaving the } \\
\text { Crossroads: } \\
\text { Threshold } \\
\text { of self- } \\
\text { authorship }\end{array}$ & $\begin{array}{l}\text { Capacity to decide which external } \\
\text { influences to pay attention to and how } \\
\text { to let such influences affect them } \\
\text { - Able to weigh and critique external } \\
\text { influences, and these influences } \\
\text { subsequently lost their pull as primary } \\
\text { driving forces in their lives } \\
\text { - Decides how and to what extent } \\
\text { external factors affect beliefs and } \\
\text { actions. } \\
\text { Cognitive } \\
\text { - Cultivate their internal voice by } \\
\text { engaging in deep introspection } \\
\text { - Able to critically evaluate and } \\
\text { coordinate multiple influences using an } \\
\text { internal voice and frame of reference } \\
\text { - Mediates external influences with } \\
\text { one's own internal voice } \\
\text { Decides how and to what extent } \\
\text { external factors affect her beliefs and } \\
\text { actions } \\
\text { - Remains open to considering others' } \\
\text { ideas, though is critical of them in } \\
\text { order to see how they align with her } \\
\text { own beliefs. } \\
\text { Intrapersonal } \\
\text { - Increasingly able to maintain an } \\
\text { authentic identity even in the face of } \\
\text { disapproval. } \\
\text { Interpersonal } \\
\text { - Capacity to make decisions that others } \\
\text { may not support } \\
\text { Internal voice is strong enough to } \\
\text { coordinate and manage the influence } \\
\text { of others' emotions } \\
\text { (King, et. al., 2009) }\end{array}$ & $\begin{array}{l}\text { "The beliefs that I've } \\
\text { grown up with, they're with } \\
\text { me but, I've taken a little } \\
\text { from [and] given a little bit } \\
\text { to them...compromising } \\
\text { things to where they } \\
\text { accommodate me and not } \\
\text { just in a general aspect, you } \\
\text { know, to where I'm } \\
\text { comfortable with them." } \\
\text { When you just don't } \\
\text { wholeheartedly take } \\
\text { something in and you } \\
\text { question it, you find a } \\
\text { whole lot more. You find a } \\
\text { whole lot more answers, } \\
\text { more solutions. And so } \\
\text { whether or not if someone } \\
\text { is asking me or telling me } \\
\text { something I will take it into } \\
\text { consideration and what will } \\
\text { influence me now if...I } \\
\text { decide to let it influence } \\
\text { me, it will be in a positive } \\
\text { way. And, even if it's } \\
\text { positive I'm still going to } \\
\text { push on it and find out } \\
\text { more about it before I make } \\
\text { my ultimate decision on it } \\
\text { and how it plays into my } \\
\text { beliefs." } \\
\text { (King, et. al., 2009) }\end{array}$ \\
\hline $\begin{array}{l}\text { I } \\
\text { Internal } \\
\text { Foundation }\end{array}$ & $\begin{array}{l}\text { Solid sense of "who I am" } \\
\text { - Participants express feeling personally } \\
\text { grounded and able to be themselves in } \\
\text { all aspects of their lives }\end{array}$ & $\begin{array}{l}\text { "Now we just kind of } \\
\text { accept these things, nothing } \\
\text { ever stays the same. If you } \\
\text { expect it, it is a lot easier... }\end{array}$ \\
\hline
\end{tabular}




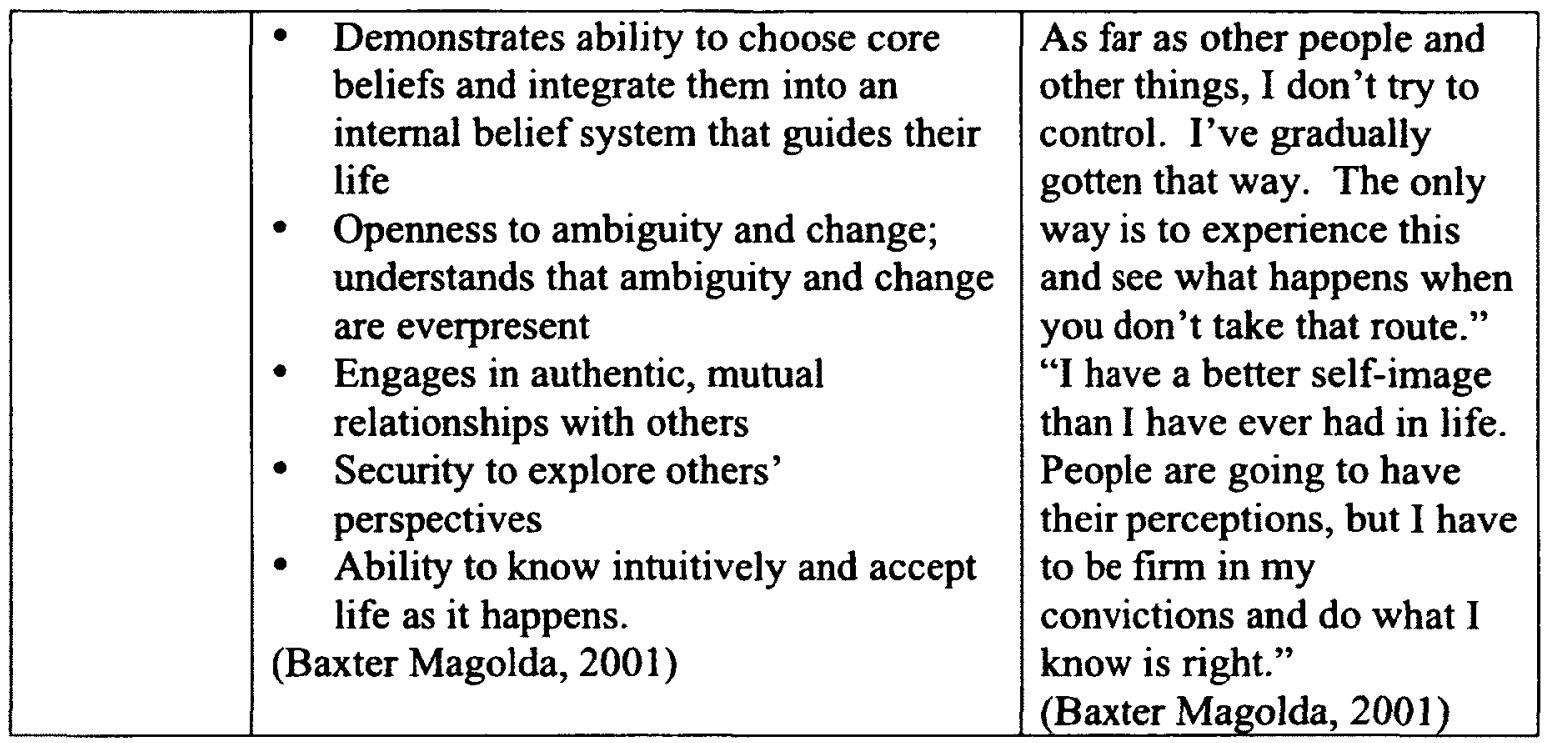


Part 2: Coding for approaches to advising students that promote self-authorship.

\begin{tabular}{|c|c|c|}
\hline Code & Demonstrations of Code & Source \\
\hline $\begin{array}{l}\text { Knowledge is complex } \\
\& \text { socially constructed }\end{array}$ & $\begin{array}{l}\text { a) Prompts student to compare } \\
\text { alternatives } \\
\text { b) Prompts students to explore } \\
\text { multiple frameworks or lenses } \\
\text { c) Exploring assumptions about } \\
\text { knowledge as universal } \\
\text { d) Encourages critique of existing } \\
\text { theories } \\
\text { e) Encourages taking a stand on an } \\
\text { issue or topic } \\
\text { f) Encourages feedback } \\
\text { g) Asks students sufficiently big } \\
\text { and complex questions }\end{array}$ & $\begin{array}{l}\text { a-e) Baxter Magolda \& } \\
\text { King, } 2004 \\
\text { f) Brown, 2004 } \\
\text { g) Brown, 2004; Daloz } \\
\text { Parks, 2000; Hodge et. } \\
\text { al, 2009 }\end{array}$ \\
\hline $\begin{array}{l}\text { Self is central to } \\
\text { knowledge construction }\end{array}$ & $\begin{array}{l}\text { a) Asks reflective questions } \\
\text { b) Asks student to identify his/her } \\
\text { perspective } \\
\text { c) Asks students to reflect on } \\
\text { his/her personal values } \\
\text { d) Encourages student to reflect on } \\
\text { his/her level of satisfaction with } \\
\text { relying on external } \\
\text { definitions/sources for decision } \\
\text { making } \\
\text { e) Asks clarifying questions about } \\
\text { whether the student's decisions } \\
\text { were driven by internal or } \\
\text { external forces (promotes } \\
\text { behavior regulation/self- } \\
\text { regulation) } \\
\text { f) Asks students to distinguish and } \\
\text { weigh internal vs. external } \\
\text { factors for decision making and } \\
\text { behavior regulation } \\
\end{array}$ & $\begin{array}{l}\text { a-c) Baxter Magolda \& } \\
\text { King, } 2004 \\
\text { d - f) Pizzolato, } 2005\end{array}$ \\
\hline $\begin{array}{l}\text { Expertise and authority } \\
\text { are mutually shared } \\
\text { among peers in } \\
\text { knowledge construction }\end{array}$ & $\begin{array}{l}\text { a) Promotes confidence by } \\
\text { validating student's voice } \\
\text { b) Encourages discussion with } \\
\text { peers with diverse perspectives } \\
\text { c) Advisor gives student authority } \\
\text { to make his/her own decisions. }\end{array}$ & $\begin{array}{l}\text { a-c) Baxter Magolda \& } \\
\text { King, 2004 } \\
\text { d) Brown, } 2004 \\
\text { e) Pizzolato \& Ozaki, } \\
2007\end{array}$ \\
\hline
\end{tabular}




\begin{tabular}{|c|c|c|c|}
\hline & & $\begin{array}{l}\text { Facilitates interpersonal } \\
\text { collaboration } \\
\text { Counsels students toward } \\
\text { cognitive interdependence in } \\
\text { which students could } \\
\text { successfully manage conflicting } \\
\text { expectations in a way that } \\
\text { considered their needs and the } \\
\text { needs of others }\end{array}$ & \\
\hline $\begin{array}{l}\text { Validate learners } \\
\text { capacity to know }\end{array}$ & a) & $\begin{array}{l}\text { Promotes confidence by } \\
\text { validating student's voice } \\
\text { Prompts student to identify their } \\
\text { own viewpoints, values and } \\
\text { world view } \\
\text { Asks student to expand on their } \\
\text { initial view of an experience }\end{array}$ & $\begin{array}{l}\text { a-c) Baxter Magolda \& } \\
\text { King, } 2004\end{array}$ \\
\hline $\begin{array}{l}\text { Situate learning in } \\
\text { learner's experience }\end{array}$ & a) & $\begin{array}{l}\text { Redirects conversation toward } \\
\text { learner's experience } \\
\text { Encourages student to apply } \\
\text { what he/she learned in this } \\
\text { situation to another situation } \\
\text { Encourages student to apply } \\
\text { what they learned in another } \\
\text { situation to this situation } \\
\text { Encourages the student to make } \\
\text { sense of their experience rather } \\
\text { than the educator making sense } \\
\text { of it for them }\end{array}$ & $\begin{array}{l}\text { a-c) Baxter Magolda \& } \\
\text { King, } 2004 \\
\text { d) Baxter Magolda \& } \\
\text { King, } 2008\end{array}$ \\
\hline $\begin{array}{l}\text { Mutually construct } \\
\text { meaning with the } \\
\text { learner }\end{array}$ & $\begin{array}{l}\text { a) } \\
\text { b) }\end{array}$ & $\begin{array}{l}\text { Displays curiosity } \\
\text { Reflects on their own } \\
\text { assumptions vs. expert, guide, } \\
\text { authority role }\end{array}$ & $\begin{array}{l}\text { a-b) Baxter Magolda \& } \\
\text { King, } 2004\end{array}$ \\
\hline $\begin{array}{l}\text { Promote volitional } \\
\text { efficacy, or the belief in } \\
\text { ones ability to persist in } \\
\text { goal oriented behavior } \\
\text { despite challenges }\end{array}$ & a) & $\begin{array}{l}\text { Asks probing questions to } \\
\text { encourage reflection about } \\
\text { possible challenges and ability } \\
\text { do persist despite them } \\
\text { Emphasizes action and } \\
\text { engagement }\end{array}$ & $\begin{array}{l}\text { a) Pizzolato, 2005 } \\
\text { b) Brown, 2004 }\end{array}$ \\
\hline Promotes coping skills & a) & $\begin{array}{l}\text { Works with student to identify } \\
\text { appropriate coping skills (ie. } \\
\text { identifying personal strengths, } \\
\text { relaxation techniques, support } \\
\text { systems, exercise options) }\end{array}$ & a) Pizzolato, 2005 \\
\hline
\end{tabular}


Appendix B

Study Email Announcement 
Participate in a study of experiences of new student affairs professionals.

I am conducting a study about experiences of new student affairs professionals who have worked full-time in student affairs for two years or less. Interviews will include questions about your experiences, perceptions, beliefs, and reflections about your experiences as a new professional, your experiences with students, and in your life outside of work.

This information will help us learn more about the experiences and perspectives of new professionals and how we can support new professionals in a way that promotes the personal development of new professionals and of students.

Interested in participating? Please fill out the brief questionnaire (link). New student affairs participants selected for the study will participate in a 60-90 minute interview and will be asked to record reflections and observations for the two weeks following the interview.

Pre-interview questionnaire:

Name

Email address

Phone number

Age

Gender (Male, female, transgender, intersex)

Length of time you have worked full-time in the field of student affairs

Job Title/Current Position in Student Affairs

Institution

Have you been in a formal or informal advising/mentoring role with students during your full-time work in student affairs?

Education

Did you attend a student affairs master's degree program? (Y/N)

If Yes, what part of the country? (Southern California, Northern California, Midwest, Northeast East, Southwest, Other.) 
Appendix C

Online Journal Entries 
Reflections on Advising Experiences with College Students.

During the two-week period following your interview, please use this online journal entry to reflect on your advising experiences with college students as they happen. If possible, please write journal entries on the day of the interaction with a student.

Participant Name

Date

1. Briefly describe the nature of your conversation with the student.

2. Describe your approach to working with the student.

3. Why did you choose that approach?

4. What kind of guidance did you offer the student? (Please provide as many details as possible).

5. What do you notice about your advising style? 